NBER WORKING PAPER SERIES

\title{
COLLUSIVE INVESTMENTS IN TECHNOLOGICAL COMPATIBILITY: LESSONS FROM U.S. RAILROADS IN THE LATE 19TH CENTURY
}

\author{
Daniel P. Gross \\ Working Paper 26261 \\ http://www.nber.org/papers/w26261 \\ NATIONAL BUREAU OF ECONOMIC RESEARCH \\ 1050 Massachusetts Avenue \\ Cambridge, MA 02138 \\ September 2019
}

I thank the Berkeley Economic History Lab and the Harvard Business School Division of Research and Faculty Development for financial support. This research began during graduate studies and was conducted in part with the support of NSF Graduate Research Fellowship Grant No. DGE-1106400 and an EHA Graduate Fellowship. The views expressed herein are those of the author and do not necessarily reflect the views of the National Bureau of Economic Research.

NBER working papers are circulated for discussion and comment purposes. They have not been peer-reviewed or been subject to the review by the NBER Board of Directors that accompanies official NBER publications.

(C) 2019 by Daniel P. Gross. All rights reserved. Short sections of text, not to exceed two paragraphs, may be quoted without explicit permission provided that full credit, including () notice, is given to the source. 
Collusive Investments in Technological Compatibility: Lessons from U.S. Railroads in the Late 19th Century

Daniel P. Gross

NBER Working Paper No. 26261

September 2019

JEL No. F14,F15,L15,L41,L92,N71

\begin{abstract}
Collusion is widely condemned for its negative effects on consumer welfare and market efficiency. In this paper, I show that collusion may also in some cases facilitate the creation of unexpected new sources of value. I bring this possibility into focus through the lens of a historical episode from the 19th century, when colluding railroads in the U.S. South converted 13,000 miles of railroad track to standard gauge over the course of two days in 1886, integrating the South into the national transportation network. Route-level freight traffic data reveal that the gauge change caused a large shift in market share from steamships to railroads, but did not affect total shipments or prices on these routes. Guided by these results, I develop a model of compatibility choice in a collusive market and argue that collusion may have enabled the gauge change to take place as it did, while also tempering the effects on prices and total shipments.
\end{abstract}

Daniel P. Gross

Harvard Business School

Soldiers Field

Boston, MA 02163

and NBER

dgross@hbs.edu 
In the early morning hours of Monday, May 31, 1886, railroads across the U.S. South simultaneously stopped running their trains, and over the next 36 hours teams of workers manually narrowed 13,000 miles of railroad track from a 5' $0^{\prime \prime}$ to $4^{\prime} 9^{\prime \prime}$ gauge (track width) to be compatible with the standard being used throughout most of the rest of the country. Today, the gauge change is celebrated as a remarkable feat of engineering and coordination and is referenced in research and popular press as an example of standardization (e.g., Shapiro and Varian 1999). However, when the story is told, a typically forgotten detail is that these railroads were also running a cartel.

Collusion has been illegal in the U.S. since the Sherman Act of 1890, out of concern for consumer welfare and market efficiency - and railroads were one of its original targets. But often overlooked is the possibility that in some settings, collusion may also contribute to the creation of unexpected new sources of value, such as standardization. This value creation might in principle even change predictions for the effects of market power on total surplus. In this paper, I bring these issues into focus by way of this historical example: the gauge change instantly integrated the South into the national transportation network, making it possible for goods and passengers to move effortlessly into and out of the region without costs and delays of interchange.

Using historical data from the Southern railroad and steamship cartel, this paper first chronicles the gauge change and shows that it triggered a redistribution of freight traffic into the South from steamships to railroads but did not affect total shipments on sampled routes through 1890. Over the same period, records show that the cartel maintained its prices, implying that railroads did not pass through any of the cost savings achieved by the conversion. Guided by this evidence, I then develop a simplified model of the market for North-South freight shipment and show that the cartel may have both facilitated the conversion to standard gauge, by providing a venue for coordination and a means of recouping the investment, and concurrently softened its effects on prices and total shipments, by limiting pass-through of carriers' resultant cost savings. Complementing the evidence from cartel data, evidence from railroads' stock returns around the time of the event indicates that investors perceived large financial returns to standardization. The effects of the gauge change were thus large, yet potentially defined by the industry's collusive conduct.

The earliest U.S. railroads were constructed as local and regional enterprises to serve local needs. At the time, opinion over the optimal gauge varied, and without the vision of a national network, distinct gauges were adopted around the country. As the national network began to emerge, these incompatibilities became increasingly costly, and railroads gradually converged on a common gauge via conversion and new construction, such that by the 1880 s, nearly all U.S. railroads were on a 4' 8.5" "standard" gauge - except for those in the South. Data from the Poor's Manual of Railroads 
confirm that whereas other regions had $95 \%$ or more of their track in standard gauge, $75 \%$ of that in the South was on an incompatible, 5' 0" "Southern" gauge (even more if excluding Virginia and North Carolina), and accounts indicate that the available adapter technologies were a substantial and costly second-best to a fully integrated network. In early 1886, members of the Southern Railway \& Steamship Association (SRSA) cartel, which together comprised a majority of mileage in the South, agreed to convert all track to a standard-compatible 4' 9" gauge en masse over the two days of May 31 and June 1, 1886, with traffic halting on May 30 and resuming by the evening of June 1, effortlessly traversing the former breaks in gauge. The conversion was carefully planned, seamlessly executed, and well-documented by contemporaries.

The cartel's primary purpose was to support noncompetitive pricing by Southern carriers through the creation and administration of a traffic pool. To implement the pooling arrangement, the SRSA compiled monthly records of freight traffic borne by individual carriers to and from Southern cities where two or more members operated, which were later reported to cartel members for key routes. I use these data to estimate the effects of the gauge change on merchandise shipments from the North into the South. In a variant on a triple-differences design, I compare within-route traffic borne by rail versus steamship, before and after the gauge change, allowing the effects to vary with route length: because breaks in gauge imposed a fixed cost of interchange on through shipments, the unit costs on each route will vary with distance. Steamships are a natural comparison group for all-rail traffic, as seaborne freight circumvented the breaks in gauge and was therefore operationally unaffected by the conversion to a standard-compatible gauge.

The cartel records yield a balanced panel of 52 routes with inbound merchandise shipments data pre- and post-standardization. Within this sample, I find that the gauge change caused a sharp increase in all-rail traffic relative to steamship traffic, with the effect strongest on shorter routes and dissipating after roughly 700 to 750 miles. When split across the two all-rail pathways into the South, I find relatively larger increases for the less-trafficked routing. The results are robust to a variety of fixed effects, as well as within assorted subsamples.

Market share models return similar results, indicating a redistribution of traffic from steamships to railroads, with effects dissipating at similar distances. However, I find no differential growth in total shipments on shorter versus longer routes through 1890: the effects are limited to substitution across modes. One possible explanation is that adjustment on the aggregate margin took several years, and the panel is too short for these effects to appear in the data; another is that the choice of mode was more sensitive to breaks in gauge than shipment overall. However, the presence of the cartel is a distinctive feature of the setting, and its potential importance is accentuated by evidence 
that cartel prices did not decline following the gauge change.

To evaluate the cartel's role in facilitating the gauge change and whether collusive pricing might have constrained total shipments, I turn to theory. I develop a simplified model of the market for freight transport on a North-South route, first using it to show how the existence of the cartel may have facilitated standardization by providing incentives for undertaking the costly investment and a venue for coordinating the regional shift to a different common-gauge equilibrium, and then demonstrating how collusion could have shaped the effects on prices, quantities, and market shares. Although traffic will shift from steamships to all-rail in any market structure, collusion reduces the pass-through of railroads' cost savings to prices and in turn the growth in total shipments, relative to a counterfactual in which railroads and steamships set prices competitively - and if cartel price adjustments are even moderately costly (e.g., due to internal re-negotiation costs), prices and total shipments may not change at all. As it were, stock returns to U.S. railroads at the time of the conversion indicate that investors believed it would generate a windfall for Southern railroads, particularly those where the gauge breaks were once located.

This episode offers an example of an unconventional dividend from collusion: the standardization of Southern railway gauge. ${ }^{1}$ The enabling role of the cartel was to make it possible for firms to internalize the externalities of their technology choices, and to provide an opportunity to coordinate on decentralized changes such as the conversion of 13,000 miles of railroad track and recover the fixed cost of conversion. This paper thus contributes to the literature on compatibility in interconnecting networks by pointing out the ways in which collusion supported standardization, whereas previous research has largely focused on how market competition shapes compatibility choices and compared markets to standards-setting committees. ${ }^{2}$ The results also suggest a regulatory tension in settings with large strategic complementarities (such as from technological compatibility), as collusion (or consolidation) can enable value creation but also harm consumers.

The historical example is also striking because it reverses the direction of the conventional relationship between standards and collusion. Standards-setting organizations (SSOs) have long attracted regulatory scrutiny, especially regarding the market power conveyed to owners of standards-essential

\footnotetext{
${ }^{1}$ History offers other such examples. For example, in the 1920 s, seven major international light bulb manufacturers colluded to divide national markets and limit the working life of light bulbs, increasing both sales and margins at the expense of consumers. But the so-called "Phoebus cartel" also served as a venue for manufacturers to exchange technical know-how and implement standards. One by-product of the cartel, for example, was the standardization of screw-in light bulbs and sockets, which persists to this day (IEEE 2014).

${ }^{2}$ Seminal contributions include Farrell and Saloner (1985, 1986, 1988, 1992); Katz and Shapiro (1985, 1986); Matutes and Regibeau (1988, 1992); and Economides (1989). See David and Greenstein (1990), Katz and Shapiro (1994), and Besen and Farrell (1994) for early reviews. Subsequent research has studied interconnection and compatibility in a wide range of settings, including electric power supply (David and Bunn 1988), U.S. telephone service (e.g., Mueller 1997), ATM networks (e.g., Knittel and Stango 2008), and more.
} 
patents and the countervailing collective bargaining efforts by the SSO to negotiate licensing terms (e.g., U.S. Department of Justice and Federal Trade Commission 2007). But researchers and policymakers have also voiced concern that SSOs may be a breeding ground for price-fixing, as it offers a venue for firms to coordinate their product market decisions with a lower risk of detection, under the cover of standards setting (U.S. DOJ and FTC 2007). In the setting of this paper, however, it was instead collusion that facilitated standards adoption.

Finally, the results bring new evidence to bear on the question of how compatibility affects market outcomes. Despite a rich theoretical literature, empirical progress has historically been challenged by the difficulty of linking compatibility to observable outcomes and a lack of standards-adoption events large enough to have measurable effects. This paper contributes to the growing body of work studying the impacts of compatibility and compatibility-dependent technologies directly (e.g.,

Knittel and Stango 2008, Li 2019, Basker and Simcoe 2019), showing that compatibility can have large effects on market shares of newly-integrated firms in settings where traffic is exchanged across connected networks, such as in communications or transportation.

The paper proceeds as follows. Section 1 reviews U.S. railroad history and the natural experiment at the heart of the paper. Section 2 introduces the data and the empirical strategy. Section 3 estimates the effects of the gauge change on route-level shipments and market shares, identifies the empirical puzzle, and discusses potential explanations, emphasizing the role of the cartel. Section 4 provides the theoretical argument for how the cartel may have both enabled the gauge change to take place but also tempered its effects on prices and shipments, with a view towards rationalizing the patterns in the data. Section 5 then shows what happened to stock prices following the gauge change. Section 6 discusses the key lessons, particularly as related to (i) the benefits of interoperability and (ii) the interaction with product market competition, and concludes.

\section{History of U.S. Railroads and Gauge Standards}

Diversity in gauge characterized U.S. railroads for most of the 19th century. The first railroads were built with a local or at most regional scope, and "there was little expectation that [they] would one day form an independent, interconnected" network (Puffert 2009), obviating any perceived benefits of coordinating on a common gauge. Gauges were instead chosen by each railroad's chief engineer, and without clear evidence of an optimal gauge standard, diversity proliferated. As Puffert (2009) recounts, the first wave of construction in the 1830s used four distinct gauges (4' 8.5'", 4' 9'", 4' 10'", and $\left.5^{\prime} 0^{\prime \prime}\right)$, a second wave in the 1840 s added three broader gauges to the mix (5' $\left.4^{\prime \prime}, 5^{\prime} 6^{\prime \prime}, 6^{\prime} 0^{\prime \prime}\right)$, 
and a "third wave of experimentation" in the second half of the century introduced several narrow gauges, the most common of which were $3^{\prime} 0^{\prime \prime}$ and $3^{\prime} 6^{\prime \prime}$. Amongst this set, only $4^{\prime} 8.5^{\prime \prime}$ and $4^{\prime} 9^{\prime \prime}$ were mutually compatible and allowed for a seamless exchange of traffic. ${ }^{3}$

The industry nevertheless recognized the advantages of interoperability, as subsequent construction typically adopted the gauge of neighboring railroads. By the 1860s, a national network had begun to emerge, but it was plagued by breaks in gauge as well as minor gaps in the physical network such that there were nine distinct "gauge regions" in the U.S. during the Civil War, and a tenth in Canada, each predominantly using a different gauge than neighboring regions. Panel (A) of Figure 1 shows the state of U.S. railroads east of the Mississippi River at this time, identifying lines with 4' 8.5" ("standard" gauge), 5' 0" ("Southern" gauge), and other track widths.

[Figure 1 about here]

In the 1850s, each break in gauge imposed a full-day delay on through shipments and necessitated significant labor and capital for transshipment, which at the time was performed manually, aided by cranes (Poor 1851, Taylor and Neu 1956). Diversity also required railroads to preserve a large fleet of idle rolling stock at each break for transferring freight. By the 1870s, several adapter technologies had developed to reduce these costs, the most common of which was bogie exchange, whereby each rail car was raised by a steam-powered hoist, and its chassis ("bogie" or "truck") replaced with one of a different gauge. Bogie exchange required not only steam hoists and extra labor for switching trucks, but also rail yards full of empty trucks of both gauges, side tracks, extra buildings, and extra clerical workers, and although changing a single rail car took only a few minutes, a full train could take much longer and might have to wait for exchange facilities to become available. Bogie exchange also yielded a mismatched car and bogie, which damaged tracks, had to run at reduced speeds, and were at risk of tipping on curves. The true cost of incompatibility was thus considerably higher than the physical act of interchange alone (McHenry 1875).

After the Civil War (1861-1865), several pressures coincided to induce private efforts towards standardization, including growing demand for interregional shipment, growing trade in time-sensitive perishable goods, competition (within routes), and consolidation (across routes). Despite known technical shortcomings (Puffert 2009), 4' 8.5'" became the standard to which railroads conformed: not only did standard gauge comprise a majority of U.S. mileage in every decade since the first

\footnotetext{
${ }^{3}$ See Puffert (2009) for a comprehensive discussion of the origins of U.S. railroad gauge. To this day, experts' opinion over the optimal gauge varies, though the choice is (i) understood to vary with operating conditions, and (ii) involves tradeoffs, such that there is no dominating standard. Even so, experts tend to agree that wider gauge is preferable to the modern standard (4' 8.5') for its speed, stability, and carrying capacity (Puffert 2009).
} 
railroads were built, but it was also the principal gauge in the Northeast and Midwest, the loci of trade in manufactured and agricultural goods. By the early 1880s, the common-gauge regions using $4^{\prime} 10^{\prime \prime}, 5^{\prime} 6^{\prime \prime}$, and $6^{\prime} 0^{\prime \prime}$ had all converted to standard gauge, effectively leaving only two gauges in widespread use: $5^{\prime} 0^{\prime \prime}$ in the South, and $4^{\prime} 8.5^{\prime \prime}$ in the rest of the country. ${ }^{4}$

\subsection{The Southern Railway \& Steamship Association}

Concurrent with (but independent of) these trends, Southern freight carriers had organized into the SRSA cartel in 1875, following a series of price wars. The cartel's express purpose was price maintenance: the cartel agreement states an intention of achieving "a proper correlation of rates," to protect its members and consumers from "irregular and fluctuating" prices (SRSA 1875). Membership was open to all railroads and steamships operating south of the Potomac and Ohio Rivers and east of the Mississippi and included nearly all major carriers in the region. Despite a rocky start, and no clear model to follow, by the 1880s the SRSA was sophisticated, successful, and "one of the most powerful and disciplined" traffic pools in the country (White 1993) - one documented several times over (e.g., Hudson 1890, Joubert 1949, Argue 1990). ${ }^{5}$

The cartel had its own full-time administration, which had the responsibility of carrying out the terms of the cartel agreement, making new rules as necessary, and settling internal disputes. The mechanism used to ensure that members adhered to the prices set by the cartel's rate committee was apportionment: carriers serving a competed route were allotted a fixed proportion of traffic, determined by "the average amount of freight hauled in past years" (Joubert 1949). In the cartel's early years, carriers who exceeded their allotment were required to submit the excess revenue for redistribution to other members, less a one-cent (later half-cent) per ton-mile allowance for the cost of carriage. This plan quickly unraveled when members reneged ex-post, and the agreement was amended to require members to deposit $20 \%$ of revenue with the cartel at the time of shipment, out of which these transfers would be made. To enforce the agreement, the cartel installed agents at stations to record carriers' daily traffic and revenue, appointed inspectors to ensure that freight was being properly weighed and classified, and regularly audited members' accounting records. For

\footnotetext{
${ }^{4}$ Over this same period, physical gaps in the network were also being closed by cross-town connections between depots (e.g., Richmond in 1867) and bridges over the major rivers (e.g., the Ohio River at Louisville in 1868 and Cincinnati in 1877), such that differences in gauge were the primary obstacle to a physically integrated network.

${ }^{5}$ The SRSA both preceded and was the model for future railroad cartels, including the Joint Executive Committee, which governed railroads running between the Midwest and East Coast and has been widely studied in the economics literature (e.g., Ulen 1979, Porter 1983, Ellison 1994, and others). Though the SRSA has received less attention, contemporaries claimed that it "came nearer to fulfilling the purposes for which it was intended than any other association ever formed for the regulation of competition in this country" (Haines 1905).
} 
a select set of routes, the cartel also compiled these data into monthly traffic reports, which it then circulated to cartel members and which have since been preserved.

The amended mechanism proved so effective that in 1887, the cartel reported that "since 1878, all balances have been paid and rates thoroughly maintained," excepting one month in 1878 (Hudson 1890) - a sharp contrast to frequent pre-cartel rate wars. There are several reasons why the cartel was successful, beginning with the mechanism itself, which muted carriers' incentives to cut prices to capture a greater share of traffic. Railroads that refused to join the cartel were denied through traffic, which effectively amounted to a boycott. The SRSA also demonstrated early on that when competing carriers (members or not) deviated from cartel prices, it would act quickly and decisively by setting destructively low rates until cartel pricing was restored.

The passage of the Interstate Commerce Act (ICA) in February 1887 presented a new threat to the cartel. The ICA prohibited traffic pooling, making the cartel's apportionment mechanism illegal, but the act "by no means put an end to the power of the Association" (Hudson 1890). ${ }^{6}$ The SRSA responded by transitioning to a system of fines for price deviations, with mileage-based deposits, and it continued collecting and disseminating members' traffic and revenue. The SRSA continued to operate in this way until 1890, when the Sherman Act delivered the lethal blow by prohibiting combinations in restraint of trade. At this point, the cartel stopped circulating traffic data. Though it took several years for the courts to resolve initial ambiguities over whether the SRSA met the statute's definition, by 1897 the cartel had dissolved.

\subsection{The Gauge Change}

As trade between the South and other regions accelerated after the Civil War, incompatibilities became increasingly costly: by the 1880s, "not a prominent point could be found on the border [of the South] without its hoist and acres of extra trucks" (Hudson 1887), and the total cost of delays were growing one-for-one with volume. The first cracks in the $5^{\prime} 0^{\prime \prime}$ network developed in 1881 and 1885, when two major lines linking the Midwest to the South (the Illinois Central and the Mobile \& Ohio) converted their tracks to standard gauge, increasing pressure on their Southern competitors and connections to follow suit, and providing a template for execution.

At the cartel's annual convention in July 1885, representatives of member railroads discussed the severity of the compatibility problem and concluded they would convert to standard gauge in the

\footnotetext{
${ }^{6}$ The act had little impact in its early years, and if anything may have empowered carriers and helped stabilized prices (Prager 1989, Blonigen and Cristea 2013), consistent with the revisionist interpretation of Kolko (1965), who notes that railroads welcomed the regulation. Other sources suggest that the content of the ICA, and the Interstate Commerce Commission it created, were subject to near-total regulatory capture.
} 
following year, and at a follow-on meeting on February 2-3, 1886, these railroads committed to and began preparing a mass conversion to a $4^{\prime} 9^{\prime \prime}$, standard-compatible gauge on May 31 and June 1 of that year. ${ }^{7}$ The gauge change was carefully planned and seamlessly executed: in the weeks leading up to the event, railroads removed the ties on their tracks and took a subset of their rolling stock (rail cars, locomotives) out of service to adjust its gauge; then, on the evening of May 30, all traffic halted, and teams of hired labor worked up and down each line, removing remaining ties, shifting one rail $3 "$ inwards, resetting ties, and moving to the next segment. By midday on June 1, 13,000 miles of track had been converted to 4' 9", and traffic had resumed, with freight now moving freely across Southern borders in a physically integrated railroad network. ${ }^{8}$

To verify the scale of the conversion, I collect individual railroads' gauges and mileage from Poor's Manual of Railroads (1882-1890), an annual publication listing the universe of railroads in North America. Table 1 shows the fraction of railroad track in standard-compatible gauge by region and year throughout the 1880s. Whereas other regions generally had $95 \%$ of their track in standard or standard-compatible gauge by 1881 , nearly $70 \%$ of Southern railroad mileage began the decade in 5' $0^{\prime \prime}$ gauge. The discrepancy remained until the year of the gauge change: between 1885 and 1887 , the total in 5' 0" gauge declined by 13,006 miles, and the fraction of Southern railroad in standard or standard-compatible gauge discretely jumped from $29 \%$ to $92 \%$. Panels (B) and (C) of Figure 1 show the updated gauge of the 1861 railroad network as of 1881 and 1891, respectively (omitting new construction), illustrating the geographic scope of the conversion.

[Table 1 about here]

The historical record suggests that network externalities were important in propelling the gauge change and were recognized by contemporaries. The returns to adopting a compatible gauge were low for railroads on the periphery if interior neighbors did not follow - the effect would be to shift the break from the top to the bottom of the line, with no benefits to through traffic - and negative for interior railroads acting alone. But the gains were higher in a coordinated, regional

\footnotetext{
${ }^{7}$ The 4' 9" gauge was chosen to match that of the Pennsylvania Railroad, an important connection in the Mid-Atlantic, and because it was thought that the smaller adjustment would reduce the cost of converting rolling stock (Puffert 2009), but it was understood to be compatible with the 4' 8.5'" standard (Puffert 2009); as Taylor and Neu (1956) write, "such a deviation was not considered a serious obstacle to through shipment."

${ }^{8}$ The execution of the gauge change is covered in greater depth by several other sources (e.g., Hudson 1887, Taylor and Neu 1956, and Puffert 2009). Extrapolating from the costs of converting the Louisville \& Nashville (detailed in its 1886 annual report) to all $5^{\prime} 0^{\prime \prime}$ mileage, the total cost of the gauge change was likely at least $\$ 1.2$ million in 1886, equivalent to $\$ 31$ million today - but another, smaller Southern railroad (the Cincinnati, New Orleans, \& Texas Pacific) spent nearly twice as much per mile. To put the cost in perspective, the L\&N's expenditure on the gauge change was $30 \%$ of its construction expense in 1886 and $37 \%$ of net income, and the CNO\&TP's expenditure was roughly 1.6 times the previous annual direct cost of its breaks in gauge.
} 
conversion. The cartel thus appears to have supported the gauge change in several ways. First, it provided an institutional venue for coordinating on a common gauge and organizing the conversion event itself. But equally importantly, collusion internalized the externalities of compatibility, and non-competitive pricing ensured that railroads could recoup the cost of the conversion. Without either collusion or consolidation, it is possible the gauge change itself might not have occurred at this time or scale - a question which I explore further in Section 4.

\section{Data and Empirical Design}

I use SRSA records of freight traffic into and out of the South by railroad and steamship to study the effects of the gauge change. ${ }^{9}$ I restrict attention to annual merchandise shipments from Northern port cities to cities in the interior South, as merchandise comprised the largest fraction of tonnage in the South at this time and an even greater fraction of value (U.S. Department of Interior 1883). ${ }^{10}$ The sample throughout the paper is a balanced panel of 52 North-South routes (4 origins x 13 destinations) with merchandise shipments apportioned, monitored, and reported by the cartel before and after the gauge change, observed over the 1883-84 to 1889-90 fiscal years. Appendix Figure A.2 maps the origins and destinations in this sample. The gauge change coincides precisely with the end of the SRSA's 1885-86 fiscal year on May 31.

Due to the diffuse ownership of the network, shipments to the interior South necessarily traversed multiple railroads, or a steamship and a railroad, to reach their destination. The SRSA tables report traffic and revenue by routing (see Appendix A), which I aggregate up to mode: all-rail versus steamship. I include separate observations for the two all-rail paths into the South, the Atlantic Coast Line (ACL) and the Piedmont Air Line (PAL), each of whose constituent railroads shared a common owner, and which are explicitly denoted in the SRSA tables. The primary sample thus has $1,092(=52 \cdot 3 \cdot 7)$ observations at the route-mode-year level. ${ }^{11}$

The analysis begins with a simple comparison of all-rail and steamship traffic within individual

\footnotetext{
${ }^{9}$ Route-level traffic data (both freight and passenger) from this period are rare. Data on the routes in this paper are available only because they were compiled into tables which were circulated to SRSA members, by order of the cartel's commissioner, and later bound and preserved. Despite an extended effort, I have been unable to find comparable data for other routes to supplement those studied below, nor to find data to study earlier conversions, such as those by the Illinois Central or Mobile \& Ohio, which were not members of the cartel.

${ }^{10}$ Cotton shipments in the reverse direction comprise a smaller sample, were dwindling over the period due to growth in Southern textile production, and could potentially be influenced by fluctuations in foreign demand, and are thus excluded. Shipments of merchandise and commodities from the Midwest are also excluded, as they grew rapidly over the decade and only became part of the collusive agreement (and thus, had their traffic monitored and recorded) beginning in 1887, subsequent to the gauge change (Hudson 1890).

${ }^{11}$ To simplify the exposition, the specifications below are presented as if the ACL and PAL were aggregated into a single observation, but the tables in Section 3 include them as separate observations.
} 
routes before and after the gauge change. Because they bypassed breaks in gauge, steamships were not directly affected by the gauge change and accordingly provide a comparison group for all-rail shipments. However, breaks in gauge imposed a fixed cost on through shipments, such that they were a larger proportion of total costs on short routes relative to long routes. I therefore relax the effects to vary with distance - with this approach, the longer, less-affected routes then serve as a triple-difference control group against the shorter and more intensively-treated ones. These specifications are thus estimated in a triple-difference form:

$$
\begin{aligned}
\ln \left(Q_{m r t}\right)= & \beta_{0} \\
& +\beta_{1} \text { Rail }_{m}+\beta_{2} \text { Post }_{t}+\beta_{3} \text { Dist }_{r} \\
& +\beta_{4} \text { Rail }_{m} \text { Post }_{t}+\beta_{5} \text { Rail }_{m} \text { Dist }_{r}+\beta_{6} \text { Post }_{t} \text { Dist }_{r} \\
& +\beta_{7} \text { Rail }_{m} \text { Post }_{t} \text { Dist }_{r}+X_{m r t} \gamma+\varepsilon_{m r t}
\end{aligned}
$$

where $Q_{m r t}$ is pounds of traffic carried by mode $m$, on route $r$, in year $t ; R_{a i l}$ is an indicator for the all-rail mode (ACL and PAL); Post $t_{t}$ indicates the post-period; and Dist $t_{r}$ is the distance from origin to destination (in hundreds of miles). Throughout the analysis, I measure straight-line distance, rather than traveled distance, which is not observed for either mode and unobservable for seaborne shipments (contemporary sources in Appendix A indicate straight-line and rail network distance are in fixed proportion for the sampled routes). The $X_{m r t}$ term includes an assortment of fixed effects. In all specifications, I cluster standard errors by route, though the results are robust to allowing spatial correlation in the error term that declines linearly in the distance between Southern destinations up to 20-, 50-, 100-, and 200-mile cutoffs (Conley 1999).

It is important to note that although the above specification will determine whether all-rail and steamship traffic diverged following the gauge change, and is useful for evaluating the robustness of the results to an assortment of fixed effects or controls, it does not precisely identify the effects of standardization on the level of all-rail shipments, as steamships may have simultaneously lost traffic to railroads. For a different view of the data not subject to this qualification, I estimate a simple logit demand model on market shares, rather than quantities, which can account for this interdependence. Suppose mode shares are generated by discrete consumer choices, for which mode $m$ on route $r$ in year $t$ has latent utility that is a function of the mode and period (all-rail versus steamship, before versus after the gauge change), the interaction with distance, and other fixed route-mode and route-year specific characteristics $\gamma_{m r}$ and $\delta_{r t}$ :

$$
\begin{aligned}
u_{i m r t}=[ & \beta_{0} \text { Rail }_{m}+\beta_{1} \text { Rail }_{m} \text { Post }_{t}+\beta_{2} \text { Rail }_{m} \text { Post }_{t} \text { Dist }_{r} \\
& \left.+\gamma_{m r}+\delta_{r t}+\xi_{m r t}\right]+\eta_{i m r t} \equiv \mu_{m r t}+\eta_{i m r t}
\end{aligned}
$$


where $\eta_{i m r t}$ is an error term distributed type-I extreme value. The market share for each mode

is then $s_{m r t}=\frac{\exp \left(\mu_{m r t}\right)}{\sum_{\ell=1,2} \exp \left(\mu_{\ell r t}\right)}$, which is jointly determined with that of the other mode. Indexing railroads as $m=1$ and steamships as $m=2$, we can reduce to:

$$
\begin{aligned}
\ln \left(s_{1 r t}\right) & -\ln \left(s_{2 r t}\right)=\mu_{1 r t}-\mu_{2 r t} \\
& =\tilde{\beta}_{0}+\tilde{\beta}_{1} \text { Post }_{t}+\tilde{\beta}_{2} \text { Post }_{t} \text { Dist }_{r}+\gamma_{r}+\varepsilon_{r t},
\end{aligned}
$$

Finally, to evaluate the effects of the gauge change on combined traffic, I collapse the sample to route-years and estimate a regression for route-level shipments:

$$
\ln \left(Q_{r t}\right)=\beta_{0}+\beta_{1} \text { Post }_{t}+\beta_{2} \text { Post }_{t} \text { Dist }_{r}+\gamma_{r}+\varepsilon_{r t}
$$

To the extent that the gauge change differentially impacted shorter versus longer routes, the effects on route-level shipments should emerge in the interaction.

\section{$3 \quad$ Standardization and Freight Shipments}

In this section, I examine the first-order effects of the gauge change, showing that the standardization of Southern gauge triggered a redistribution of traffic from steamships to railroads but does not appear to have affected total shipments on these routes. It may be helpful to provide a roadmap to these results in advance. I first present descriptive statistics for the sampled routes, pre- and postgauge change, which foreshadow the results that follow. I then estimate the effects of the gauge change on all-rail versus steamship traffic, as well as on overall shipments, where the empirical puzzle emerges. At the end of the section, I discuss possible explanations for the results, focusing especially on the ways in which cartel pricing may have limited the growth in total shipments and (implicitly) the consumer welfare gains from standardization.

\subsection{Descriptive Statistics}

Table 2 provides descriptive statistics for the sampled routes, comparing shorter and longer routes ( $<25$ th and $>75$ th percentiles, respectively), pre- versus post-gauge change. The table shows means and standard errors of tonnage, revenue, and all-rail shares. The shorter routes in the sample had less traffic than longer routes throughout the sample period but carried more of this traffic by rail. Total shipments grew at similar rates for the shorter and longer routes over the sample period. However, following the gauge change, the all-rail share of traffic on shorter routes jumped from 
an average of $40 \%$ to an average of $56 \%$, an increase significant beyond the one percent level. In contrast, the all-rail share on longer routes declined from $23 \%$ to $19 \%$, not a statistically significant difference. These results provide the first hints of the puzzle that will emerge below: the gauge change was important enough to prompt substitution across modes, but evidently not enough to increase aggregate shipments in the short- to medium-run.

[Table 2 about here]

\subsection{Effects of the Gauge Change}

\subsubsection{Distributional Effects}

Table 3 estimates the specification in Equation (1), with a slight transformation to estimate modespecific constants instead of shared constants (for purposes of presentation). Column (1) estimates this model as specified, and Columns (2) through (6) add an assortment of fixed effects for routes, years, route-modes, and route-years. Only the focal, post-period parameters are shown in the table, which measure within-mode changes over time (Columns 1 to 4), or alternatively, when comparisons are within route-years, the mode difference-in-differences (Columns 5 and 6 ). ${ }^{12}$

[Table 3 about here]

This first cut indicates that after the gauge change, all-rail traffic increased and steamship traffic declined on the (more intensively-treated) shorter routes in the data, with these effects diminishing with route length (indeed, in the data, the pattern inverts for the longest routes, with steamship traffic growing and all-rail traffic falling on these routes, which serve as a comparison group; see Table 2). To put the magnitudes in perspective, the estimates imply a $50 \%$ increase in all-rail traffic and $30 \%$ decrease in steamship traffic on the shortest route in the sample (500 miles), and inverted patterns on routes longer than 700 to 800 miles.

In Table 4, I split the all-rail estimates by carrier, to both (i) confirm that effects are present for each of the two all-rail paths into South (the ACL and PAL) and (ii) explore any heterogeneity in their magnitude. We see effects for both paths, with the initially less-trafficked one (the ACL) seeing a larger percent increase in traffic (off of its lower base). I also find that the effects dissipate to zero at similar distances for the two routings (roughly 700 miles).

\footnotetext{
${ }^{12}$ In Columns (5) and (6), all residual variation is between modes, and the steamship coefficients drop out of the regression (being absorbed by the fixed effects). The all-rail coefficients in these columns are comparable to the difference between all-rail and steamship coefficients in the previous columns.
} 
[Table 4 about here]

As previously discussed, a specification in quantities can establish whether all-rail and steamship traffic diverged following the gauge change, and whether the results are robust to controls. However, steamships are a problematic control group, due to the interdependence of all-rail and steamship traffic with imperfect competition: steamships may have also been affected by the gauge change if they lost traffic to railroads, and as a result, they do not provide a clean counterfactual to the railroads. For an alternative approach, in Table $5 \mathrm{I}$ estimate a simple logit demand model that accounts for this interdependence (Equation 2), in which the outcome variable is the log difference in all-rail and steamship shares of traffic in the given route-year. In taking this difference, most of the fixed effects from the previous table are eliminated, such that Table 5 contains only two variants of the regression: without and with route fixed effects.

[Table 5 about here]

The results continue to show positive effects on all-rail shares that decline with distance, significant beyond the one percent level. The estimates are similar across the two specifications, and the effect of the gauge change is estimated to dissipate at roughly 720 miles, statistically and economically comparable to the previous tables. When these effects are split out for the ACL and PAL, they are again larger for the less-trafficked ACL, consistent with previous results.

In Appendix D, I test the sensitivity of these results to dropping individual origins, destinations, and years from the cartel sample. Given the limited number of routes (52) and the somewhat short panel (3 years pre-gauge change, 4 years post), these checks are necessary to establish that the results are not driven by outliers or subsamples (for example, by routes originating in Baltimore, the origin nearest to the South). I find consistent results throughout. I also run similar regressions for revenue, which is provided alongside the traffic statistics in the SRSA tables, and find identical effects of the gauge change in sign and magnitude. This result is a natural consequence of the high correlation between quantities and revenues in the data $(\rho=0.99)$.

\subsubsection{Aggregate Effects}

The results thus far show that the gauge change caused growth in all-rail market share, but leave ambiguous to what degree this effect is strictly substitution across modes versus new activity in the market. Table 6 addresses this question, collapsing the data to the route level and examining 
the effects on total traffic and revenue (Equation 3). The even-numbered columns include route fixed effects. Across all specifications, we see no evidence that shorter routes (where previous tables showed the gauge change had the strongest effects on market shares) grew more quickly than longer routes following the gauge change: the variation in the post-gauge change growth in traffic for routes of different length is a true, and precisely-estimated, zero. ${ }^{13}$

[Table 6 about here]

\subsubsection{Other Views of the Data}

We can also break these regressions out into annual effects, to test for pre-trends and to explore how the response to the gauge change varied over time. A priori it is unclear whether the effects would be immediate or would phase in: on the one hand, the change was immediate and comprehensive, and improved service available from the first day after the conversion; on the other hand, it may have taken time for information to spread, or for shippers to adjust. I estimate Equations 1 and 3 with route fixed effects for (i) all-rail versus steamship traffic and (ii) combined traffic, allowing the coefficients to vary by year. The estimates are plotted in Figure 2.

[Figure 2 about here]

Relative to the omitted year of 1884, differences between all-rail and steamship traffic did not vary in a statistically significant way in the years leading up to the gauge change (Panel A). However, beginning in 1887 (the first year post-gauge change), we see a growing divergence through the end of the panel, leveling out by around 1890. As in the regression tables, these effects are strongest for short routes and tempered by distance. Total shipments, however, are relatively stable throughout the period for both short and long routes (Panel B).

\subsection{Explaining the Results}

The evidence that the gauge change shifted traffic from steamships to railroads is sensible, albeit non-obvious, given contemporary use of adapter technologies. But juxtaposed against this result,

\footnotetext{
${ }^{13}$ In unreported analysis, I also verify that the estimates in Table 3 are consistent with on average a net zero effect on total shipments, and one that does not vary with route length. To do so, I begin with the true (observed) log shipments for each route-mode-year in the pre-gauge change sample, apply the estimates from Column (1) of Table 3 to calculate (linearly-projected) counterfactual log quantities with standardized gauge, exponentiate to levels, aggregate up to observed and counterfactual total quantities for route-years, and calculate the difference between them, as a measure of the implied "aggregate effect" of the gauge change at the route level. The average difference is $0.5 \%$ of observed values ( 25 th percentile $-5.4 \%, 75$ th percentile $7.0 \%$ ), and more importantly, consistent with the results in Table 6 , this difference is uncorrelated with route length $(\rho=0.07)$.
} 
the lack of an effect on total shipments poses an empirical puzzle. An additional piece of evidence to be considered is what happened to cartel prices: the SRSA's Circular Letters periodically include rate tables, which list current cartel freight rates on different routes, by class of merchandise. These tables show the prices that all carriers on the given route were committed to charging shippers, and they make it possible to track route-level price changes over time.

Figure 3 shows the distribution of rate changes on the routes in these circulars that are also in the sample for this paper (total of 36 routes, out of the 52 routes with traffic data). Panels A to D show a histogram of changes in class-level freight rates between July 1883, April 1884, February 1885, July 1885, and March 1886, a few months prior to the gauge change. Panel E shows the equivalent histogram for March 1886 to July 1887, one year after the gauge change. Each observation is a route-class, and with 36 routes and 13 freight rate classes, there are 468 observations per panel. An overwhelming fraction of routes do not see any price changes after April 1884, and the handful of price changes after the gauge change were (small) increases, rather than decreases, and limited to two routes: Philadelphia-Montgomery and Philadelphia-Selma. ${ }^{14}$

[Figure 3 about here]

Theoretical predictions for prices are ambiguous, as the quality of all-rail service increased at the same time as the cost of providing that service declined. For example, if the gauge change caused all-rail demand to shift out and marginal costs to decline on short routes, equilibrium prices could in principle be unchanged - although in a classical supply-and-demand framework, total quantities would then necessarily increase, so the puzzle remains. But there are other reasons why prices may have been rigid. For example, cartel freight rates applied uniformly to all carriers on a route to avoid perceptions that individual members were favored, and steamship companies in the cartel were unlikely to agree to rate reductions, as were interior railroads - neither of which saw direct cost savings as a result of the gauge change. A closer reading of SRSA documents reveals that the rate-setting process was contentious, and in the event of disagreement, rate-setting escalated to the cartel's board of arbitrators, which in practice was often the rate-setting body. Given the absence of price changes, either the matter was never raised for discussion or the board of arbitrators did not view a rate reduction as the appropriate action. In effect, it appears that the cartel believed prices were sufficiently close to profit-maximizing to leave them unchanged.

\footnotetext{
${ }^{14}$ Cartel prices were not always this stable: until the early 1880s, prices were reduced regularly, under pressures of competition from alternative routing outside the scope of the cartel. Multiple sources have documented this decline, while also observing that price reductions ended in the early- to mid-1880s (e.g., Hudson (1890) documents prices from Boston, New York, Philadelphia, and Baltimore to Atlanta from 1875 onward, and shows that rate reductions occurred every 1-2 years until 1884, after which rates went unchanged).
} 
That this price rigidity explains the empirical puzzle is merely one possibility. Another possibility is that the market for final goods needed more time to adjust, and the panel is too short to see the aggregate effects materialize. It might also be that on the demand side, the choice over mode was simply more elastic to the gauge change than the decision to ship at all. However, the presence of a well-functioning cartel is a conspicuous feature of the setting which likely contributed to these outcomes. In the next section, I use theory to explore how the gauge change and its observed effects might relate to collusion. Proofs are provided in Appendix E.

\section{Compatibility and Collusion}

\subsection{Incentives for standardization}

Suppose that to get from a Northern origin on the $4^{\prime} 8.5^{\prime \prime}$ network to a Southern destination on the $5^{\prime} 0^{\prime \prime}$ network, a shipment may traverse up to two connecting Southern railroads, R1 and R2. Shipments from the North to $D_{1}$ (at the endpoint of R1) and $D_{2}$ (at the endpoint of R2) incur a fixed cost of $\theta$ per ton for interchange at the border, as illustrated in the inset below:

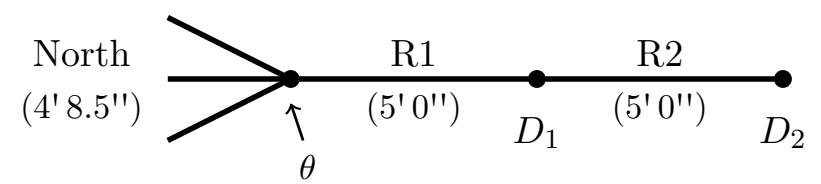

Annual shipments (e.g., tonnage) to destination $d$ can be written $Q\left(P_{d}\right)=M_{d}-a P_{d}$, where $M_{d}$ is the market size, $P_{d}$ is the freight tariff (per ton), and $a>0$ (to simplify the task of illustrating basic principles, I invoke linear demand throughout this section). We will assume $D_{1}$ is a waypoint and $D_{2}$ is a larger market (or collection of markets) further downstream, with $M_{2}>2 M_{1}$, which is broadly consistent with the historical setting. Suppose R1's segment is length $\ell_{1}$ and R2's is $\ell_{2}$, and let $c_{d}$ denote the per-ton shipment cost to $d$ incurred independent of any breaks in gauge (the cost of carriage), which is proportional to route length. Shipment revenue and costs are in turn divided among the carriers involved, as they appear to have been historically (for example, for shipments to $D_{1}, \mathrm{R} 1$ retains all revenue but also bears all of the costs, whereas for shipments to $D_{2}, \mathrm{R} 1$ and R2 divide costs and revenues proportionally; see Appendix B). Let the railroads' cost of converting to standard gauge be $C_{1}$ and $C_{2}$, also proportional to route length.

To simplify the exposition, I will further assume that R1 and R2 are equal length, and that breaks in gauge create an interchange cost but do not directly enter demand, though these assumptions 
are not essential to the results and can be relaxed, as the latter will be in the next section. Because $\ell_{1}=\ell_{2}$, we can define $c \equiv c_{1}$ be the cost of carriage to $D_{1}$, such that $2 c$ is the cost to $D_{2}$, and let $C \equiv C_{1}=C_{2}$ be each railroad's cost of standardizing its gauge.

In this setting, each firm's returns to standardization depends on the other's choice. If R1 converts alone, a gauge break is eliminated for shipments to $D_{1}$ but remains for those to $D_{2}$, as the break moves down the line. If $\mathrm{R} 2$ converts alone, a second break would be introduced for shipments to $D_{2}$. And if R1 and R2 both adopt standard gauge, breaks are removed entirely, eliminating the cost of interchange. Prices may decline as well, insofar as the cost savings are passed through to prices. To allow for this possibility, we must specify the railroads' profit maximization problem. $\mathrm{R} 1$ and $\mathrm{R} 2$ thus set prices $\left\{P_{d}\right\}$ to each destination $d$ to maximize:

$$
\Pi_{d}\left(P_{d}\right)=\left(P_{d}-c_{d}\right) Q_{d}-\theta\left(B_{d} Q_{d}\right)
$$

where $\Pi_{d}$ are the profits on shipments to destination $d$, and $B_{d}$ denotes the number of gauge breaks en route to destination $d$ (each incurring a cost of $\theta$ ). Taking into account the division of profits by $\mathrm{R} 1$ and R2, firm-specific profits are $\pi_{R 1}=\Pi_{1}+\frac{1}{2} \Pi_{2}$ and $\pi_{R 2}=\frac{1}{2} \Pi_{2}$, respectively. This construction leads to the following lemma characterizing the payoffs to standardization, where the superscripts in the notation indicate the choices of $\mathrm{R} 1$ and $\mathrm{R} 2$, respectively.

Lemma 1. Standardization can generate the following payoffs to $R 1$ and $R 2$ relative to the status quo, before accounting for the fixed cost of conversion $C$ :

a. If $R 1$ converts alone: $\Delta \pi_{R 1}^{10}>0, \Delta \pi_{R 2}^{10}=0$

b. If R2 converts alone: $\Delta \pi_{R 1}^{01}<0, \Delta \pi_{R 2}^{01}<0$

c. If $R 1$ and R2 convert jointly: $\Delta \pi_{R 1}^{11}>\Delta \pi_{R 1}^{10}, \Delta \pi_{R 2}^{11}>0$

In view of this lemma, we will make one more assumption: suppose $\Delta \pi_{R 1}^{10}<C<\Delta \pi_{R 2}^{11}$, such that this cost is at least as large as the direct savings that $\mathrm{R} 1$ would realize if it converted to standard gauge alone (otherwise R1 would have already done so), but not so large that it R2 would never find it profitable to standardize its gauge. ${ }^{15}$ As long as this is the case, the following proposition establishes that there are two equilibria of the simultaneous-move game in the adoption of standard gauge: joint conversion and the status quo (no change).

\footnotetext{
${ }^{15}$ The size of the downstream market ensures that $\Delta \pi_{R 1}^{10}<\Delta \pi_{R 2}^{11}$ (see Appendix E). The independent conversions of the Illinois Central and the Mobile \& Ohio can be explained in this model as a violation of this assumption, where $\Delta \pi_{R 1}^{10}>C$ - meaning that it was profitable to convert to standard gauge alone. This can be the case if, for example, the markets which these lines directly served were sufficiently large.
} 
Proposition 1. In the absence of competition, provided $\Delta \pi_{R 1}^{10}<C<\Delta \pi_{R 2}^{11}$, there are two equilibria for standardization: either both firms convert to standard gauge, or neither firm converts (the status quo). Unilateral conversion to standard gauge is never an equilibrium.

Standardization is thus an equilibrium (and the Pareto-efficient) outcome in this model, but given that the status quo is also an equilibrium, conversion requires coordinated decision-making. This coordinated effort was supported by the existence of the cartel, beginning with the discussion at the cartel's annual convention in July 1885 where members agreed to convert their tracks, and the meeting half a year later where they finalized the date of the conversion, selected the new gauge, and planned the technical details of how to execute the change. ${ }^{16}$

To see the importance of collusive pricing to standardization, now suppose service is competed. We can add symmetric railroads $\mathrm{R} 3$ and $\mathrm{R} 4$, which compete against $\mathrm{R} 1$ and $\mathrm{R} 2$ to provide service to $D_{2}$, through a different intermediate point $D_{3}$ as illustrated below:

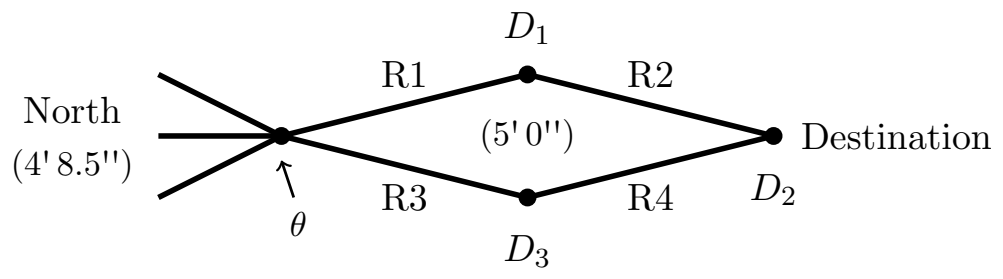

Consider shipments to $D_{2}$ (the only route on which the carriers compete), and let $Q_{R_{12}}$ and $Q_{R_{34}}$ be the quantity (in tons) carried by R1-R2 and R3-R4, but now let:

$$
Q_{i}(P, B)=M-\lambda B_{i}-a P_{i} \quad \text { for } \quad i, j \in\left\{R_{12}, R_{34}\right\}
$$

where $B_{i}$ indicates the presence of a gauge break on $i, \lambda$ is the direct effect of breaks on demand, and the other parameters are defined as before. As long as they are on the same gauge, shipment to via R1-R2 and R3-R4 is undifferentiated, demand will go to the lower-priced routing, and prices will be competed to marginal cost (as they often were throughout this era in the absence of collusion, e.g. Chandler 1977, Kolko 1965). If both R1-R2 and R3-R4 standardize, the per-ton cost savings $(\theta)$ will be passed through, leaving the firms with no means of recovering the fixed cost of changing the gauge $(C)$. As a result, collective standardization is not an equilibrium outcome. If instead the

\footnotetext{
${ }^{16} \mathrm{It}$ is worth noting that this proposition is in part a function of the static nature of the game. With multiple periods and sufficiently patient players, one party might be able to standardize at a short-run cost but realize long-run profits if its neighbors are then incentivized to follow. Indeed, the history (of other railroads) in Section 1 suggests that standardization of Southern railroads' gauge might have nevertheless eventually taken place in the absence of collusion, albeit perhaps not as early, as quickly, or at the same scale.
} 
carriers collude and set prices jointly, the Proposition 2 establishes that collective standardization can be an equilibrium outcome with mild regularity conditions.

Proposition 2. Collective standardization is only an equilibrium outcome with collusion.

\subsection{Effects of standardization under collusion}

The results thus far have demonstrated two ways in which collusion may have facilitated the gauge change, via coordination and incentives. However, collusion may have also tempered the effects on prices and total shipments if it limited pass-through, relative to what the effects would have been in a competitive environment. Even if the gauge change would have been less likely in a competitive market, this counterfactual offers a comparative benchmark. Can we explain the absence of a significant effect on prices or total quantities in the data with collusion?

To explore this question, we can continue to focus on a single route between an arbitrary Northern origin and Southern destination, as above, but enrich the model and now assume that rather than being served by two railroads, it is served by a railroad and a steamship (these can be interpreted as vertically-integrated all-rail versus steamship-to-rail, and are differentiated). Let $Q_{R}$ and $Q_{S}$ represent the quantity carried by railroad and by steamship, with:

$$
Q_{i}(\mathbf{P}, \mathbf{B})=M-\lambda B_{i}+\lambda B_{j}-a P_{i}+b P_{j} \quad \text { for } \quad i, j \in\{R, S\}, i \neq j
$$

where $B_{i}$ indicates the presence of a break on mode $i$ (breaks in gauge for all-rail / intermediate ports requiring transshipment for steamships); $\lambda$ is the direct effect of these breaks on demand, and can be interpreted as a quality parameter; $a$ and $b$ are own- and cross-price effects on demand, with $a>b>0$; and $M$ is the market size, which henceforth will be normalized to $M=1$. Each mode's demand is thus a function of own price and quality and the other mode's price and quality. As written, breaks in gauge have offsetting direct effects on demand $( \pm \lambda)$, such that market shares are sensitive to service quality, but total shipments are not - a feature which is necessary but not sufficient in explaining the earlier empirical patterns, as prices will also be endogenous to breaks in gauge and can shift aggregate demand independently of quality.

Suppose both modes have common per-ton marginal costs $c$, and an incremental per-ton cost of $\theta$ incurred at breaks, where transshipment or interchange is required. If the two carriers collude, they set a single price $P$ which applies to both carriers to maximize joint profits, whereas if they compete, they set prices $P_{R}$ and $P_{S}$ to maximize individual profits. With this simple model, we can 
explore the potential effects of the gauge change on prices and shipments with competition versus collusion. We begin by comparing collusive prices and quantities pre-gauge change $\left(B_{R}=B_{S}=1\right)$ versus post-gauge change $\left(B_{R}=0, B_{S}=1\right)$. Joint profits under collusion are:

$$
\Pi(\mathbf{P}, \mathbf{B})=(P-c)\left(Q_{R}+Q_{S}\right)-\theta\left(B_{R} Q_{R}+B_{S} Q_{S}\right)
$$

Proposition 3 establishes that in this setting, standardization should generate a reduction in the collusive price of a relatively low (but nonzero) fraction of the cost savings, modestly increase total shipments, and shift market share to the all-rail carrier. An immediate corollary is that there are two conditions under which prices and total shipments may not be affected by the gauge change, even as market share shifts across the two modes: (i) if $\theta=0$, such that transshipment and interchange were actually costless, or (ii) if there is a transaction cost to cartel price changes, and this cost exceeds the incremental profits that the carriers would realize by adjusting prices after standardizing the gauge. In the first case, breaks in gauge enter demand but not supply costs. The elimination of the gauge break will increase demand for all-rail shipping and generate an offsetting reduction in demand for steamships, and these effects in turn offset in the price-setting problem, such that the profit-maximizing cartel price is unchanged. In the latter case, small price adjustments may be too costly to justify, due to uncertainty or disagreement among cartel members over such changes and the previously-discussed difficulty of re-negotiation.

\section{Proposition 3. Effects of standardization on collusive price and quantities}

Eliminating the break in gauge reduces the collusive price by $\frac{1}{4} \theta$, redistributes market share from steamships to all-rail, and increases total shipments by $\frac{1}{2} \theta(a-b)$.

\section{Corollary 3.1. Conditions under which prices and total quantity may not change}

(i) If $\theta=0$, the collusive price and total shipments are unaffected by removing the break in gauge.

(ii) If $\theta>0$, and collusive prices and quantities do not adjust after removing the break in gauge, the cost of price adjustments must be greater than the foregone profits, $\frac{1}{8} \theta^{2}(a-b)$.

\subsection{Effects of standardization in differentiated oligopoly}

For comparison, we can evaluate the effects of the gauge change on prices, market shares, and total shipments when the two carriers compete on prices. We will consider the same route, but we now permit that the two carriers set their respective prices $P_{R}$ and $P_{S}$ individually and competitively 
in equilibrium. Each carrier's profits are thus:

$$
\Pi_{i}(\mathbf{P}, \mathbf{B})=\left(P_{i}-c\right) Q_{i}-\theta B_{i} Q_{i} \quad \text { for } \quad i \in\{R, S\}
$$

In this setting, the conversion to standard gauge has an ambiguous effect on the all-rail price, with upward pressure from increased demand and downward pressure from the reduction in costs. Steamship prices, however, unambiguously decline, due to their relative drop in demand. Substitution across modes still takes place, as in the collusive scenario, but more notably, total shipments will increase by more than they do in the collusive environment.

\section{Proposition 4. Effects of standardization in a competitive market}

Eliminating the break in gauge has an ambiguous effect on the all-rail price, depending on the size of a demand effect, which puts upward pressure on the all-rail price, and the pass-through of cost savings, which puts downward pressure. Steamship prices strictly decline, market share shifts from steamships to all-rail, and total shipments increase by $\frac{a \theta(a-b)}{2 a-b}$.

\section{Corollary 4.1. Comparing the effects by market structure}

Standardization generates a larger increase in total shipments under competition than collusion.

\subsection{Discussion}

This simple model can explain both the effect of the gauge change on mode shares and the absence of an effect on prices and total shipments, while demonstrating that price competition may have increased pass-through but would have also made the gauge change less likely. However, the two explanations proposed for why cartel prices might not adjust - that adjustments were costly, and that breaks in gauge were not actually costly - warrant further attention.

Ample evidence from cartel records - especially minutes from rate committee meetings - suggests that price changes were relatively difficult: rate-setting was contentious, requiring unanimous agreement of representatives from cartel members who almost always deadlocked. When rate cases then escalated to the cartel's internal board of arbitrators, which could issue a ruling by simple majority, these arbitrators often declined changes too (see Section 3).

Likewise, the historical evidence suggests that transshipment and interchange were also costly. The most reliable measures of railroads' direct costs from breaks in gauge are accounting costs, which can be obtained from annual reports. For example, the Cincinnati, New Orleans, \& Texas Pacific (CNO\&TP, which was an SRSA member and participated in the gauge change) reported its direct 
expense for breaks in gauge to be $\$ 32,365$ in 1884 and $\$ 33,355$ in 1885 , or $350 \%$ and $21 \%$ of the railroad's net income in each of these years $(\$ 9,210$ and $\$ 159,011$, respectively), with roughly half this cost attributed to the operation of steam hoists, and the other half to the payroll of transfer clerks and laborers. The CNO\&TP's annual reports further note that these figures do not include the indirect costs of "extra switching engines, extra yard crews, and no allowance is made for the loss... from delay to business" or for the opportunity cost of "freight thereby diverted" because its tracks are "blocked with loaded cars waiting their turn," nor do they account for the other ancillary costs discussed in Section 1 - such that the accounting cost is understated. Transshipment at port was similarly costly: although data from the 1880s are not available, in 1908, the transfer expense for freight transshipped from coastal steamships to the Georgia Railway (a former SRSA member) at Savannah, Georgia was 8 cents per hundred pounds for merchandise and 5 cents for commodities - which is on the order of $10-20 \%$ of the lowest merchandise and commodity rates for the routes in this paper - and rates for other Southern ports and other Southern railroads connecting to them were "practically the same" (U.S. Department of Commerce 1910).

Collectively, the evidence thus supports attributing the price rigidity seen in Section 3 to a combination of collusion (which dampened pass-through) and costly price adjustment (which impeded any residual changes), rather than to breaks in gauge not actually having been a material cost to carriers, which is further contradicted by their revealed preference for standardizing the gauge. In the absence of prices changes, total shipments were also unaffected.

\section{The View from Wall Street}

Taken together, the results in Sections 3 and 4 suggest the gauge change might have generated a windfall for Southern railroads (which reduced costs and gained share), at the expense of steamship operators (which lost share), with only limited benefits to consumers (as prices and total shipments were evidently unaffected). Although data for studying the impact of the gauge change on consumers is constrained to what is available in cartel records, our understanding of the impact on carriers can be rounded out by studying their stock prices.

To do so, I collect daily New York Stock Exchange (NYSE) closing prices from historical editions of the New York Times for January 1 to October 31, 1886. The vast majority of traded securities at this time were issued by railroads (146 of 177, including preferred stock), and a dozen Southern railroads were traded during this period. Using these data, we can perform an event study on 
railroad stock prices around the gauge change. ${ }^{17}$ Although some information about the impending conversion was provided in annual reports, Southern newspapers, and specialized railroad journals (see Appendix C), the event itself was uncertain until the date drew closer, and its effects could only be known ex-post. The gauge change appears to have not been a focus of the financial press until May 29, when the Commercial and Financial Chronicle (CFC) published a lengthy article notifying readers of the imminent event and explaining its importance.

I define an event window of two months around the gauge change (May 1, 1886 to June 30), estimate a standard market returns model on the preceding four months of railroad stock returns (through April 30, 1886), predict returns through the event window, and compute cumulative abnormal returns for each of the Southern railroads. Throughout the exercise, I restrict the sample to securities with at least 50 trading days in the estimation window and 100 trading days in the full sample to ensure that all estimates and tests are sufficiently-powered, although the results are not sensitive to the precise restriction imposed.

The gauge change coincides with large, positive abnormal returns to the Southern railroads that were most directly affected. Figure 4 shows the cumulative abnormal returns to the Louisville \& Nashville (L\&N), the largest railroad in the South by mileage and one of two that directly connected the South to other regions and were listed on the NYSE. The L\&N's cumulative abnormal returns are near zero and roughly constant until May 29 - the date that the CFC article is published when it realized a 4 percentage point positive abnormal return. Between May 29 and the end of the event window, the cumulative abnormal returns grew to 17 percentage points, as the impacts of the gauge change began to materialize. I find similar (albeit slightly higher variance) patterns for the Richmond \& Danville, another major system spanning the Southern border, but no such effects for interior Southern railroads - suggesting that investors believed the benefits were mainly realized by the lines where breaks in gauge were once located.

[Figure 4 about here]

The magnitude of the cumulative abnormal returns to the L\&N through the end of June suggests that the gauge change had a substantive financial impact on the affected railroads, and paired with earlier evidence that prices and overall quantities did not change, it suggests most of the benefits of the gauge change were appropriated by these carriers.

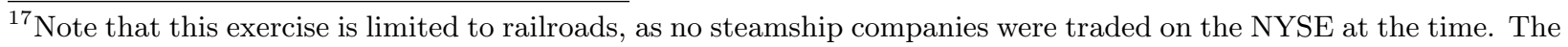
results are also limited to stock price changes and cannot be extended to measure changes in market capitalization (or other measures of value), because the number of outstanding shares is not observed.
} 


\section{Implications and Conclusion}

In summary, I find that the gauge change generated significant growth in all-rail market share that declines with route distance, but it did not affect prices or total shipments. To explain these results, I use theory to argue that the presence of the cartel may have enabled the gauge change to take place as it did, while likely also tempering the effects on prices and total shipments. The theory indicates that prices and total shipments may not be affected by standardization if either cartel price adjustments are sufficiently costly, or if interchange is in fact costless. Contemporary evidence appears to favor the former, as cartel meeting minutes document contentious debate around price changes, whereas railroads' annual reports demonstrate that the costs of servicing breaks in gauge were large enough to make an otherwise-profitable railroad unprofitable, and evidence from stock market returns indicates that investors perceived a windfall.

These results bring into focus a nuanced interaction of interoperability and product market competition. Although antitrust scholars and regulators have traditionally been more concerned with standards-setting efforts by competitors being a bridge to product market collusion, in this paper, it appears that collusion instead contributed to standards adoption - but with some of the classical downstream consequences. The tension between the two (effectively, between value creation and consumer welfare) can arise in any setting with strategic complementarities, but it may be particularly liable to occur in networked settings, where transactions are executed through intermediaries that interconnect for delivery, and the technological complementarities are therefore large - such as freight carriers (for physical trade), Internet service providers (communications), or financial exchanges (asset purchases). This tension is underappreciated in the academic literature but ripe for attention, especially since firms in many network industries not only benefit from interoperability but also have a natural tendency towards concentration.

The results also contribute to the largely-theoretical academic literature on technological compatibility. Compatibility standards can be found in nearly every technical product and industry, but to-date there is limited evidence directly linking them to firms' or market outcomes. In unveiling the ways in which the Southern gauge change affected the market for freight shipment, this paper provides a historical datapoint on the effects of compatibility on transactions and has implications for other settings where traffic is exchanged across connecting, incompatible networks, such as the those identified above. With archival data becoming increasingly accessible, historical settings such as the early U.S. telephone and railroad industries present a growing opportunity for future research on network connection, compatibility, and related themes. 


\section{References}

Argue, David A., Cartel Operation with Revenue Pooling and Output Quotas: The Southern Railway and Steamship Association 1990. Unpublished dissertation.

Atack, Jeremy, Historical Geographic Information Systems (GIS) database of U.S. Railroads for 1861 September 2015.

- and Robert A. Margo, "The Impact of Access to Rail Transportation on Agricultural Improvement: The American Midwest as a Test Case, 1850-1860," Journal of Transport and Land Use, 2011, 4, 5-18.

_, Michael Haines, and Robert A. Margo, "Railroads and the Rise of the Factory: Evidence for the United States, 1850-1870," in Paul W. Rhode, Joshua Rosenbloom, and David Weiman, eds., Economic Evolution and Revolutions in Historical Time, Palo Alto: Stanford University Press, 2011.

Basker, Emek and Timothy Simcoe, Upstream, Downstream: Diffusion and Impacts of the Universal Product Code. 2019. Working paper.

Besen, Stanley M. and Joseph Farrell, "Choosing How to Compete: Strategies and Tactics in Standardization," Journal of Economic Perspectives, 1994, 8 (2), 117-131.

Blonigen, Bruce A. and Anca Cristea, "The Effects of the Interstate Commerce Act on Transport Costs: Evidence from Wheat Prices," Review of Industrial Organization, 2013, 43 (1-2), 41-62.

Chandler, Alfred D. Jr., The Visible Hand: The Managerial Revolution in American Business, Cambridge: The Belknap Press, 1977.

Cincinnati, New Orleans \& Texas Pacific Railway Co., Report and Statement of Accounts 1884. Fiscal year ending December 31, 1884.

_, Report and Statement of Accounts 1885. Fiscal year ending December 31, 1885.

_, Report and Statement of Accounts 1886. Fiscal year ending December 31, 1886.

Conley, Timothy G., "GMM Estimation with Cross-Sectional Dependence," Journal of Econometrics, 1999, 92 (1), 1-45.

David, Paul A. and Julie Ann Bunn, "The Economics of Gateway TEchnologies and Network Evolution: Lessons from Electricity Supply History," Information Economics and Policy, 1988, 3, 165-202.

- and Shane Greenstein, "The Economics of Compatibility Standards: An Introduction to Recent Research," Economics of Innovation and New Technology, 1990, 1 (1-2), 3-41.

Economides, Nicholas, "Desirability of Compatibility in the Absence of Network Externalities," American Economic Review, 1989, 79 (5), 1165-81.

Ellison, Glenn, "Theories of Cartel Stability and the Joint Executive Committee," The RAND Journal of Economics, 1994, 25 (1), 37-57.

Farrell, Joseph and Garth Saloner, "Standardization, Compatibility, and Innovation," The RAND Journal of Economics, 1985, 16 (1), 70-83.

_ and _ , "Installed Base and Compatibility: Innovation, Product Preannouncements, and Predation," American Economic Review, 1986, 76 (5), 940-955.

_ and _, "Coordination through Committees and Markets," The RAND Journal of Economics, 1988, 19 (2), $235-252$.

_ and _, "Converters, Compatibility, and the Control of Interfaces," Journal of Industrial Economics, 1992, $40(1), 9-35$. 
Haines, Henry S., Restrictive Railway Legislation, New York: The MacMillan Company, 1905.

Hudson, Henry, "The Southern Railway and Steamship Association," Quarterly Journal of Economics, 1890, $5(1), 70-94$.

Joubert, Willam H., Southern Freight Rates in Transition, Gainesville: University of Florida Press, 1949.

Katz, Michael L. and Carl Shapiro, "Network Externalities, Competition, and Compatibility," American Economic Review, 1985, 75 (3), 424-440.

_ and _ , "Technology Adoption in the Presence of Network Externalities," Journal of Political Economy, $1986,94(4), 822-41$.

_ and _ , "Systems Competition and Network Effects," Journal of Economic Perspectives, 1994, 8 (2), 93-115.

Knittel, Christopher R. and Victor Stango, "Incompatibility, Product Attributes and Consumer Welfare: Evidence from ATMs," The B.E. Journal of Economic Analysis 83 Policy, 2008, 8, 1-42.

Kolko, Gabriel, Railroads and Regulation, 1877-1916, Princeton: Princeton University Press, 1965.

Krajewski, Markus, "The Great Lightbulb Conspiracy," IEEE Spectrum, 2014. September 24.

Li, Jing, Compatibility and Investment in the U.S. Electric Vehicle Market. 2019. Working paper.

Louisville \& Nashville Railroad Co., Annual Report to Investors 1886. Fiscal year ending June 30, 1886.

Matutes, Carmen and Pierre Regibeau, "Mix and Match": Product Compatibility without Network Externalities," The RAND Journal of Economics, 1988, 19 (2), 221-234.

_ and _ , "Compatibility and Bundling of Complementary Goods in a Duopoly," Journal of Industrial Economics, 1992, 40 (1), 37-54.

McHenry, James, "Atlantic and Great Western," The Railway Times, 1875, 38 (15), 361-362.

Minnesota Population Center, National Historical Geographic Information System: Version 2.0, Minneapolis: University of Minnesota, 2011.

Mueller, Milton L., Universal Service: Competition, Interconnection and Monopoly in the Making of the American Telephone System, Washington: AEI Press, 1997.

Poor, Henry V., "Cincinnati and Seaboard Railways," American Railroad Journal, 1851, 7 (37), 386.

_, Poor's Manual of Railroads of the United States. 1868. Volumes 1882, -84, -86, -88, -90.

Porter, Robert H., "A Study of Cartel Stability: The Joint Executive Committee, 1880-1886," The Bell Journal of Economics, 1983, 14 (2), 301-314.

Prager, Robin A., "Using Stock Price Data to Measure the Effects of Regulation: The Interstate Commerce Act and the Railroad Industry," The RAND Journal of Economics, 1989, 20 (2), 280-290.

Puffert, Douglas J., "The Standardization of Track Gauge on North American Railways, 1830-1890," The Journal of Economic History, 2000, 60 (4), 933-960.

_ , "Path Dependence in Spatial Networks: The Standardization of Railway Track Gauge," Explorations in Economic History, 2002, 39 (3), 282-314.

_, Tracks across Continents, Paths through History: The Economic Dynamics of Standardization in Railway Gauge, Chicago: University of Chicago Press, 2009.

Shapiro, Carl and Hal R. Varian, Information Rules, Boston: Harvard Business School Press, 1999. 
Siddall, William R., "Railroad Gauges and Spatial Interaction," Geographical Review, 1969, 59 (1), $29-57$.

Sindall, Charles A., "Development of the Traffic between the Southern States and the Northern and Northwestern States," in U.S. Treasury Department, ed., Report on the Internal Commerce of the United States, Washington: Government Printing Office, 1886.

Southern Railway and Steamship Association (SRSA), Circular Letters. 1875. Volumes 1-24.

Taylor, George R. and Irene D. Neu, The American Railroad Network, 1861-1890, Urbana and Chicago: University of Illinois Press, 1956.

Ulen, Thomas S., Cartels and Regulation: Late Nineteenth Century Railroad Collusion and the Creation of the Interstate Commerce Commission 1979. Unpublished dissertation.

_, "The Market for Regulation: The ICC from 1887 to 1920," American Economic Review: Papers and Proceedings, 1980, 70 (2), 306-310.

U.S. Department of Commerce and Labor, Report of the Commissioner of Corporations on Transportation by Water in the United States, Part III: Water Terminals, Washington: Government Printing Office, 1910.

U.S. Department of Justice and Federal Trade Commission, Antitrust Enforcement and Intellectual Property Rights: Promoting Innovation and Competition 2007.

U.S. Department of the Interior, Statistical Report of the Railroads in the United States in 1880, Washington: Government Printing Office, 1883.

White, John H. Jr., The American Railroad Freight Car, Baltimore: The Johns Hopkins University Press, 1993. 


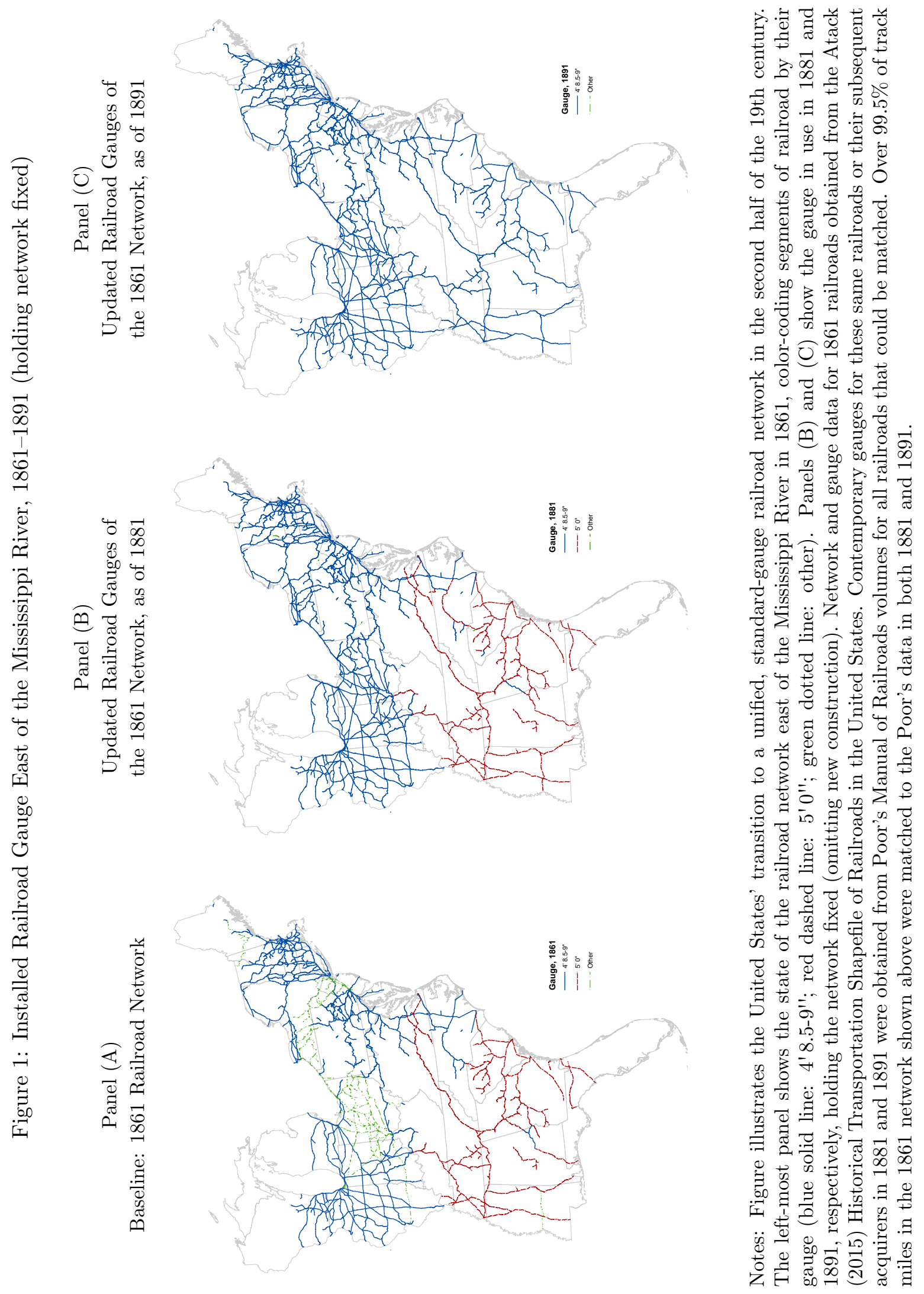


Figure 2: Changes in All-rail vs. Steamship Traffic and Total Traffic over Time

Panel A: All-rail vs. steamship DID

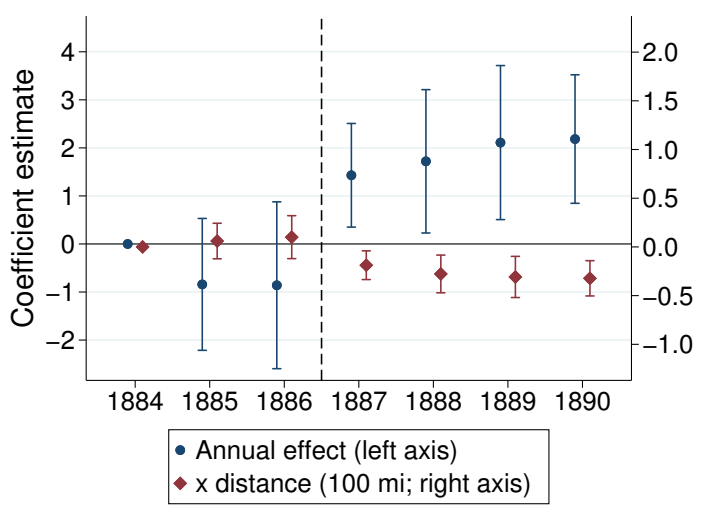

Panel B: Total route-level traffic

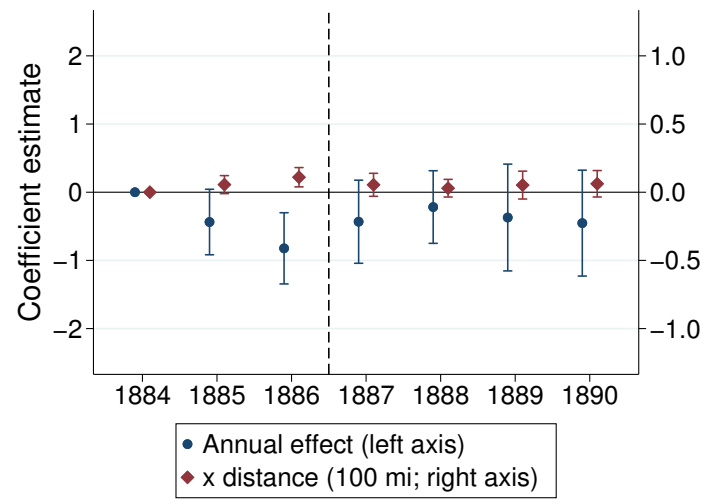

Notes: Figure shows the estimated changes in all-rail vs. steamship traffic (Panel A) and in total route-level traffic (Panel B) on the sampled routes by year, relative to 1884. Panel (A) plots coefficients from a regression in which log quantities are regressed on an indicator for the all-rail mode, interacted with indicators for year (in blue), and triple-interacted with route length (in red). Panel (B) plots coefficients from a regression of log quantities at the route-year level on indicators for year (in blue), interacted with route length (in red). SEs clustered by route and $95 \%$ confidence intervals provided around each point estimate. 
Figure 3: Distribution of Cartel Price Changes, pre- vs. post-Gauge Change

Panel A:

Jul. 1883 to Apr. 1884

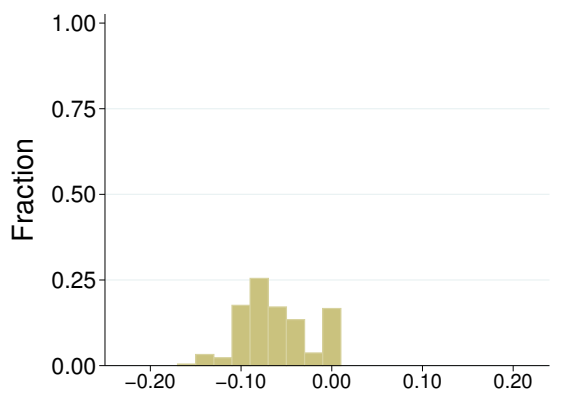

Panel C:

Feb. 1885 to Jul. 1885

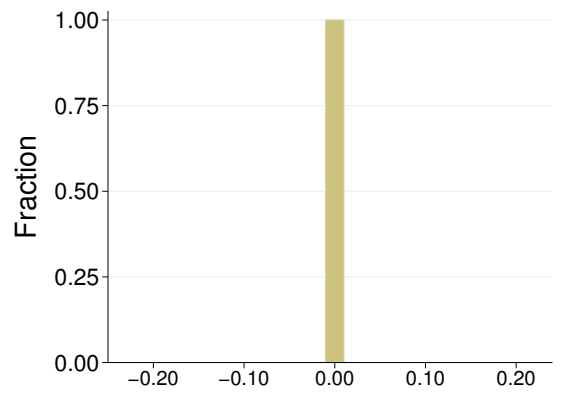

Panel B:

Apr. 1884 to Feb. 1885

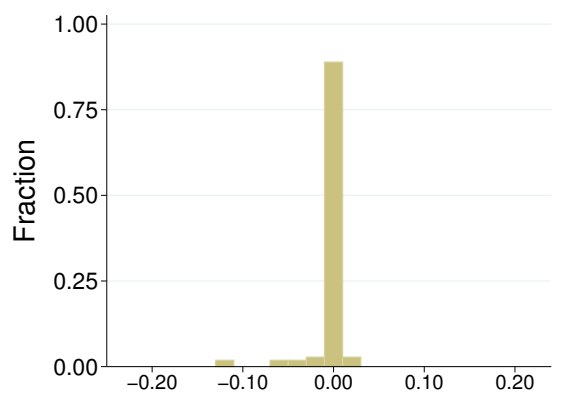

Panel D:

Jul. 1885 to Mar. 1886

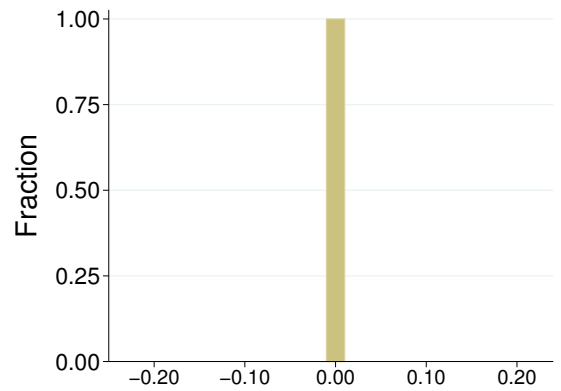

Panel E:

Mar. 1886 (pre-gauge change) to Jul. 1887 (post-change)

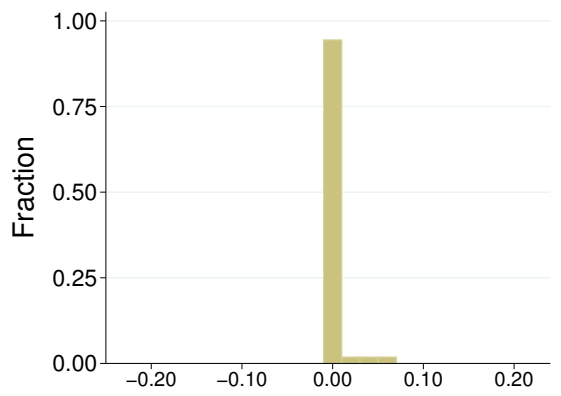

Pct. change in freight rates, across routes and class of merchandise

Notes: Figure shows the distribution of cartel price changes across routes and classes of merchandise throughout the sample period, for the subset of routes appearing in both the SRSA freight traffic tables and the rate tables. The handful of rate increases in Panel E come entirely from two routes: Philadelphia to Montgomery, and Philadelphia to Selma. Data from SRSA Circular Letters, Volumes 13-24. 
Figure 4: Cumulative Abnormal Returns to L\&N Stock, May 1 to June 30, 1886

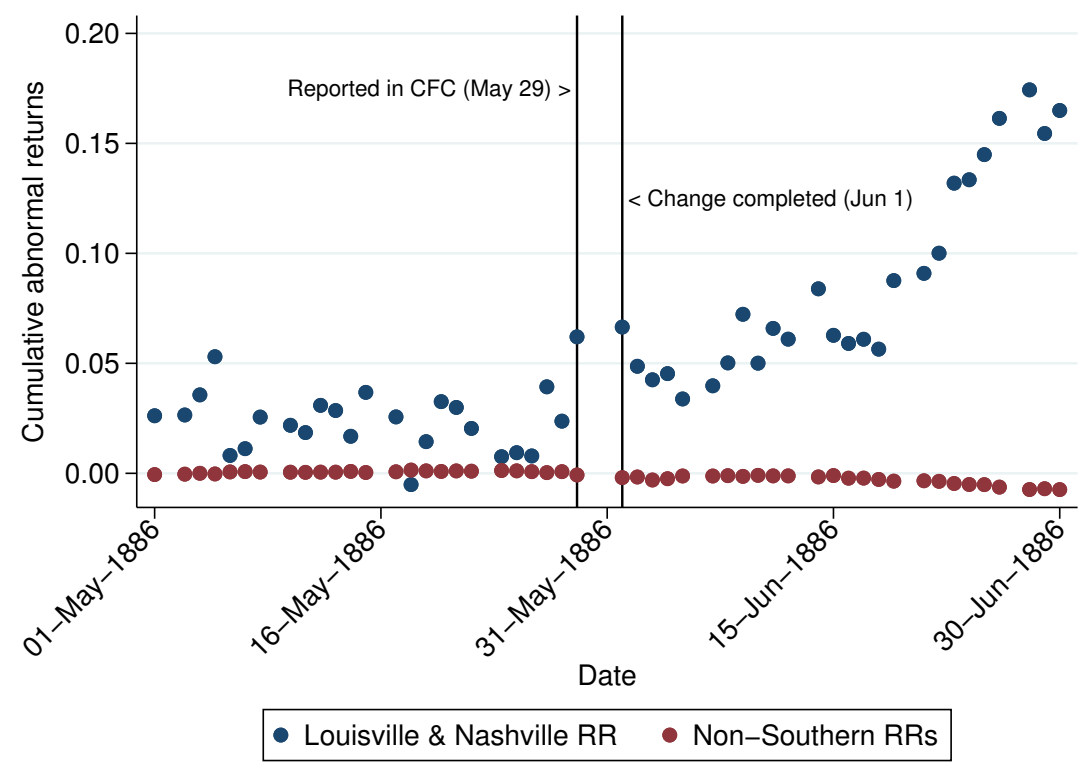

Notes: Figure shows cumulative abnormal returns to the stock of the Louisville \& Nashville Railroad, the largest railroad in the South by mileage and one of two that directly connected the South to other regions and were listed on the NYSE, in a two-month window around the gauge change. The figure marks two key dates around the gauge change: May 29, when the event was first announced and discussed at length in the Commercial and Financial Chronicle, and June 1, when the change was completed. See text for additional discussion. Data from New York Times historical stock quote tables. 
Table 1: Approx. Miles of Railroad in each Gauge, by Region, 1881-1889 (Poor's Manual of Railroads)

\begin{tabular}{|c|c|c|c|c|c|c|}
\hline & & \multicolumn{3}{|c|}{ Pre-Gauge Change } & \multicolumn{2}{|c|}{ Post-Gauge Change } \\
\hline & & 1881 & 1883 & 1885 & 1887 & 1889 \\
\hline \multirow[t]{2}{*}{ New England } & Total Miles & $6,251.3$ & $6,283.8$ & $6,418.2$ & $6,784.9$ & $6,744.1$ \\
\hline & Pct. 4' 8.5-9" & $97 \%$ & $97 \%$ & $97 \%$ & $97 \%$ & $98 \%$ \\
\hline \multirow[t]{2}{*}{ Mid-Atlantic } & Total Miles & $15,845.6$ & $18,588.1$ & $19,792.2$ & $19,420.9$ & $20,893.3$ \\
\hline & Pct. 4' 8.5-9" & $94 \%$ & $95 \%$ & $96 \%$ & $96 \%$ & $97 \%$ \\
\hline \multirow[t]{2}{*}{ Midwest } & Total Miles & $37,246.4$ & $41,470.0$ & $40,495.6$ & $43,559.5$ & $46,966.7$ \\
\hline & Pct. 4'8.5-9" & $94 \%$ & $93 \%$ & $94 \%$ & $97 \%$ & $98 \%$ \\
\hline \multirow[t]{2}{*}{ South (focal region) } & Total Miles & $17,257.5$ & $19,316.6$ & $20,694.3$ & $23,596.7$ & $26,793.4$ \\
\hline & Pct. 4' 8.5-9" & $25 \%$ & $25 \%$ & $29 \%$ & $92 \%$ & $94 \%$ \\
\hline \multirow[t]{2}{*}{ Western States } & Total Miles & $29,834.8$ & $39,575.8$ & $41,078.0$ & $51,948.4$ & $58,318.5$ \\
\hline & Pct. 4' 8.5-9" & $88 \%$ & $85 \%$ & $89 \%$ & $92 \%$ & $93 \%$ \\
\hline
\end{tabular}

Notes: Table shows the approximate miles of railroad in the U.S. from 1881 to 1889 in two-year intervals and fraction in standard-compatible gauge, confirming the scale of the conversion: 13,000 miles of Southern railroad converted from 5'0" to 4' 9" between 1885 and 1887. Data from Poor's Manual of Railroads, which provides a near-complete, annual enumeration of U.S. railroads.

Table 2: Descriptive Statistics: Traffic, Revenue, and All-Rail Shares, for Short vs. Long Routes

\begin{tabular}{|c|c|c|c|c|}
\hline & \multicolumn{2}{|c|}{$\begin{array}{l}\text { Short Routes } \\
(<25 \text { th pctile })\end{array}$} & \multicolumn{2}{|c|}{$\begin{array}{c}\text { Long Routes } \\
\text { (>75th pctile) }\end{array}$} \\
\hline & Pre & Post & Pre & Post \\
\hline Route-years & 39 & 52 & 39 & 52 \\
\hline Route Distance (mi) & $\begin{array}{c}589.01 \\
(6.90)\end{array}$ & $\begin{array}{c}589.01 \\
(5.95)\end{array}$ & $\begin{array}{l}977.65 \\
(10.54)\end{array}$ & $\begin{array}{l}977.65 \\
(9.09)\end{array}$ \\
\hline Tons $(1,000 \mathrm{~s})$ & $\begin{array}{c}715.88 \\
(130.58)\end{array}$ & $\begin{array}{c}818.55 \\
(134.66)\end{array}$ & $\begin{array}{l}1066.39 \\
(210.85)\end{array}$ & $\begin{array}{l}1161.54 \\
(221.31)\end{array}$ \\
\hline Revenue $(\$ 1,000 \mathrm{~s})$ & $\begin{array}{c}8.61 \\
(1.48)\end{array}$ & $\begin{array}{c}8.97 \\
(1.41)\end{array}$ & $\begin{array}{l}14.59 \\
(3.03)\end{array}$ & $\begin{array}{l}15.21 \\
(3.02)\end{array}$ \\
\hline All-Rail Share, Tonnage & $\begin{array}{c}0.40 \\
(0.04)\end{array}$ & $\begin{array}{c}0.56 \\
(0.03)\end{array}$ & $\begin{array}{c}0.23 \\
(0.03)\end{array}$ & $\begin{array}{c}0.19 \\
(0.03)\end{array}$ \\
\hline All-Rail Share, Revenue & $\begin{array}{c}0.41 \\
(0.04)\end{array}$ & $\begin{array}{c}0.57 \\
(0.03)\end{array}$ & $\begin{array}{c}0.24 \\
(0.03)\end{array}$ & $\begin{array}{c}0.20 \\
(0.03)\end{array}$ \\
\hline
\end{tabular}

\footnotetext{
Notes: Table reports average tonnage, revenue, and all-rail shares of traffic and revenue for shorter versus longer routes (below the 25th percentile and above the 75th percentile of route length, respectively), before versus after the gauge change. Standard error of each mean in parentheses.
} 
Table 3: Change in All-Rail Traffic

\begin{tabular}{lcccccc}
\hline \hline & $(1)$ & $(2)$ & $(3)$ & $(4)$ & $(5)$ & $(6)$ \\
\hline All-rail x post-change & $1.658^{* * *}$ & $1.672^{* * *}$ & $1.663^{* * *}$ & $1.721^{* * *}$ & $2.466^{* * *}$ & $2.541^{* * *}$ \\
& $(0.316)$ & $(0.298)$ & $(0.307)$ & $(0.316)$ & $(0.559)$ & $(0.582)$ \\
$*$ distance (100 mi) & $-0.227^{* * *}$ & $-0.239^{* * *}$ & $-0.238^{* * *}$ & $-0.244^{* * *}$ & $-0.331^{* * *}$ & $-0.341^{* * *}$ \\
& $(0.042)$ & $(0.041)$ & $(0.041)$ & $(0.042)$ & $(0.073)$ & $(0.075)$ \\
Steamship x post-change & $-0.779^{* *}$ & $-0.756^{* *}$ & $-0.761^{* *}$ & $-0.763^{* *}$ & & \\
& $(0.319)$ & $(0.306)$ & $(0.320)$ & $(0.312)$ & & \\
$\quad *$ distance (100 mi) & $0.096^{* *}$ & $0.089^{* *}$ & $0.090^{* *}$ & $0.090^{* *}$ & & \\
& $(0.040)$ & $(0.037)$ & $(0.037)$ & $(0.038)$ & & \\
\hline $\mathrm{N}$ & 1036 & 1036 & 1036 & 1036 & 1036 & 1036 \\
$R^{2}$ & 0.32 & 0.67 & 0.67 & 0.73 & 0.70 & 0.75 \\
Route FE & & $\mathrm{X}$ & $\mathrm{X}$ & & & \\
Year FE & & & $\mathrm{X}$ & & & $\mathrm{X}$ \\
Route-mode FE & & & & $\mathrm{X}$ & $\mathrm{X}$ & $\mathrm{X}$ \\
Route-yr FE & & & & & & \\
\hline \hline
\end{tabular}

Notes: Table estimates effect of the gauge change on merchandise shipments for shorter versus longer routes. Observations are route-mode-years. The dependent variable in all columns is log pounds of traffic. Estimates in Columns (1) to (4) should be interpreted as mode-specific changes relative to the pre-period; those in Columns (5) and (6) as differencesin-differences due to the route-year FEs. ${ }^{*},{ }^{* *},{ }^{* * *}$ represent significance at the $0.1,0.05$, and 0.01 levels, respectively. SEs clustered by route in parentheses.

Table 4: Change in All-Rail Traffic, ACL and PAL

\begin{tabular}{|c|c|c|c|c|c|c|}
\hline & (1) & $(2)$ & (3) & (4) & $(5)$ & (6) \\
\hline A.C.L. $\mathrm{x}$ post-change & $\begin{array}{c}2.061 * * * \\
(0.443)\end{array}$ & $\begin{array}{c}2.082^{* * *} \\
(0.472)\end{array}$ & $\begin{array}{c}2.074^{* * *} \\
(0.477)\end{array}$ & $\begin{array}{c}2.064^{* * *} \\
(0.477)\end{array}$ & $\begin{array}{c}2.848^{* * *} \\
(0.686)\end{array}$ & $\begin{array}{c}2.809^{* * *} \\
(0.671)\end{array}$ \\
\hline * distance $(100 \mathrm{mi})$ & $\begin{array}{c}-0.302^{* * *} \\
(0.059)\end{array}$ & $\begin{array}{c}-0.310^{* * *} \\
(0.064)\end{array}$ & $\begin{array}{c}-0.309^{* * *} \\
(0.064)\end{array}$ & $\begin{array}{c}-0.306^{* * *} \\
(0.064)\end{array}$ & $\begin{array}{c}-0.403^{* * *} \\
(0.094)\end{array}$ & $\begin{array}{c}-0.396^{* * *} \\
(0.090)\end{array}$ \\
\hline P.A.L. $\mathrm{x}$ post-change & $\begin{array}{c}1.030 * * * \\
(0.356)\end{array}$ & $\begin{array}{c}0.973^{* *} \\
(0.435)\end{array}$ & $\begin{array}{c}0.956^{* *} \\
(0.438)\end{array}$ & $\begin{array}{l}1.045^{* *} \\
(0.432)\end{array}$ & $\begin{array}{l}1.748^{* *} \\
(0.754)\end{array}$ & $\begin{array}{l}1.829^{* *} \\
(0.754)\end{array}$ \\
\hline * distance (100 mi) & $\begin{array}{c}-0.143^{* * *} \\
(0.050)\end{array}$ & $\begin{array}{c}-0.151^{* *} \\
(0.062)\end{array}$ & $\begin{array}{c}-0.150^{* *} \\
(0.061)\end{array}$ & $\begin{array}{c}-0.158^{* *} \\
(0.062)\end{array}$ & $\begin{array}{c}-0.247^{* *} \\
(0.100)\end{array}$ & $\begin{array}{c}-0.253^{* *} \\
(0.101)\end{array}$ \\
\hline Steamship x post-change & $\begin{array}{c}-0.779 * * \\
(0.320)\end{array}$ & $\begin{array}{c}-0.770^{* *} \\
(0.311)\end{array}$ & $\begin{array}{c}-0.776^{* *} \\
(0.326)\end{array}$ & $\begin{array}{c}-0.763^{* *} \\
(0.313)\end{array}$ & & \\
\hline * distance (100 mi) & $\begin{array}{c}0.096^{* *} \\
(0.040)\end{array}$ & $\begin{array}{c}0.092^{* *} \\
(0.038)\end{array}$ & $\begin{array}{c}0.093^{* *} \\
(0.038)\end{array}$ & $\begin{array}{c}0.090^{* *} \\
(0.038)\end{array}$ & & \\
\hline $\mathrm{N}$ & 1036 & 1036 & 1036 & 1036 & 1036 & 1036 \\
\hline$R^{2}$ & 0.48 & 0.83 & 0.84 & 0.89 & 0.86 & 0.91 \\
\hline $\begin{array}{l}\text { Route FE } \\
\text { Year FF }\end{array}$ & & $\mathrm{X}$ & $\begin{array}{l}X \\
X\end{array}$ & & & \\
\hline Route-mode FE & & & & $\mathrm{X}$ & & $\mathrm{X}$ \\
\hline Route-yr FE & & & & & $\mathrm{X}$ & $\mathrm{X}$ \\
\hline
\end{tabular}

Notes: Table estimates effect of the gauge change on merchandise shipments for shorter versus longer routes. Observations are route-mode-years. The dependent variable in all columns is log pounds of traffic. Estimates in Columns (1) to (4) should be interpreted as mode-specific changes relative to the pre-period; those in Columns (5) and (6) as differencesin-differences due to the route-year FEs. ${ }^{*},{ }^{* *},{ }^{* * *}$ represent significance at the $0.1,0.05$, and 0.01 levels, respectively. SEs clustered by route in parentheses. 
Table 5: Effects on Traffic Shares

\begin{tabular}{lcc}
\hline \hline & $(1)$ & $(2)$ \\
\hline All-rail x post-change & $2.281^{* * *}$ & $2.400^{* * *}$ \\
& $(0.428)$ & $(0.450)$ \\
$*$ distance $(100 \mathrm{mi})$ & $-0.315^{* * *}$ & $-0.327^{* * *}$ \\
& $(0.056)$ & $(0.058)$ \\
\hline $\mathrm{N}$ & 676 & 676 \\
$R^{2}$ & 0.12 & 0.45 \\
Route FE & & $\mathrm{X}$ \\
\hline \hline
\end{tabular}

Notes: Table estimates effect of the gauge change on allrail traffic shares on shorter versus longer routes. The dependent variable is the $\log$ difference in all-rail and steamship shares within route-years. ${ }^{*},{ }^{* *},{ }^{* * *}$ represent significance at the $0.1,0.05$, and 0.01 levels, respectively. SEs clustered by route in parentheses.

Table 6: Change in Total Traffic/Revenue

\begin{tabular}{lcccc}
\hline \hline & \multicolumn{2}{c}{ Ln(Freight traffic) } & \multicolumn{2}{c}{ Ln(Revenue) } \\
& $(1)$ & $(2)$ & $(3)$ & $(4)$ \\
\hline Post-change & 0.039 & 0.051 & -0.114 & -0.091 \\
& $(0.230)$ & $(0.222)$ & $(0.183)$ & $(0.186)$ \\
$*$ * distance (100 mi) & -0.000 & -0.006 & 0.009 & 0.003 \\
& $(0.031)$ & $(0.028)$ & $(0.023)$ & $(0.022)$ \\
\hline $\mathrm{N}$ & 360 & 360 & 360 & 360 \\
$R^{2}$ & 0.01 & 0.96 & 0.01 & 0.97 \\
Route FE & & $\mathrm{X}$ & & $\mathrm{X}$ \\
\hline \hline
\end{tabular}

Notes: Table estimates the effect of the gauge change on total shipments. Observations are route-years. The dependent variable in Columns (1) to (2) is log quantities; in Columns (3) to (4), log revenue. *, **, *** represent significance at the $0.1,0.05$, and 0.01 levels, respectively. SEs clustered by route in parentheses. 
Web Appendix 


\section{A Data Appendix}

This paper draws on several sources of data, most importantly the SRSA records of freight traffic on the set of routes apportioned, monitored, and reported to cartel members. As the paper explains, the SRSA collected daily data on the traffic and revenue of carriers on any route where at least one member requested apportionment, compiled these data into monthly and annual totals, and then circulated the data for select routes to cartel members. These tables, as well as other SRSA circulars, were organized into semiannual volumes and have been preserved in original hard copy at the New York Public Library and Yale University archives. ${ }^{1}$

Figure A.1 provides an example table from these records. The table shows pounds and revenue of merchandise shipments from Boston to Augusta, GA for the 1886-87 and 1887-88 fiscal years. The table lists five different paths that freight traveled for this route: three by steamship plus rail, and two entirely by rail. All-rail shipments can be identified as "via A.C.L." or "via P.A.L.", while the steamship line items indicate the intermediate ports where freight was transshipped (here, Savannah and Charleston). Similar tables are available for other destinations, origins, and years, although in most cases a table shows data for one period only.

Figure A.1: Example of Table from SRSA Traffic Reports

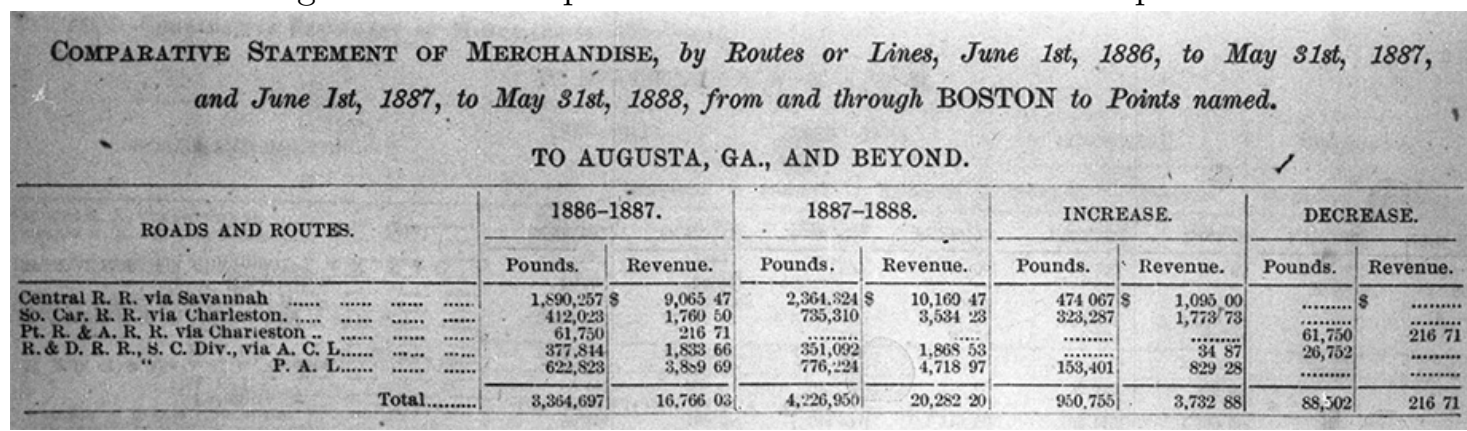

Notes: Figure shows an extracted table from the source data. The table lists total pounds of traffic and revenue from merchandise shipments from Boston to Augusta, GA by carrier, for June 1 to May 31, 1886 and for the same period in 1887. All-rail paths (termed "routes" in the table) can be identified as either A.C.L. or P.A.L.

For the second half of the sample, the cartel operated on a June to May fiscal year and reported annual data accordingly. This accounting period is ideally suited to the purposes of this paper, as the gauge change occurred over May 31 and June 1, 1886 - such that the cartel's annual data provide the cleanest possible comparison. However, until 1886, the cartel operated on a September to August fiscal year. For this earlier period, I therefore collected year-to-date (YTD) traffic in May and August, in order to back out shipments for the June to May period. Concretely: The 1884 fiscal year spanned September 1883 to August 1884, but this paper requires totals from June to May. To obtain them, I transcribed data from three YTD tables in the cartel traffic reports: September 1882 to May 1883 (1), September 1882 to August 1883 (2), and September 1883 to May

\footnotetext{
${ }^{1} \mathrm{~A}$ subset of the content in these circular letters are also available on microfilm from HBS Baker Library, though the microfilm omits the monthly traffic reports which yield the data in this paper.
} 
1884 (3). I then impute June 1883 to May 1884 traffic as (2)-(1)+(3).

The primary sample in the paper contains 52 routes, with 4 Northern origins and 13 Southern destinations. Table A.1 lists the origins and destinations in this sample (also mapped in Figure A.2). To make clear how all-rail freight reached Southern interior cities, Figure A.3 shows maps of the A.C.L. and P.A.L. circa 1885. Both served nearly every route in nearly every year, with a few exceptions: the P.A.L. did not deliver freight to Macon in 1884-86, Athens in 1886, or Albany in any year, and the A.C.L. did not deliver to Albany in 1890 (as inferred from their absence from the respective traffic tables). Additionally, no data are available for Albany in 1887. As a result, the sample reported in tables is reduced from $1,092(=52 \cdot 3 \cdot 7)$ to 1,036 .

Table A.1: Origins and Destinations for Sampled Routes

\begin{tabular}{|c|c|c|c|}
\hline \multicolumn{2}{|c|}{$\begin{array}{l}\text { Destinations } \\
\quad \text { (south) }\end{array}$} & \multicolumn{2}{|c|}{$\begin{array}{l}\text { Origins } \\
\text { (north) }\end{array}$} \\
\hline Albany & GA & Boston & MA \\
\hline Athens & GA & New York & NY \\
\hline Atlanta & GA & Philadelphia & $\mathrm{PA}$ \\
\hline Augusta & GA & Baltimore & MD \\
\hline Macon & GA & & \\
\hline Milledgeville & GA & & \\
\hline Newnan & GA & & \\
\hline Rome & GA & & \\
\hline Montgomery & $\mathrm{AL}$ & & \\
\hline Opelika & $\mathrm{AL}$ & & \\
\hline Selma & $\mathrm{AL}$ & & \\
\hline \multirow{2}{*}{\multicolumn{2}{|c|}{ A. \& W. Pt. stations (GA) }} & & \\
\hline & ions (GA) & & \\
\hline
\end{tabular}

Notes: Table lists the origin and terminus of routes in the sample of Northern merchandise shipments used in the remainder of this paper. These 52 routes ( 4 origins $\mathrm{x} 13$ destinations) are those for which data was reported by the Southern Railway and Steamship Association both before and after the gauge change. "A. \& W. Pt. Stations" refers to stations on the Atlanta and West Point Railroad between East Point and West Point, GA (70 mi), whose traffic was reported collectively; "W. \& A. Stations" refers to stations on the Western and Atlantic Railroad between Chattanooga, TN and Marietta, GA (87 mi). These destinations are geotagged to the centroid of their respective endpoints. 
Figure A.2: Map of Sampled Origins (North) and Destinations (South)

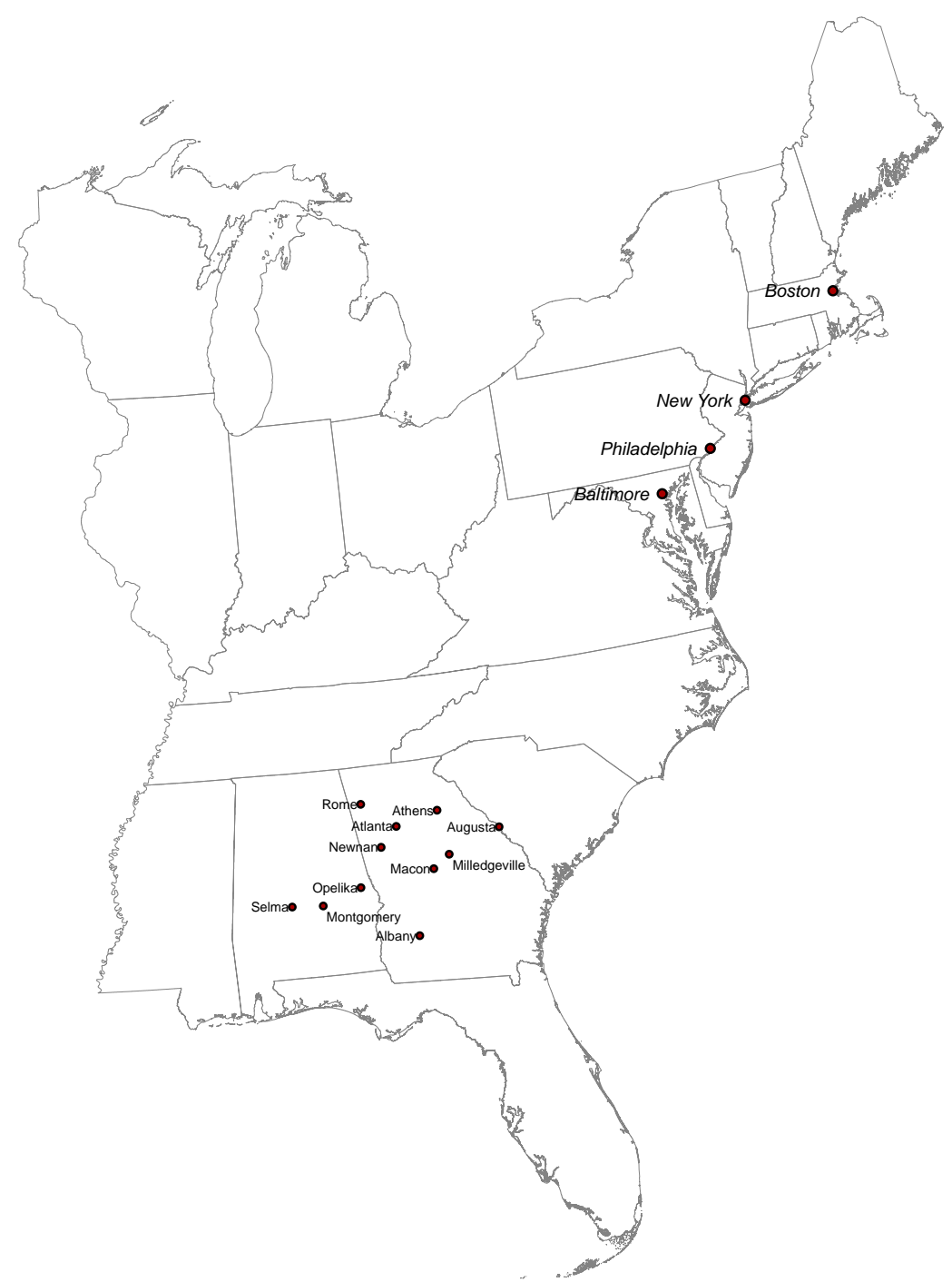

Notes: Figure shows the northern route origins and southern destinations for routes in the sample. These destinations are those for which data was reported by the Southern Railway and Steamship Association both before and after the gauge change. Not shown are two additional destinations in the data, "A. \& W. Pt. Stations" (stations on the Atlanta and West Point Railroad between East Point and West Point, GA, 70 mi., whose traffic was reported collectively), and "W. \& A. Stations" (stations on the Western and Atlantic Railroad between Chattanooga, TN and Marietta, GA, 87 mi.); these destinations are geotagged to the centroid of their respective endpoints. Freight transportation was available by all-rail routes traversing Virginia, Tennessee, and the Carolinas or by a combination of steamship and railroad, via southern port cities such as Charleston, Savannah, Norfolk, and Port Royal. 
Figure A.3: All-Rail Paths connecting North and South ca. 1885

Panel A: Atlantic Coast Line (A.C.L.)

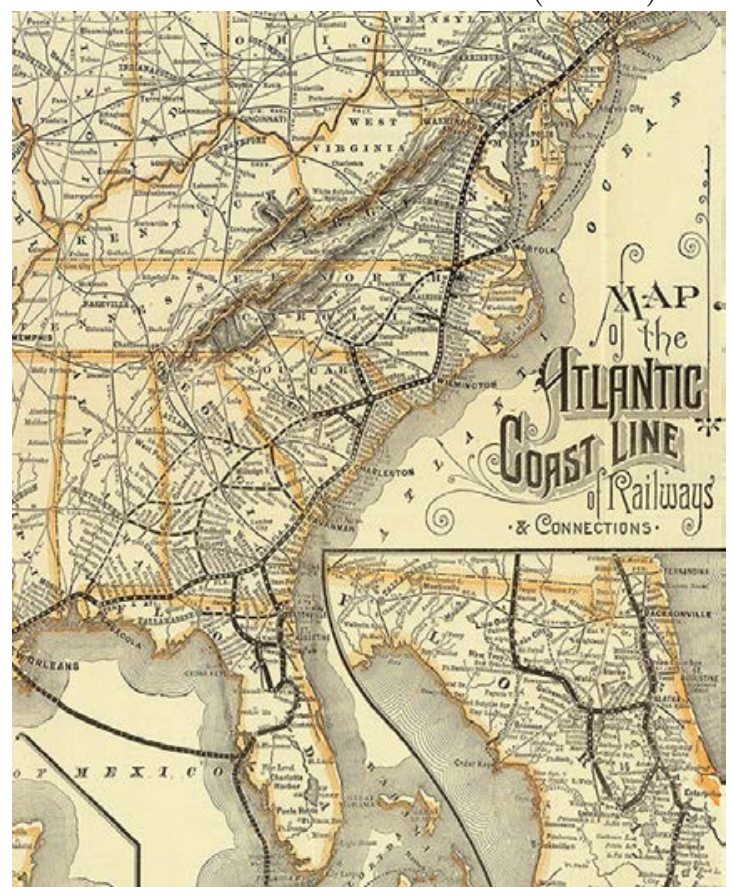

Panel B: Piedmont Air Line (P.A.L.)

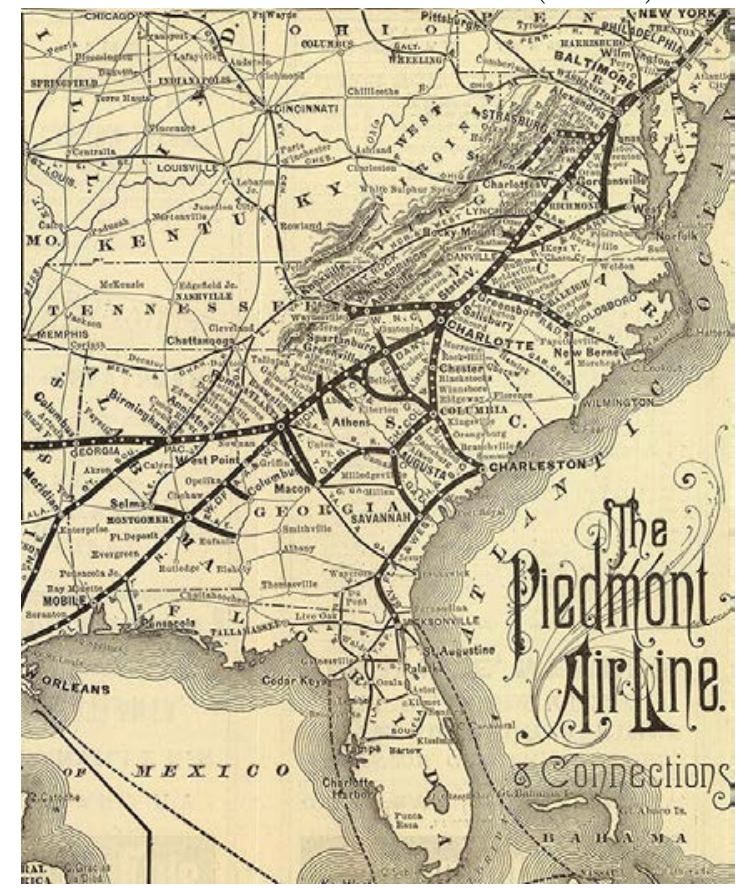

Notes: Figure provides maps of the two all-rail paths between the North and South, as of 1885: the Atlantic Coast Line and Piedmont Air Line. Each was established by mutual agreement among the traversed railroads to facilitate interregional traffic. Maps acquired from the David Rumsey Historical Map Collection.

On a few routes, merchandise shipments between Northern and Southern cities are occasionally indicated to have entered the South from the West, via the Louisville and Nashville or the Cincinnati Southern - crossing the Ohio River at Louisville and Cincinnati, respectively. In these cases, it remains ambiguous whether the active mode was all-rail versus river steamer plus connecting railroad. I thus omit these shipments from the analysis. As Figure A.4 shows, little is lost: the omitted shipments on average comprise $0.8 \%$ of traffic in any given year. 
Figure A.4: Western paths' share of North-South traffic

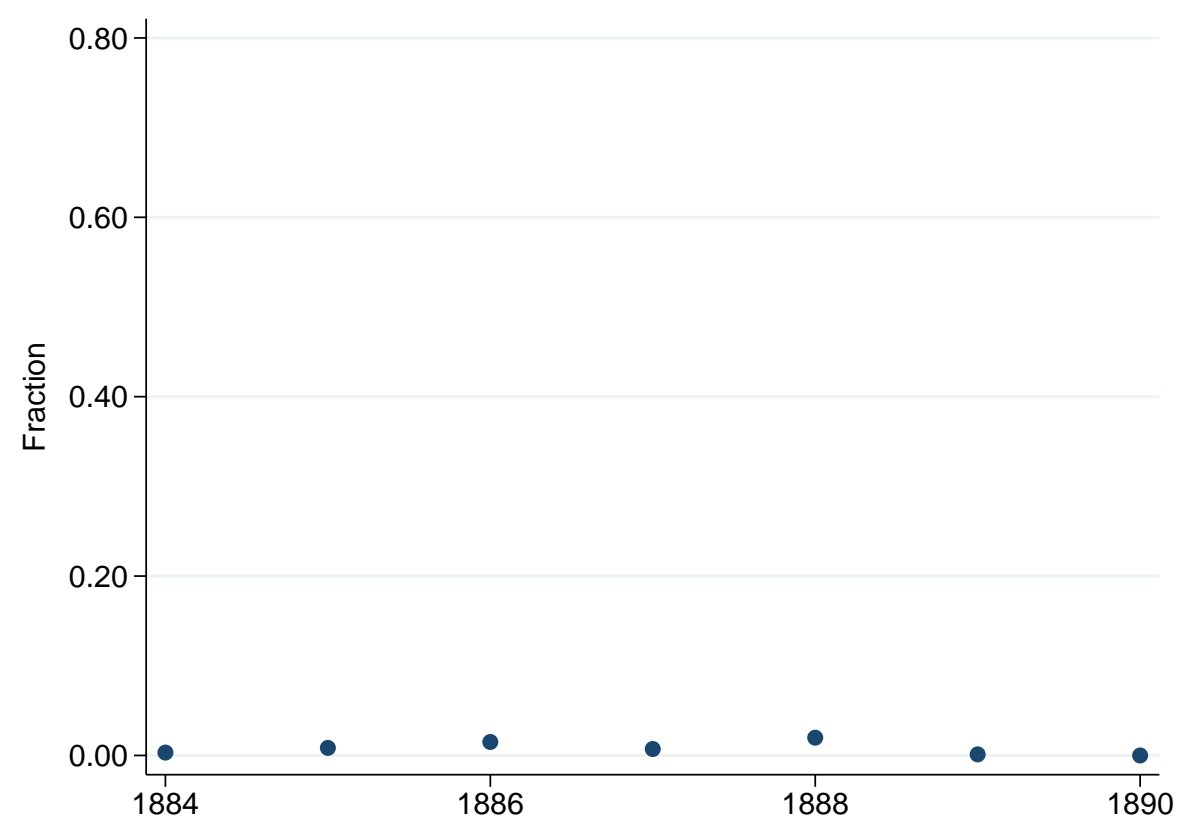

Notes: Figure shows the annual proportion of total traffic on the sampled routes reported to have been by the L. \& N. and the C.S. Railroads, ostensibly after having crossed the Ohio River. Due to ambiguity over the mode of westward travel, this traffic is omitted from all analysis.

To estimate effects that vary with route length, I must measure distances between origin and destination. Throughout the paper, I measure distance as "straight-line" (geodesic) distance, rather than traveled distance, which is not observed. Though traveled distance can in concept be computed for all-rail routes using maps and mapping software, the same cannot be done for steamships, and it is unclear what additional information is generated. Indeed, one early-twentieth century source (Ripley 1913) lists all-rail shipping distances from Boston, New York, Philadelphia, and Baltimore to Atlanta, and as Table A.2 shows, straight-line distance is a roughly fixed proportion (85\%) of the point-to-point track length between origin and destination.

Table A.2: Comparison of Straight-line and Track Distances

\begin{tabular}{llccc}
\hline \hline Origin & Destination & Straight-line (mi.) & All-rail (mi.) & Ratio \\
\hline Boston & Atlanta & 937 & 1089 & 0.86 \\
New York & Atlanta & 747 & 876 & 0.85 \\
Philadelphia & Atlanta & 666 & 786 & 0.85 \\
Baltimore & Atlanta & 577 & 690 & 0.84 \\
\hline \hline
\end{tabular}

Notes: Table compares straight-line (geodesic) distances and all-rail shipping distances between the points shown. Shipping distances from Ripley (1913).

With a limited sample of routes - and particularly, with origins all in the northeast and destinations in Georgia and Alabama - one might be concerned that the sample does not exhibit sufficient variation in distance to identify this source of heterogeneity. Table A.3 lays this concern to rest, 
showing that across the 52 routes in the sample, distance varies from 500 to 1,100 miles, with a 25th-75th percentile spread of over 300 miles.

Table A.3: Descriptive Statistics: Distribution of Route Distances

\begin{tabular}{lcccccccc}
\hline \hline & $\mathbf{N}$ & Min & p10 & p25 & p50 & p75 & p90 & Max \\
\cline { 2 - 8 } Route Distance (mi.) & 52 & 501.0 & 585.8 & 661.1 & 749.5 & 889.0 & 971.7 & 1111.8 \\
\hline \hline Notes: Table summarizes the distribution of routes in the sample by straight-line & (geodesic) distance between northern origins and southern destinations. See Table A.1 \\
for a list of origins and destinations, and Figure A.2 for a map.
\end{tabular}

\section{Other Data}

I also collect data from annual volumes of Poor's Manual of Railroads (1868) to confirm the scale of the gauge change. The Poor's Manual was an annual compendium of railroads in the U.S. and Canada that provides railroads' location, mileage, information on their financial performance (when available) - and conveniently, their gauge. These volumes allow me to calculate annual mileage by region and gauge for the universe of U.S. railroads, and thereby observe both the growth of the network and the standardization of gauge across the country.

To do so, I recorded the name, total mileage, and principal gauge of every railroad in five Poor's Manual volumes: 1882, 1883, 1886, 1888, and 1890 (which provide data from 1881, 1884, 1885, 1887, and 1889). ${ }^{2}$ I also recorded the region in which each railroad had principal operations: New England (ME, NH, VT, MA, RI, CT); Middle Atlantic (NY, NJ, PA, DE, MD); Central Northern (OH, IN, IL, MI, WI); South Atlantic (VA, WV, NC, SC, GA, FL); Gulf and Mississippi Valley (KY, TN, AL, MS, LA); Southwestern (MO, AR, TX, KS, CO, NM); Northwestern (WY, NE, IA, MN, Dakota Territory); and Pacific (CA, OR, WA, NV, AZ, UT). In two of the sampled volumes, railroads are sorted alphabetically by these regions; in two other volumes, by state; and in one volume, at the national level. Where available, I use the Poor's Manual-designated region or state as a railroad's location. For the volume with national sorting, I infer each railroad's location from previous or later volumes, or from the address of its principal office (if not otherwise available). There was of course a great deal of new construction and consolidation over this period, but all of it is accounted for in these volumes - indeed, each volume concludes with a table listing all mergers and acquisitions since the first volume in the series was published in 1868.

The collection of the Poor's Manual data proved to be a painstaking process that required significant attention to detail, as many railroads owned subsidiary lines that were listed twice (alone and under the owner), and many railroads leased lines that were listed twice (alone and under the owner). All subsidiary and leased lines were therefore cross-checked against the entered to data to ensure they were not double-counted. The volumes also included railroads under construction, and every

\footnotetext{
${ }^{2}$ Please contact the author at dgross@hbs.edu if you would like to make use of these data. I extend a hearty thanks to the Historical Collections team at HBS Baker Library for providing access to the Poor's Manual volumes, and to Mary Vasile for her help in compiling the data.
} 
effort was made to count only completed mileage - though this count includes railroads which were complete but not yet (or no longer) in operation. In a few cases, a gauge was not provided - when this occurred, I inferred the gauge from previous or later volumes, from separately-listed parents or subsidiaries, or from information obtained through Internet searches. There were also a few railroads which listed multiple gauges, and I count these railroads as standard-gauge roads of one of the listed gauges is standard gauge. Finally, in each volume there are a handful of railroads for which the gauge could not be determined, and these railroads are omitted from all analysis, as the cumulative mileage with unknown gauge in any given year is less than $0.1 \%$ of the network. In Table 1, I sum railroad mileage by year, region, and gauge, consolidating the Poor's regions into five super-regions: New England, Mid-Atlantic, Midwest, South, and West.

I also make use of mapping data from two sources. I use the NHGIS state boundary shapefiles to sketch states east of the Mississippi River, and Atack's (2015) Historical Transportation Shapefiles to map the railroad network. The Atack (2015) railroad shapefile includes railroads constructed between 1826 and 1911; within this file, individual segments are identified by owner and gauge through the Civil War, but this identifying information is not available for later periods. Given the importance of this information to mapping the network by gauge, I restrict attention to set of railroads in operation by 1861. I use these data to illustrate the diversity of gauge in 1861 and then

the standardization that took place through 1881 and 1891, leveraging the Poor's Manual data to identify later gauges of railroads in the Atack (2015) shapefile.

To perform the stock price event study in Section 5, I have also collected daily stock prices from the New York Times for stocks traded on the New York Stock Exchange between January 1 and October 31, 1886. The stock quote tables in the New York Times report opening, closing, high, and low prices and estimated trading volume for stocks traded each trading day. Stocks that did not trade on a given day are not reported in the daily stock quote table, and I treat their price as unchanged from their previous trading day.

\section{Appendix references not in paper:}

Ripley, William Z. Railway Problems, Boston: Ginn and Company, 1913. 


\section{B Vertical Structure of Freight Shipping}

Long-distance freight shipment in the 19th century had an inherent vertical character: to get from origin to destination, traffic had to traverse the tracks of multiple, separately-owned connecting lines. Frictions in the vertical transactions required for through shipment were the source of decades of holdup, and led to the formation of numerous innovative contractual relationships, which could be the subject of an entire separate paper - and indeed are the focus of a large contemporary and historical academic literature. For the purposes of this paper, a better understanding of vertical contracting arrangements is both useful context and important to evaluating the model used to estimate demand and supply and simulate competitive conduct.

\section{B.1 How were long-distance shipments priced?}

To fix terms, freight shipments borne by multiple, connecting carriers were known as "through" shipments, typically traveling long distances. Shipments which could be delivered by the originating carrier were "local" shipments. There were two approaches to pricing through shipments: the most primitive method was a combination of local rates, whereby a shipment from point $\mathrm{A}$ to point $\mathrm{C}$ would be charged the first carrier's local rate from A to B plus the second carrier's local rate from $\mathrm{B}$ to $\mathrm{C}$, which were independently determined. Given the number of local rates that had to be considered on routes with many connections, and the frequency of rate changes, predicting the cost of shipping under combination rates was a formidable challenge for shippers.

To simplify pricing, railroads began to set joint rates (also/more often termed as "through rates"), which were point-to-point freight rates set jointly by carriers involved in the route, with a negotiated division of revenue. By the dawn of the regulatory era, through rates were by far the most common means of pricing through traffic. However, while there's abundant discussion of the definition and applications of through rates in historical records, there's unfortunately remarkably little coverage of how through rates were set, and how revenue was divided among carriers.

With effort, it was possible to unearth some contemporary references to the issue, which consistently point to prorating of through revenue according to the distance of each carrier's leg in the journey. Proportions were determined by the "constructive mileage" of each leg, which is derived from true distances but allows adjustments (Haney 1924). For example, in Congressional testimony in 1874, the P.A.L. general manager claimed to prorate through revenue with the water lines with which it connects (U.S. Congress 1874, p. 401), with ocean steamships prorating 3 miles for every 1 railroad mile. In the same Congressional record, a representative of the Green Line (a fast freight line, see next subsection) stated that all railroads in the organization received the same rate per mile from through revenue (p. 786). Division pro rata thus appears to have been the norm, although there were exceptions in the form of "arbitrary divisions", which often applied to the use of bridges or terminals, compensated carriers for a shipment's fixed costs such as loading and unloading, and were allocated before the remaining revenue was prorated (Haines 1905). It is unclear whether 
arbitraries were used to compensate carriers for the cost of breaks in gauge - and because joint rates came into use around the same time that the gauge was being standardized, no contemporary references to the precise question could be located.

Joint pricing was not the only means of contracting around vertical transfers of shipments. Trackage rights were also common, which gave an originating carrier rights to travel freely over a connecting carrier's tracks. An alternative was vertical integration via merger or acquisition, which was also occurring at a rapid pace during and after the Reconstruction era.

\section{B.2 Who owned/controlled the rolling stock?}

Vertical transfers of rolling stock were an entirely different contracting problem that was resolved in a distinct way. While not as important to the paper as the process determining rates, it is useful to understand how rolling stock was transferred across railroads, and who maintained ownership and control, as freight traveled the tracks of multiple carriers along its route.

The root of the problem is that, to send shipments over long distances on the same car, originating railroads had to (i) send their rolling stock across connecting lines, and (ii) get it back. Conversely, intermediate railroads had to host the rolling stock of their connections. The moral hazard problems arise in several places: not only does the originating carrier have to relinquish control over its rolling stock, but it also retains liability for damage or loss of its shipments on connections. Moreover, different railroads might have different quality cars and different maintenance practices, and a lowquality or poorly-maintained car could damage the tracks it traveled. As a result, until the 1860s, freight had to be unloaded, unregistered, reregistered, and reloaded every time one line ended and another began, imposing enormous costs and delays on through traffic.

To address these issues, railroads around the country formed "fast freight lines" in the 1860s and 1870s, which were joint ventures between connecting railroads which pooled their freight cars into a shared rolling stock. The largest of these in the South was the Green Line fast-freight company, established in 1868. Under the agreement, members of the Green Line submitted rolling stock to the common pool in proportion to their total track mileage, and members were paid 1.5 cents per car-mile when other carriers used their cars. Ordinary maintenance was performed by the railroad operating the car and charged to its owner, but if a railroad damaged another carrier's car, it would be responsible for repairing or replacing it - though enforcement of this latter provision was inherently challenged by the difficulty of determining the party at fault. ${ }^{3,4}$

\footnotetext{
${ }^{3}$ When asked by Congress "How do you know whether it is the fault of the road or ... the car?" a Green Line agent responded that the issue was an ongoing source of contention (U.S. Congress 1874, p. 788).

${ }^{4}$ For more information on the Green Line, see the following sources: Sindall (1886, pp. 680-861), Joubert (1949, pp. 31-40), Taylor and Neu (1956, pp. 67-76), and Puffert (2009, p. 134).
} 


\section{B.3 What was the vertical structure in the South?}

Though these contracting innovations were being developed around the country during Reconstruction, the key question for this paper is ultimately what vertical contracting arrangements were in place in the South around the time of the gauge change, to evaluate whether the model of industry conduct is appropriate. The fundamental issues are (i) whether SRSA freight rates were for endto-end North-South freight traffic, (ii) whether they applied to both railroads and steamships, and (iii) whether they were determined in coordination with Northern carriers (which comprised half of each all-rail route) and how revenue from each shipment was divided. If the answer to any of these questions is in the negative, or if revenue division was endogenous, the model of the market could require nonstandard features such as bargaining or a vertical dimension.

Information on the SRSA's vertical contracting arrangements is thin, but a few key details are available from the cartel's records. What is clear from these records is that the cartel rates were through rates, from origin to destination, and that these rates applied to all lines in the cartel. However, the records yield no insight into what role Northern railroads played in price-setting. My understanding from cartel documents and later accounts is that the SRSA fundamentally controlled prices on shipments into and out of the South - in part due to its outsize influence over these routes, and in part because Southern traffic was relatively unimportant to Northern carriers in volume and value - and it is thus appropriate to model the SRSA as a price-setter. ${ }^{5}$ The cartel's records also make clear that revenue division was negotiated outside of the cartel, and typically pro rata, following industry norms - such that revenue division is orthogonal to price-setting and would not enter or affect the cartel's profit-maximization problem.

\section{Appendix references not in paper:}

Haney, Lewis H. The Business of Railway Transportation, New York: Ronald Press Company, 1924. U.S. Congress. Reports of the Select Committee on Transportation Routes to the Seaboard, Washington: Government Printing Office, 1874.

\footnotetext{
${ }^{5}$ Total railroad tonnage in the New England, Mid-Atlantic, and Great Lakes regions was over 10x that in the South in 1880, and the difference in ton-miles even greater (U.S. Department of Interior 1883).
} 


\section{Contemporary Accounts of the Gauge Change}

The gauge change received broad coverage in contemporary railroad periodicals and Southern newspapers. The Atlanta Constitution reported on the SRSA's gauge change convention as it was underway (Figure C.1), and the Louisville Courier-Journal reported several weeks later on the planning, preparations, and procedure for converting 13,000 miles of track in one day (Figure C.2). Though not widely covered in the North, the impending gauge change was nevertheless reported in a lengthy article in the Commercial and Financial Chronicle on May 29, where the paper acknowledges that "the matter is hardly attracting the attention it deserves," and the New York Times reported on May 31 that the Louisville and Nashville - the only Southern railroad of real importance to Northern shippers and investors - had completed its changeover that day, with no mention of the other railroads simultaneously converting to standard gauge (Figures C.3 and C.4).

Contemporary accounts were not limited to reporting on the mechanics of the gauge change: some newspapers speculated on the effects it might have, or was already having, on the Southern economy. For example, the Wilmington Morning Star wrote in April 1886 that to date, "very little lumber [goes] North by rail, for the reason that Southern roads [have] a different gauge from the Northern roads," and that "Southern lumber ports are bound to suffer a considerable loss of business" following the gauge change (Figure C.5) - a prediction consistent with this paper's results.

A year after the gauge change, in July 1887, The Railroad Gazette and other railroad journals published a detailed postmortem analysis (Figure C.6) - covering the history of Southern gauge and its "burden [on] both railroads and shippers," the SRSA's gauge change convention in February 1886 and the decision to convert to a 4' 9'" gauge on June 1, the plans and procedures for the day of the conversion and the months leading up to it, the engineering challenges, and even estimates of the aggregate expense of converting the rails and the rolling stock. For those interested, this article is the best source for understanding how 13,000 miles of railroad track could be converted to standard gauge in just 36 hours, and confirmation that it was. 
Figure C.1: Report of the Gauge Change Convention (Atlanta Constitution, February 3, 1886)

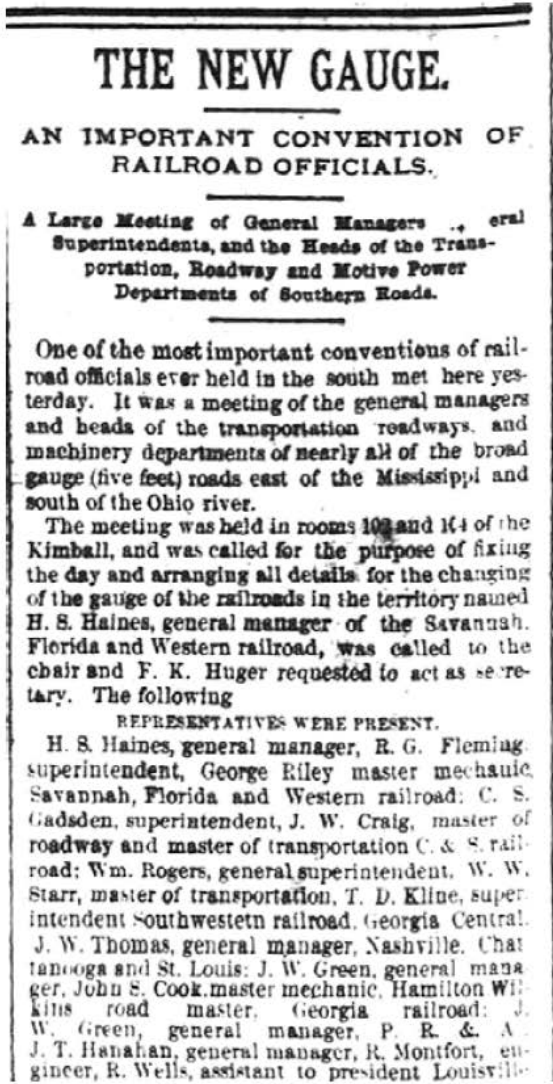

and Sashrille; J. B. Beck, gevieral manager, J. H Averell, master of transportation. D. E. Mas 5 et general superiutenden Florida railway and $\mathrm{Nal}$ gation company fouth Camlins railroad: Cecil (iabbott. general mapager, J. F. Wor wick, mast. mechanic Atlanta and West Point, Western mi way of Alabams. Cincinnati. jelma and Yobih railway; C. IC. Hudson, geners! manager. F. h Huger, superintendent. W. H. Thomas, sup rit endemt mothve yower East Temesvee, Virrinia and Georgia: S. B. Thomas general manager. Peytos Randolpb, assigtant general msnager. If. H. treet uperintendent Richmond and Danville division -uperintendent Berkeler, Air-Line di vision Ricbmond and Daswllle railrus? R. D. Wade, superintendent motive power, $C$ Eulton, engineer, C. P. Hammond, road maver. ? W. Gentry, master mechsnic, Rome and Dalton: 1:. Andrews, presidedt, Frank Coxe, vice pre-ided . C. McBee superintenclent, G. II Gits maste mecbanie, Western of North Carolina: Joseph $\mathrm{H}$ Sands, general manager, Frank Huger, superinten ent, W. W coe, chicfengincer, S. B. Haupt. S rerintendelit M. P., Norfolk and Western; 'i. K Talcolt, superiendent. Thos. Bernard, a sistant es Giver, (barlotte, Columbia and Auglas: 1. mbia and fue master necbance hartotte.

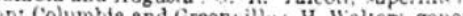

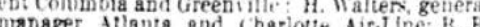
Dunn

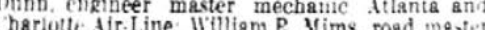
Litanta engineer Columbiand macter of road way =sy. Florida and W. D. Rilf 15. Ree loaver of

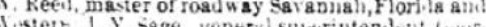

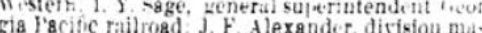

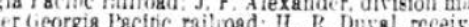
tortala railuay and uarigaion compans is

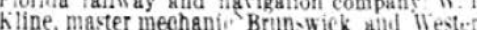
railroad J. $\mathrm{X}$. Brow 11, road mavter Brincsic Wester railimad $\mathrm{A}$ Bridges, rogi master Co

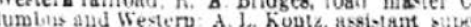
intendent pullmat palace car rompas J. F. Jivine, geperal rperintament Allanta an tharchte. If, 1 . Tewman, master mechanic, , eor

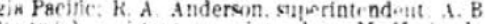

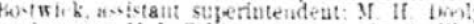

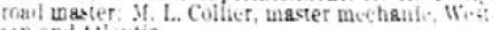
tin xDdA:la:itic.
Mr. Haines upon taking the hair briety vated o the convention the olyent for whith the meet ing bad been rallewl, and announcel tha: : world

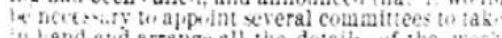
and hand atd grrattge all the detalk of the Wwa

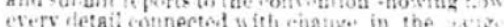
mis be arraugt ot that the work vot the cumplolied castly and sativiugr

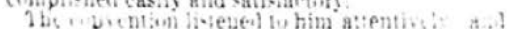

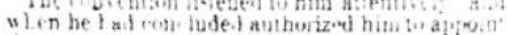

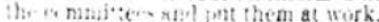

thaiman Haince theil aprointed the fvitowing combittees:

comuitter on date of bange of gruxe-F. B Thomas, ehairman J T. Horroban, C. Hud Ho: Wm. Rogers, II. R. Lural, Henry Walters, R. Fleming I, W. Thomas, J. W. (ireen, J H. Fands. Kline.

commitce on transportation-J. F. Devine chair man: J. B. Averill. D. E. Maxwell, F. $k$. Ifuzer l'yton Ramiol, h, A. B. Audrews, Frank Cose, I"

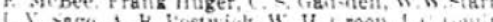

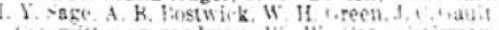
C. Habmond, M. H. Jooly. William Mima. II

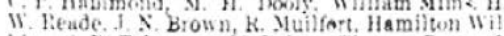

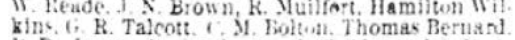

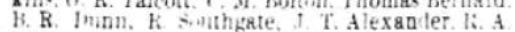
Jridges. J. W. I mix, E. Burkley, B. K. Swoop.

1 on mittee on marbinety- lieuben Wells than mats: F. D Kline. J. D. Wa.te - B. Hauph, Jus oh H. Grene, G. II 1. Riley J. 8. Cook. II. L Collie? Wunw w. W. T. Terman.

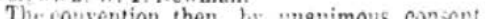
1. sdopitud the reuns the medting

The meeting then a journed until 4 p. In. 90 as their the commithe to at to work and prepary their repirts to preselted at that hour for conside? bied. The cummittes made reports, wbich were read and discussed.

Ininter of changes in the reports were sug. sested. atd they were recommitued, wh that thece changescould be properly ern-idered and seter Hocles the morning. 
Figure C.2: Preparations and Procedures for Conversion (Louisville Courier-Journal, March 23, 1886)

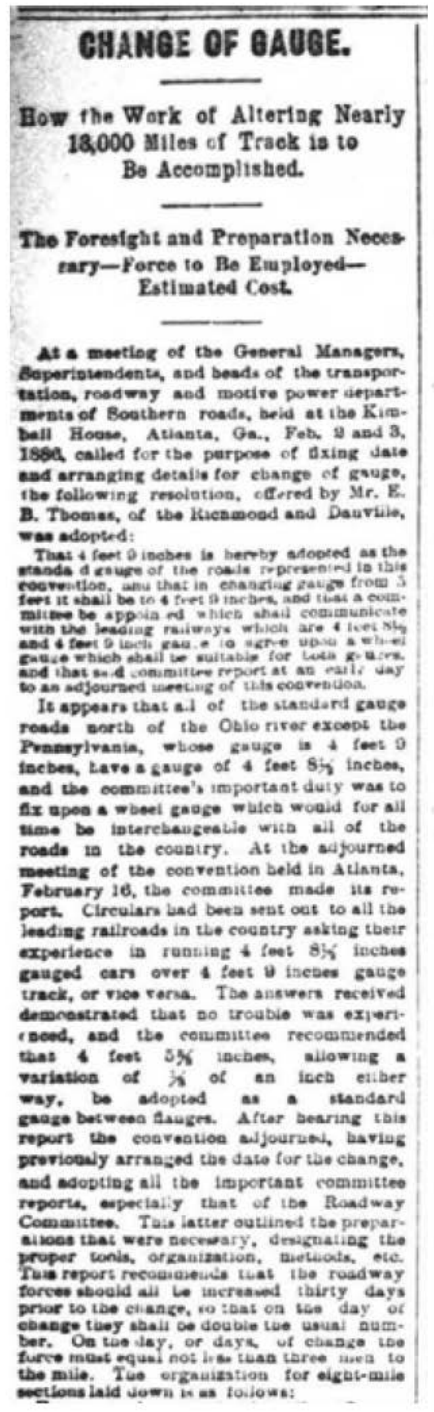

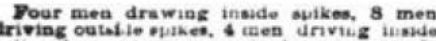

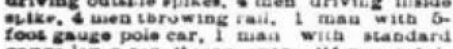

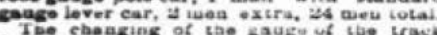

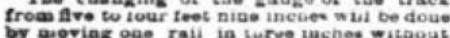

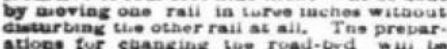

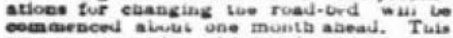

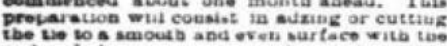

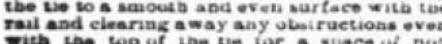
Tith tao wo of has to for syace of nut Doved in. wingat thes the eange is

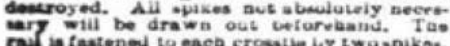

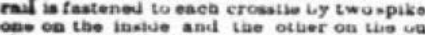

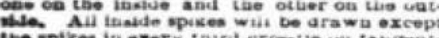

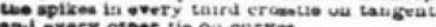

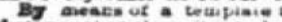
couare that the rail is to is muvew a greal

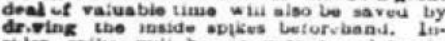
wives spikes wit bo bot with teasplates in

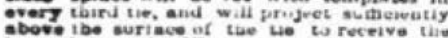

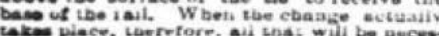

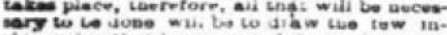

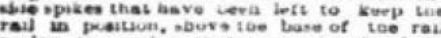

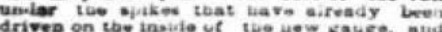

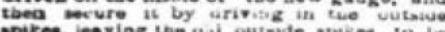
gotkes, leaving the o.d outside ppises to to

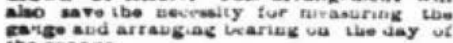
Lis:

Monday, May 31, and rueeday, Juno 1,

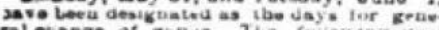

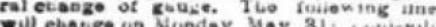

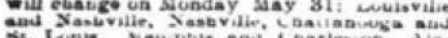

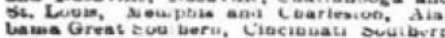

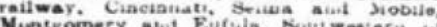
Suatsodery and Eufula, boutwesiera Railway anu Sivakation conspay. All Juber main lues wit eluange uu luesday. every ratiand wouth of the Ueiv nd Poter mae rivers Exloudiag over abus it, 1:

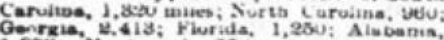

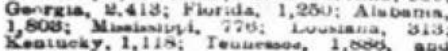

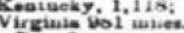
Tos Sulbers gange bas been an eadlen

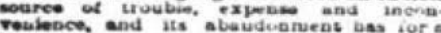
long tion been regarued as a ceriaiaty, and

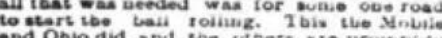

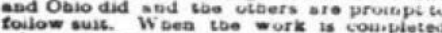

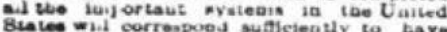

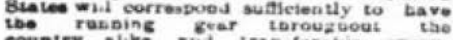

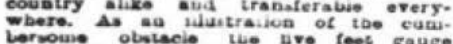

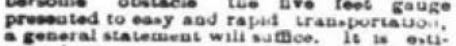

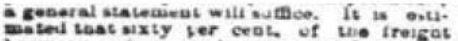

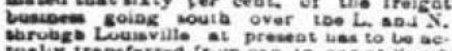

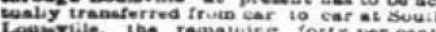

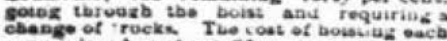
car is placed at about nfty conts for trans.

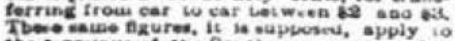

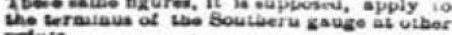
pelate sigantie eadertakiog bas siready ionotbougbt on to part of thom to w won

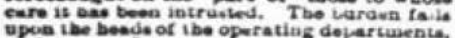

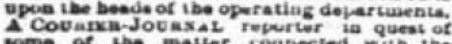

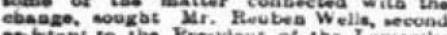

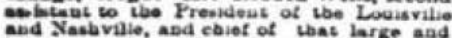

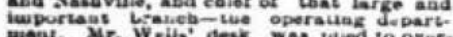
Aow io mit ponated iostruetious to too dif. toreat ibope divisions, ite. whiea bo bad

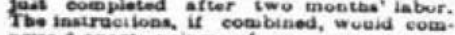
Prino a quarto volvoue of no weau propor.

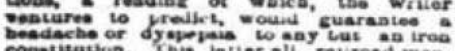

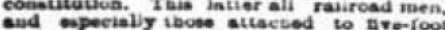

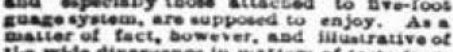
the mide diverseves in natters of laste trod

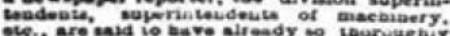

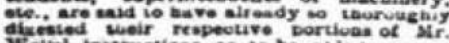
Wollo' lastruetions, as 10 bo allo 20 recic

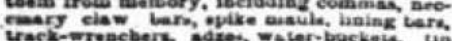

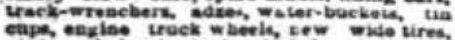

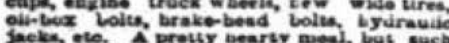

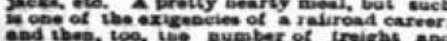

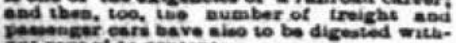

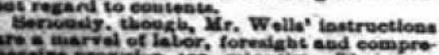

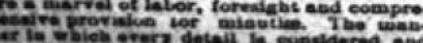

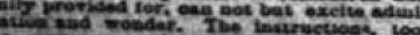

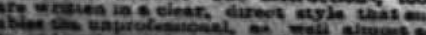
stroectons for ebangting fause of roling

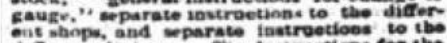

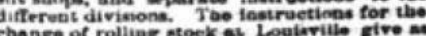

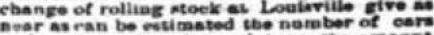

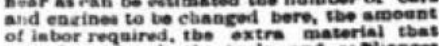

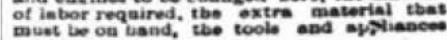

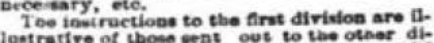

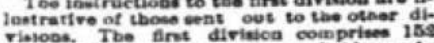

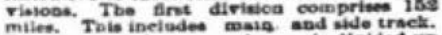

Thas divisuve, for conveniesere to divided up

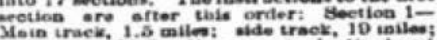
otsi miles, 20.3. Men required, sui basus Danik, 14: liaing bark, 8; track cauger, 8 ;

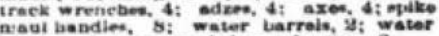
bacsets. 4 i tia eupe, 4 i ieszs of opices, a.

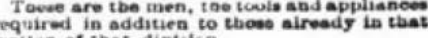
wetuon of taat divtaice

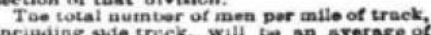
four wea on wections bavis 2 no more than the usual number of carves. atsd fre men on

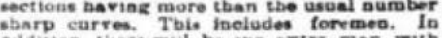
ajditioa, wero wil bo ves extra man witb

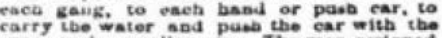

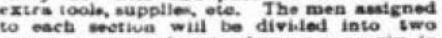
gange. corrmeneling to eliangs as neariy in the middle of tha nettiun, as ung to deetided

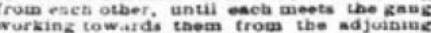
sectioses to to toroman will go with one of tho Kangs: bis stavasurd gauge band car will fol. otber gaus. and aaye bis pust car of nive foot of the tho kangs is not 10 be coublened to thetr

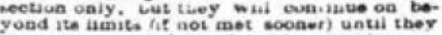
meet two kaug from the otoer section, ro-

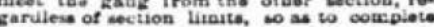

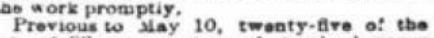
ot of 38 now ongines of standard gauge coived, put tozocoer aud tontad. "o tar as that is jirnctickites, and be resuly for corvice

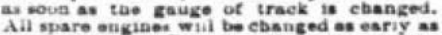
prartueabie. "Doutuing." or having tbe

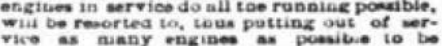

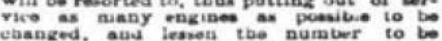
changed the day the trask is changed and

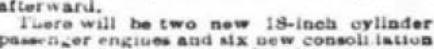

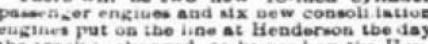
tho track to eliagerd. to bo used ou the Hay.

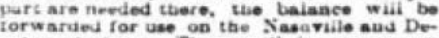

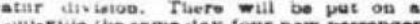

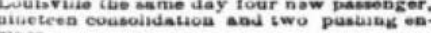

The rolling stoek to be changed at the nev-

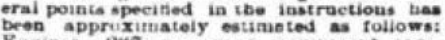

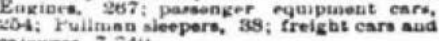

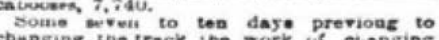

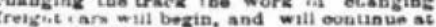
tos racto of tes per aey. in grosecer number if rone cost of the changs of gaugh it. on

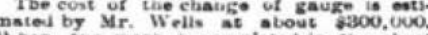
Whe toe work to completed in the short abor and inteliligeuh, compretenaivo tore 
Figure C.3: Report on the Conversion (Commercial and Financial Chronicle, May 29, 1886)

\section{THE UNIFICATION OF OUR RAILROAD GAUGE.}

On Mondsy and Tuesday next, according to previous arrangement and agreement, sn important work will be undertaken and carried through. This is nothing less than the changing of the guage of all Southern roads whose width of track now is 5 feet, to a standard that
will bring these lines more closely in conformity with the standard now in uge in other parts of the country.

The matter is attracting hardly as much sttention as it deserves. It is a task of no little magaitude. Practically it involves the taking up and relaying of one rail over the entire length of all the roads (and in some cases a change in the road bed and of course alterstion of the rolling stock) in the territory bounded by the Atlantic Ocean on the one side and the Missiseippi and Ohio Rivers on the other, and comprising the States of Virginis, West Virginis, Kentucky, Tennessee, Missis sippi, Alsbama, Georgis, Florida and North and South Carolins. Some of the newer systems in these States, like the Chesapeske \& Ohio snd its accessories, and the Louis. ville New Orleans \& Texse, are of the standard Northern gauge, and so is the Southern Line of the Illinots Central, while the Mobile \& Ohio was last year slso altered to con. form to this standard. But the vast bulk of the mileage in the Southern States at the present moment has a track width of five feet, sad it is estimated that next week's operations will embrece fully 14,000 to 15,000 miles, from which one can judge of the dimensions of the work. And but the rolling stock-locomotives and cars-will have to be adjusted to the new guage (where it has not previously been done) the latter being reslly the most difficult part of the undertaking. All the preliminaries, however, have been completed, preparations for the event hav ing been in progress for several months, and much of the equipment hsving been already sltered, so when on the 31 st of Msy and 1st of June the 14,000 or 15,000 miles of track are simul. taneously changed (some branches and minor pieces will be changed a day or two earlier), everything will be in readiness, snd the business and operstions of the rosds proceed as if nothing had happened, while the means of intercourse between the different sections of the country will have been improved and our transportation interests benefited.

The new gauge will not be precisely the same as the commonly accep'ed standsrd, but it will be so nesrly so $\Delta s$ to be equivalent to the same thing. It will be 4 feet 9 inches, whereas the prevailing width is 4 feet $8 \frac{1}{2}$ inches. The Pennsylvania, however, has a gauge of 4 feet 9 inches, and the Southern lines have adopted the same figure. In reality, though, the difference-half an inch-is so small that the rolling stock of the one can and is being freely used upon the track of the other, so that for all practical tond purposes the two gauges are identical. Moreover, these after. two gauges embrace together the greater part of the railrosd mileage of the country-the Southern roads with their five foot gauge forming the only important exception. According to the Census Report of 1880, of the total track in the country at that time (July 1) 66.3 per cent belonged to the roads with $4 \mathrm{ft}$. $8 \frac{1}{2}$ in. gauge, and 11.4 per cent belonged to those of the $4 \mathrm{ft} .9$ in. gauge, making together 77.7 per cent, while of the 5 -foot gauge (almoet exclusively Southern roads and now to be changed) rule. there was 11.4 per cent more, giving in the sggregate the report of the Mobile \& Ohio for the late fiscal year. (the total track in the country. The The Mobile \& Ohio was changed to atandard gauge on the remaining 10 per cent was distributed chiefly between 8th of last July, and an itemized statement in the report roads with the 6-foot gauge, some of which have since places the expenditures on that account up to the close of been changed to the standard, and narrow gauge roads August at $\$ 66,329$, of which $\$ 11,069$ was paid out directly with the 3-foot gauge, the most of which contemplate for labor and $\$ 25,260$ for the necessary materisl. This changing where they have not alresdy changed. It included all the track, engines, cars, tools, bridges, etc. follows, then, that after next week the mileage of the We infer, however, that it does not comprise the whole United States will be substantially of one and the charge involved in the work, for in his remarks we find same gauge, the exceptions of a wider or narrower Mr. Duncan saying that the total cost, which had been gange being so few merely to emphasize the originslly estimated at $\$ 95,777$, would probably be less than $\$ 80,000$. The Mobile \& Obio has 527 miles of main

The step which the Southern rosds have taken is of line and branches, and on the basis of $\$ 80,000$ for the course an important one, both in its immediate effects in whole the cost of effecting the change (including rolling ontsiling an exceptional outlay in making the change, snd stock and everything else) per mile of road would be a in its ultimate effects in bringing Southern lines in closer little over $\$ 150$. On the same basis, the 14,000 miles communication with Northern snd Western systems. In now to be changed would involve sn outlay of $\$ 2,100,000$, the latter particular the importance of the move can showing that the work is not only one of impurtance, but hardly be overestimated. The free interchange of traffic one also involving in the aggregate a great expense. The which a common standard will permit, we need hardly roads on which this burden of cost will chiefly fall are of asy will be of benefit to all interests concerned. The course the larger systems like the Louisville \& Nashville, ahipper will be saved delsys, the railrosd will be able to the Richmond \& Danville, the Cincinnati New Orleans chespen the cost of handling the traffic, and the mercan. \& Texas Pacific, the East Tennessee, the Norfolk \& West. tile and finsncisl community generslly will feel the effects ern, and the Central R.R. of Georgis ; but the minor roads in the increased stimulus that this gives to the develop. all over the South will slso have their expenses increased ment of trade and industry between the different sections. on the same account.

Hitherto the South has been in a measure shut off from It is interesting to note how completely the standard the rest of the country by this lack of uniformity. On gauge of 4ft. $8 \mathrm{t}$ in. and 4ft. 9:n. has supplanted sil other the north, the Obio River manted the limit beyond which gauges. Only a few years ago, when hardly enough Southern freight could not go without a transfer of the could be said by the adrocates of the 3 foot gauge in contents of the csr, or at least a change of trucks, and favor of the narrow guage plan, it Beemed as if a new and on the West the Mississippi River also formed a dividing dangerous rival were sbout to arise. But s short tris ine, for Texas and Arkansas roads are of standard gange. has served to demonstrate that the advantages claimed for After the change however, this barrier will no longer the narrow guage syatem were largely illusory, and the exist, and traffic can then be moved to the North or West three-foot gauge has now fallen into pretty geneval without breaking bulk. Astde from the saving of expense disrepute, whila nearly all the companies thas that this will involve, good results may be expected to had built their lines on that guage have become dis. follow from the fact that the equipment of Northern and credited, sod are in the hands of the officers of the law. Western roads will be placed at the service of Southern The Toledo Cincinnati \& St. Louis was to be the most brilroads, which rasy prove of considerable advantage to these, liant exponent of the new theory, "the grandest narrow especially during the months when the c)tton move. guage enterprise on the Continent," but slas! there never ment is most active. And upon the sections was a road so deeply involved in finsncial and other diff themselves the effect of such sn interchsnge culties as this, and when it finslly succeeds in getting out in bringing the people closer together, is not to be lightly of the dilemms in which it now tinds itself, the road will be dismissed. It should even help to attract attention to the widened to the standard guage. Then there is the Texas South as a field for the profitable employment of capital. \& St. Louis, which also has an extensive narrow guage That section has been comparatively neglected heretofore. mileage, now to be changed to standard widtb. The Tnere has of course been growth in recent years-very Denver \& kio Grande is the only narrow guage system decided growth indeed,- but as compared with the West of consfquence remsining, and there the mountainous and Northwest, the South has not gained as much as the character of the country renders a comparison with other especially has passed her by. It is unnecessary to inquire special kinds of traffic the narrow guage sometimes snswers into the causes of this. It is sufficient to know that the very well, and there are some pieces of this character that change of gauge will make the union between the sections pay, but on any large or extensive scale, and with ordi more complete, and in connection with the new industrial nary kinds of traffic, experience seems to have demon. do to give grester prominence to that section here. ments called for, and most of the companies of this sin As to the cost of the change on such an extensive body disaster.

of rosds, that cannot be stated with any great degree of As to the old brosd gasge, that has long since gone out accuracy till after the work has been accomplished. of fashion. The Erie was constructed on that psttern, but Reducing the gauge of track is, of course, a simple was changed to standard in 1878 . Its principal connecproblem, but the adjusting of engines, equipment, tools tion-the Atlantic \& Great Western-was also of six foot and the various parsphernalia connected with thẻ opera guage, and this was changed in 1880 . We may remark tion of a railrosd, is what constitutes the largest propor. that the Canadian system is likewise of atandard guage. tion of the expense. We have no exact dats for There were varying ganges in Canads at firat, but in 1873 estimating the cost of the work, but an approximste a common movement was made towards the adoption of ides of the smount required csn be gained by using the standard, and since then that has been generally fol. the figures which Mr. Willism Butler Duncan gives in lowed. The'Mexicsn Central (El Paso to City of Mexico) 
Report on the Conversion ( $C F C$, cont'd)

is slso of 4ft. 8 inin. gauge, snd so is the Mexican Railway (Vers Cruz to City of Mexico), though the Mexican National is narrow gauge. Practically, therefore, it may te said that the whole railrosd system of the North American Con. tinent is of standard gauge. And elsewhere this gauge also chielly prevails, that being the usual width in Grest Britain and other Europesn countrieg. In fact the experience of the world seems to have settled in its favor as offering a maximum of service at a minimum of cost.

Not the least aignificant feature about the change now to be made on Southern roads, is that it is undertaken voluntsrily and without any external pressure whatever. In this it is like the adoption of a uniform time standard, effected not so very long ago. The rosds sre yielding simply to the demands of necessity. They find that a gauge at variance with that of the rosds in most other sections of the country is an impediment which interferes greatly with the free operation and full development of their business. So they determine to remove the impedi. ment. But there is no force or compulsion - no law except the natural law of trade, in obedience to which they make the change. They are exercising their own volition en. tirely. Nevertheless, the agreement between them is unanimous. Is there not in that s lesson to those who never weary in calling for legal easctments and Govern. ment intervention to accomplish this or that ? When the necessity for an important stop is clesr and imperativeand who can be a better judge of this than those moet directly concerned-railrosd managers take that step (whether it be a reduction of rates or a change of custom or condition) promptly snd without heaitstion or com plaint. In fact in this way the laws of trade and the in stinct of self preservation effect reforms and improve. ments that all the legislative bodies combined could not nooomplish, as is so evident in the present case. 
Figure C.4: Report on the Conversion (New York Times, May 31, 1886)

\section{CHANGING THE GAUGT.}

WORK ON THE LOUISVILLE AND NASHVILLE COMPLETRD-OTHER SOUTHERN ROADS.

LouISville, Ky., May 30.-The great work of ohanging the gauge of the Loulspllle and Nashville Rallway from wide to standard is completed. Eight thousand men were scattered over the divisions of the main stem at daylight this morning, and at sundown the track was standard all along the line, and test trains had been run over the different divisions and $B$ ritches, and reports had been sent in to General Manager Harahan, in thls clty, pronouncing the work complete and everything in good shape. Some of the divisions were completed as early as 9:30 o'clock this morning. and the great bulk of the work was fintshed by noon, everything boing finlahed up in proper shape by the middle of the afternoon. Tho day was propitious, the elements offerink no interference at any point except Memphís, where thunder storms interrupted the work to some extont. But in spite of that the Memphis division was finfohed before noon. No trains were run out last night or to-dny but at midnlght to-night the regular schedule will be resumed and the rolling stock of the Tuurvillo and Nashollil Louisvilo and Nashrille will have onls been treated to a Sunday's rest. The following branches were changed yesterdas: Pensacola and Atlantio Railway, Metumpka branoh; Birmingham Mineral Ratiray, both branches; Owensborough and Nashville, Madisonville branch; Elkton and Guthrie, Glascow branch, Bardstown branch. The following are the roads changed to-day: Maln stem, first and second divlsions, Knoxville Division, Evansville, Henderson and Nashville Division, Memvhls Line, Nashville and Decatur Division, South and North Dlyigion, Mobilo and Division, New-Orleans and Mobile Division, and Pensacola Railroad. 
Figure C.5: Example of Anticipated Effects (Wilmington Morning Star, April 16, 1886)

T TREATENED LOSS, OF
BUSINESS.
Savannah News.
The change of gange on Sonthern
railroads, which, it is expected, will be
made in July next, will hring abont
some important changes in the lum-
ber business in the South. Southern
lumber now reaches the Northern
markets by sea. It is transported
from the mills to the nearest ports,
and sent by sailing veseels to the
Nerthern distributing points.
This way of getting lamber from
the produoer to, the consumer is ra-
ther slow. It has to be handled sev-
eral times-onee at the mills once,
and sometimes twice, at the port of
shipment, generally twice at the port
of its destination, and, finally, once
at the place of consumption. It bas
to be insured against the of
the sea, and frequent handlings often
cause considerable breakage. An-
other drawback to shipments by ses
is the long time required for lumber
to reach the Northern markets after
it has been shipped.
Very little lumber has gone North

by rail for the reason that Southern roads baving a different gauge from the Northern roads, it is rather troublesome and somewhat expense to change the trucks.

Southern lumbermen say, however, that when the gauge of the Sonthern roads is changed they will be able to ship lumber without breaking the bulk direct from their mills in Geor. gia, Florida or any other Southern State to any point in the country, and that the difference between the cost of rail and water transportation will be more than overcome by the saving that will be effected in insur. ance, bandling and breaksge.

While mueh of the lumber will contunue to be shipped by sea, there is no doubt that a great deal of it will not seek the seaboard for trans. portation to market when it can be transported as cheaply and much more quickly by rail, and Southern lumber ports are bound to suffer a considerable loss of business. Other kinds of business, however, will doubtless take the place of whatever part of the lumber businese that may be lost to them.

Very little lumber has gone North 
Figure C.6: Technical Summary of the Gauge Change (Railroad Gazette, October 14, 1887)

668

THE RAILROAD GAZETTE.

[OCr. 14, 1887

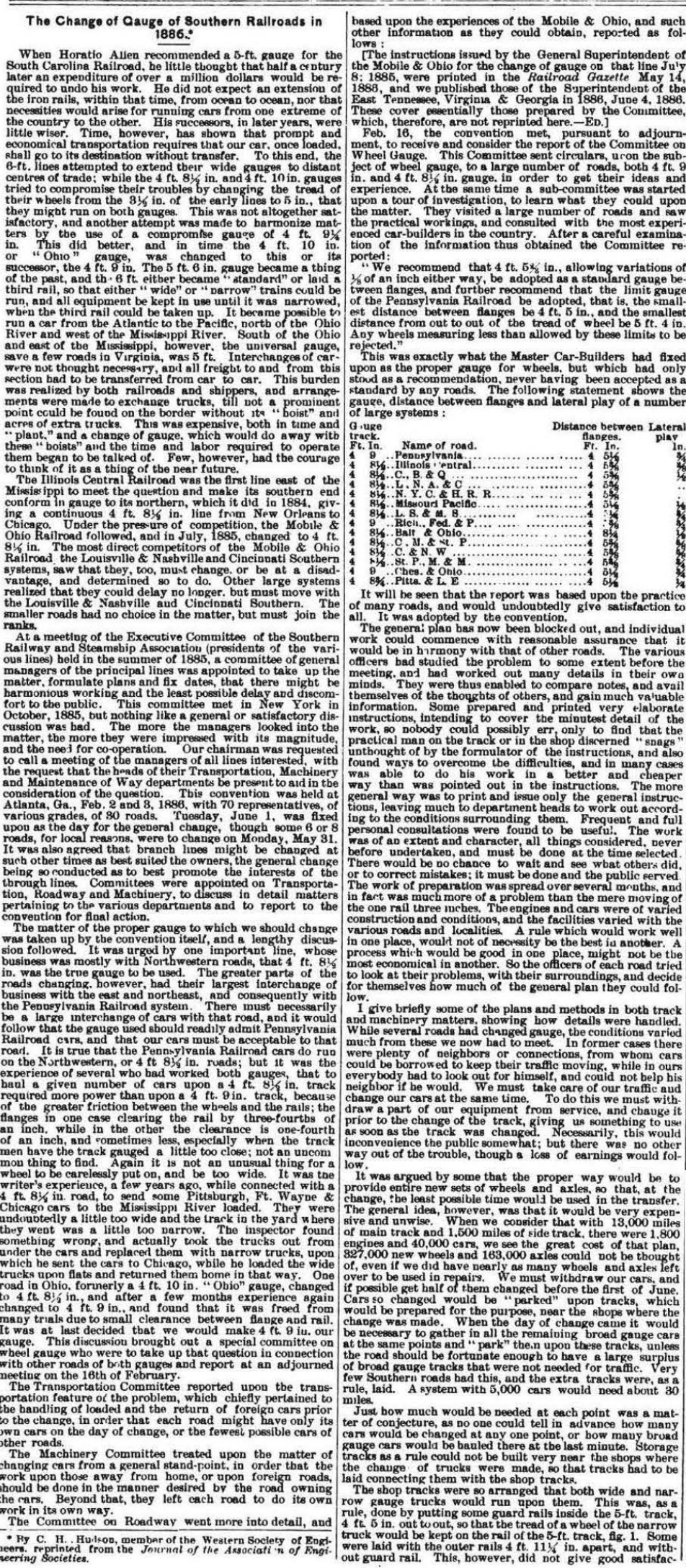

tion, as the bearing surface was so small that a slight imper-
fection in the rail, or a curve that let the wheel run to one side, would cause a wheel to drop in and pive trouble and
delay. The tracks from storage yards to shops were some-
timg.

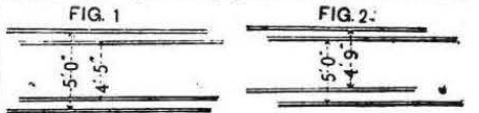
separate tracks on the same ties, as shown in fig. 2. This
last was most satisfactory. Severel ingenious devices were last was most satisfactory. Severel ingenious devices were
used to switch front une track to another, all temporary in character and inexpensive. Expensive Irogs in some why
were avoided, where two tracks or rails were crossed and corpound frogs ordinarily used.
In changes teretofore made full sets of bridles for switches

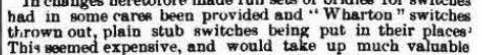
time on the day of change.
We have various kinds of bridles. The old-fashioned one

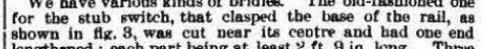

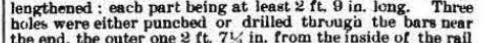

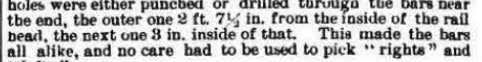
all alike, and no care had to be used to pick "rights" and
"lefte." bole of one bar over the second bole in the other FIIG.3. FIG.5. then put through, a unt put on the bolt, and a spring cotter
put in a bole which bad been drilled through the bolt. Another bolt through the other holes, and the bar was se-
cure. On the day of change the bolts were easily removed, the bars moved 8 in., the tolts replaced, and our track was
4 ft. 9 in. Fig. 4 shows the bars as changed and ready to be put together. Fis. 5 showe a a bar which took hold of the
lange of the switch rail, treated in the same way. Fig. 6 shows another kind. and the manner of its treatment is
readily seen by the sketch. A hole is diriled 3 in. back trom the one through which the original ivet or bolt was put.
With the "Wharton" there was more trouble, as the bars could not easily be removed to be prepared for change It
was found bowever, that a casting could be made that could
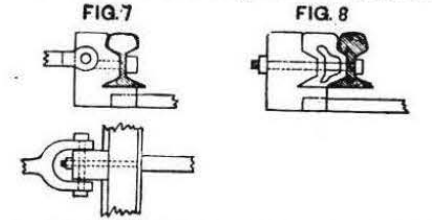

be placed benind the elevated rail, which would hold it in 8
inches securely. a longer bolt being needed. Figk 7 and 8

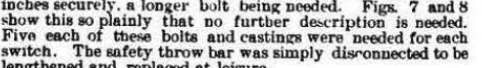
lengthened and replaced at leisure.
Crossings were prepared by cutting out at the centre the

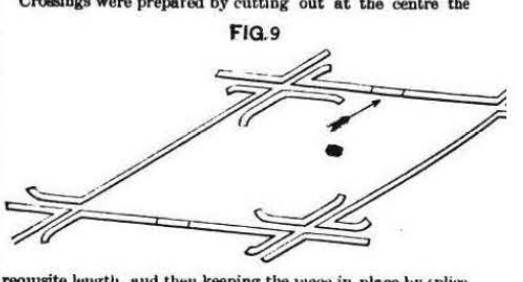
requisite leuxth, aud thru keeping the prece in place by splice
bars till the day of change, when the cut pieces were taken
out and one side moved up to proper gauge, see flg. 9 .

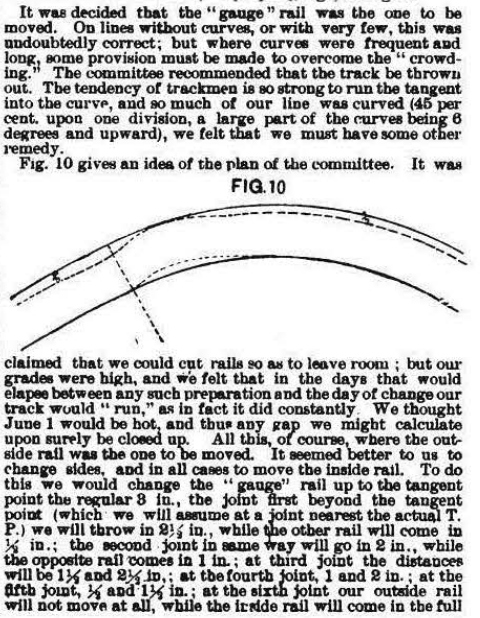


3 in.: we continue to move the inside rail till within six
joints of the next tangent point, when we commence to re verne, the process. In the procees of preparation spikes have

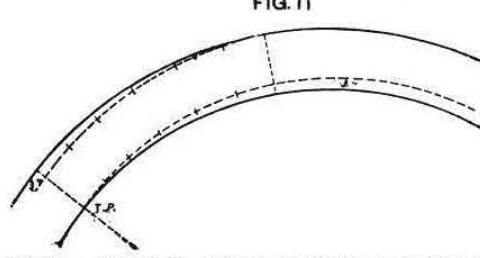

this plan. The outaide or elevated rail is the one usunlly used on which we started, viz: : to move the "gauge" rail. The wiadom of the plan was shown when the dny of change came
and curves changed on this plan were found to be in batter line than those chang
three plans spoken of
In the matter of

In the matter of of locomotives the conditions varied much probabil been the most far-seeing. For twenty years they
had looked forwarid to this change, and had during that tume oo constructer their frames and fire-boxes that, by using new
driving whel contres, the change could be made without changing other parts. Few otber builders had, nutil comparatively recently, given the matter any tbought, and, as a by moving tho frames in, and not unfrequently the tire box peose. Many engines were thrown out of service by the fact of The 5-tt. engines measured between flanges of drivers (and otber wheels as well) 4 ft. $8 \%$ in. As the gauge was

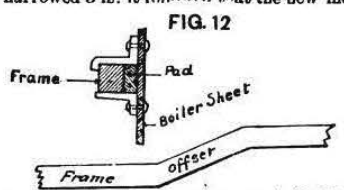

be 4 ft. $5 \%$ in. was the measure convention, with of $1 / x$ in. eitber must be enough
lese than this from a reasosable clearance, or say $4 \mathrm{ft} .5$ in. I think sll our wider frum out to out of frames. the frames being set out
wrom the fire-box and a "pad" placed between them ; see Ag. 12. The "pad" could be cut out and the frame set in
against side of the fire box ; but to do it, this frame had to be offset, as shown in fig. 18. This was done bebird the rocker arm and in front of the pedestal or " "jaw" thus render-
ing unnecessery the chsnging of machinery, but enabled us
to get in the boxes and wheels or tires to the proper width without cutting into tho frame.
To get proper informstion about all the engines, accurate measurements were taken of width of fire-box, width be tween frames, from out to out frames. between bubs, be
tween inside of tires, between rims of and wedges, thickness of
hubs, rims of wheels, etc.
Blue print diagrams were 13
FIG. 14 prepared upon which we placed all these measure-
ments with the number o head of the machinery de partment could sance at a for each engine. It was expected at the start that new
driving wheel centres would be required for all engines;
but examination of our blne prints showed that upon our
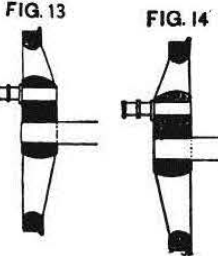

sary. Bome few enfines, notably some of the old Rogers, ing them off and putting on again, with the outeide face in 18 as originally, and fig. 14 as turned. It was found in prac tice that a new crank pin had to be put in. In many cases
we found that we had thick bubs and heavy flanges to both

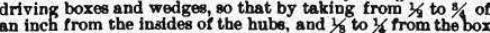
an inch from the insides of the hubs, and 8 to $3 /$ from the bo and wedge flanges, we could gain at least one inch, and
some cases did more. This left not to exceed half an on the inside. neither an unreasonable nor an un usual projection. This change was a trifing one and
done at a cost per engine of about $\$ 180.67$, including new crank pins. A new set nf wheel centres, finished and in place, including pins, which would probably be needed, would
cost $\$ 264.46$. When changes were decided upon, and an enput on at the old gauge, projecting outside the centrme The

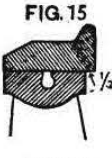

F1G. 17
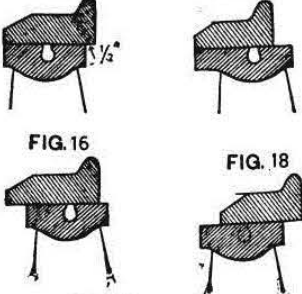

were used in this way without trouble until the day of chang
came; fla. 15, original; fig. 18 , changed. engines had their wheel centres bullt expresely with would be required with the new gauge: but the rim projected outwardly an inch and a half more than usual, so that the
tire could be placed for the $5 \mathrm{ft}$. gauge and still have its ful tire could be placed for the $5 \mathrm{ft}$. gauge and still have its full
support, Bee flg. 17. When the tire was eventually moved
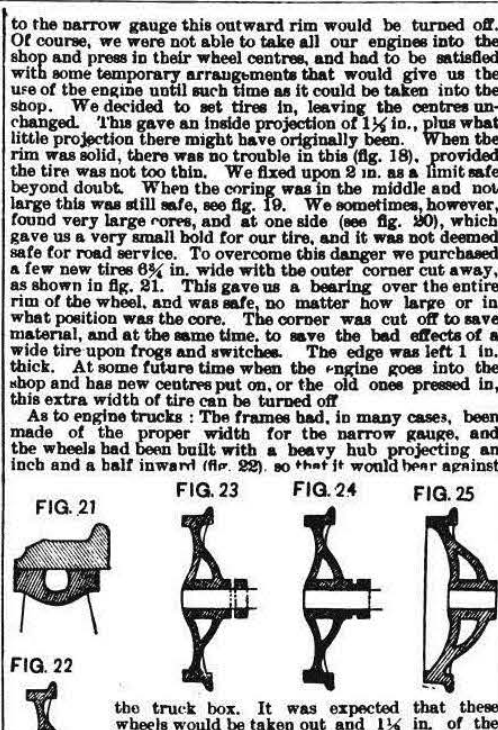

the truck box. It was expected that the
wheels would be taken out and $11 \%$ in. of the

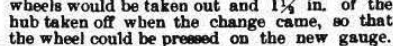
the wheel could be presed on the new gange.
This would have taken too much time. so the wheels, but a cast iron collar or washer $1 \%$ in thick was placod upon the axle inside each whet day of change came 8 few blows of the hammer upon a cold chisel split this collar of and we were ready to Many of the wheels that were still in use with the long bu back from the face, leaving our cast collar; which was easily split tif as before. (Fig. 24)
With tender wheel 8 , as with our car wheels, the case was

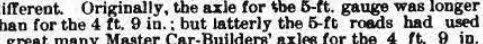
great many Master Car-Builders' axles for the $4 \mathrm{ft} .9$ in
gauge, namely, $6 \mathrm{ft}$. 11 1/. in. over all, thus making the width isbed wheel, or rather a wheel with \& greater dish by $11 \%$ in. han previnusly used was needed, so that the tread of the
wheel could be at its proper place; course, many of the wheels with small dish and long axles
still in use. Their treatment, ho came, did not vary from that of the short axles. It had bee
the rule for some years that all axles should be turned bac $11 / 2$ in. furth r than needed; but unfortunately the rule
had not heen cloeely followed, and many were found pot to be sn turned. To make the matter worse, quite a number o
the wheels were found to have been counterbored about in. deep at the back end. and the axle turver up to fit thi the wheel worked loose, but bed frmm thn otandpoint of
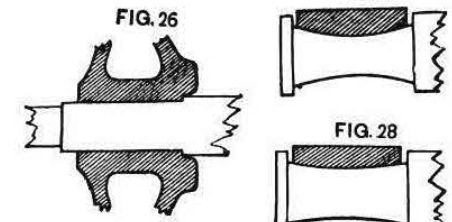

FIG. 28

change of gange. In such cases the wheels had to be started ofr before the axle could be turned back, so that the wheel
could be pusbed on in their proper position. (Fig. 22.) If the work was done where they had a lathe large enough to swing
a pair of wheels, they were preseed off but half an inch, the
wheels gwung in the lathe, the axles turned back 11, in. wheels swung in the lathe, the axles turned back $11 /$ in.
and the wheels then preesed on 2 in. or $11 / 2$ in. inside of their first position. Where no large lathe was in use, the wheels
came entirely off before the axles could be turned back. The
work in the former work in the former case was both the quicker and the
cheaper. Where the large lathes wers used they were either Wheels would easily roll int ince, or a raised platiform was put betore the latbe, with a er than to hoist the wheels up, as is usually dono. Inpressing the whels on, where the axles had previousiy been turned
beck, much trouble was at first experienced becanse of the back, much trouble was at first experienced becanse of the
rust that had gatbered upon the turned part behind the wheel. forming a ridge over or upon which the wheel must per cent. of the wheels so presed on. By saturatiog this
surface with coal oil, bowever. it was found that the rust was 作 zorkman would leave a ridge at the starting point of the turning. Frequently, a aso, the beles were a little scant upon one side when compared with the old surface, and upon the opposite
side a little full. As an indication that these diffeulties were overcome as they appeared, I will say that upon our line
only 202 wheels burst, out of nearly 27,000 pressed on, an excedingly smail percentage.
After the cbange upon the early roads they were troubled
for weeks with hot boxes, caused, as we bylieved, by the for weeks with hot boxes, caused, as we b?lieved, by the
changing of brasses. A brass once fitted to a journal will Work upon it without trouble; but when placed upon some
other journal will probably not at. If the fournal bad been worn hollow (and it was surprising to see bow many were flg. 27, exargerated of course. The next wheel may bave an
axie worn little or nove, as in fig. 28. Now, if these brasses are exchanged, we have the conditions, as shown in figs. 29
and 30 , and we must expect they will heat. The remedy was simply to keep esch brass upon its own journal. To do
this the brasser were fastened to the axle by a plece of 8 gmall wire, and went with it to the latbe and press. When its
truck was rencher', the brass was there with ite inurnal. Worn
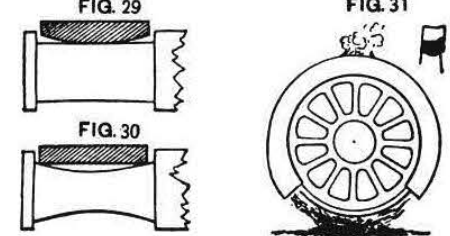

out brasies, of course, could not be put in, and new ones were the cbange showed the efficacy of the remedy. The manner in which the tires of engines were to be changed,
when the final day came, was a serious question. The old Mobile \& Obio bad used a fire of pine under the whel. Which was covered by a box of sheet iron, so arranged that the flame aperture at the top; If. 81. Many thought this perfect, while otbers wer wot pot satistled, and began expernments for
something better. A device for using gas had been patented, but it was somewhat complicated, as well as expensive, and
did not meet with general favor. A very simple device was on bit apon. A two-inch pipt was bent around in a
circle \& little larger than the outer rim of the wheel. Holes to inch in diameter and 8 or 4
inches apart were drilled throagh the pipe on the
inside of the circle. To this pine was fastemed another inside of the circle. To this pine was fastened another
with a branrb or fork upon it. To one branch or tork was
counected a pas-rine from the reter, while to the other was FIG. 32

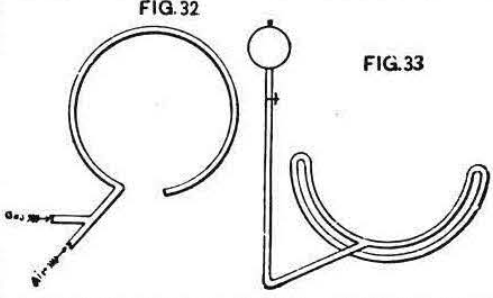

connected a pipe from an airpump. With the ordinary
pressure of city gas upon this pipe it was found that the pressure of city gas upon this pipe it was tound that the and gas might mix properly at the branch or fork, "so we
could get the best combustion and most heat from our "blowpipe," for such it was. See fig. 32. We were able to beat a
tire, so it could be moved in ten to twenty minules, and the machine may be said to bave been satisfactory. Gas, how.
ever, was not to he bad at all places where it would be neers. ary to change tires, and the item of cost was considerable. gun with coal ofl (bead-ligbt oil). They were crude and unwas bent to ft the lower hall of a wheel pretty closely, aud distant from it. This under part bad boles in in. in diameter
and 3 or 4 in, apart, drilled upon its upper side, or unoer the upper pipe. Connected witt the upper pipe at its centre was
pipe which ran to one side and up to the can containing a pipe which ran to one side and up to the can containing
the kerosene. Betwreen the can and the pipe under the whee was a stop-cock l,y which the flow of oil could be controlled.
To use the device, open the cock and let a small amount of sil fiow: a pply fire to the pipe under the wheel, and the ofi in the upper pipe is converted into gas, which flows ont of
the small holes in the lower pypes, takes fire and heats not only the tire. but the upper pipe. thus converting more oil
into gas. We bad here 2 lot of blue flame jots and the result as with gas, but at less cost. We bad aleo a machine that was inexpensive and easily handled anywhere. Bnzes might pass close to the tire. This device was extensively used by our people, and with great satisfaction. Care had
to be taken that in starting the fire it did not cover the tire with carbon or " lampblack," which is a non. onductor of beat. Experiments were made with oir forced
tbrough gasoline, and with oil heated in a can to form gas. blow-pipe devire, and no better results were obtained, though With the change of the wheels, the brakes bad to be
inged the same amount, that is, each one get in $11 / 3$ in. his it was thought would either require new bangere, or a hangers could easily be bent without removal. Fig. 34 sbows three hangers after passing throukh the hending process A
short lever arranged tw clasp the hanger just below the point

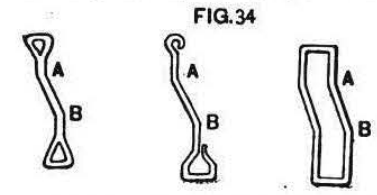

A was the instrument. A forked " shore " is now placed. with the fork against the point $A$, and the other end agains
the car sill; press down on the lever and you bend the bang process and you bave the bend at $B$; the wbole thing taking
ess than two minutes per hanger. A new bolt hole, of course bas been bored in the brake beam $11 / 3$ in. inside the
old bolt. It takes but a short time after this to change the position of the head and shoe.
Before the day of change, a portion of the spikes were rawn from the inside of the rail to be moved, and a spike and the third left. At least every third spike was get for the new gauge, and in some cases every other one. There were
several devices with which to set the splke. A small piece of iron 3 in. wide was common, and answered the purpose well. hand to clasp, while others bad a handle long enough for $a$ man to use it without stooping down. See figs. 35 and 38. 


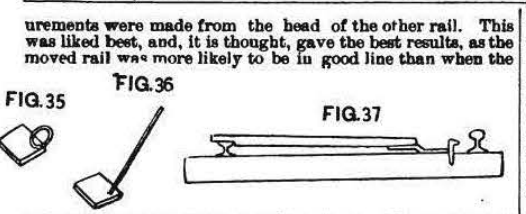

measurements were taken from the flange. It was intender
that great care should be taken in driving the spikes, that they were in the proper place, square with the rail, and left
sticking up about an incb. The ties, of course, were all adzed dowa betore the day of chauge
Hand-spikes were oripinally used to throw the rails, as were linug bars. We found, however, that small cant-
hooks were more easily handied and did better work. The hooks were more easily handied and did better work. The
fint. ware made like fig. 88 , with a spike in the end of a stick, \begin{tabular}{l|l} 
FIG.38 & $\begin{array}{l}\text { while the hook was fastened with } \\
\text { bolt about } 10 \text { or } 12 \text { in. above the } \\
\text { foot. We afterward made them of a }\end{array}$
\end{tabular} $11 /$ in. red, $31 /$ f feet long, thinted at one end, with a ring shruuk on 1 fout
from the bottom. Then the hoo

from the bottom. Then the hook flg. 39, which slipped down over the
top of the main rod. This was
gimple and cheap, and the iron was simple and cheap. and the iron was
to be used for repair purposes when this work was doove. Upon the system with which the writer was connected wo had some branches where we could experiment upon the
moving of the rail. Between Selms and Lauderdale the traffic was light, and at Lauderdale it connected with the
Mobile \& Obio Railroad, which was narrow, and to whicb
all freight had to be transerred, either by hoisting the cars all freight had to be transferred, either by hoigting the cars,
or by bandling through the house. By changing our gauge We would simply change the point of transfer to
Here was a chance to experiment pupon one hundred miles
and cause little trouble to traffic. We could gee the practiand cause little trouble to traffic. We could gee the practiWork. It had been our plan to do it somewbat earlier, hut
floods prevented. Most of the rail was old chair iron, sbort, snd consequently more time was used in making the chance
than would have been required had our work boen on fish
plate rail. Our sections bere were about eight miles long plate rail. Our sections bere were about eigbt miles long,
and we arranged our men on the basis blocked out by the committee, viz.: 24 to 28 men to the esction, consisting of
6 spike pullers, 4 throwing rails, 12 spikers, 2 to push the cars and carry water.
We soon found 5 -ft. cars useless and threw them into the ditch to be picked up at some future time.
The men were spread out so as not to be in each other's way, and, when the organization was understuod and conhours and ten minutes, including a number of switches. We on later work. that after 5 or 6 miles the men began to lag.
We believed we bad the best results when we had sections of about that length. It was arranged tbat two pections, alter.
nately, commenced work together at one point, working from nately. commenced work together at one point, working from
each other and continuing until the forre of anotber section was met, working from the opposite direction.
The foreman in charge was expected to examine the work a good test as to gauge. A work train was started from each end with a small force (20 or 25 men) to run over the changed track. This train, of course, had been changed on a previous
day to be ready for this work. If a force was overtaken by at once spread out to aid in its completion. This done the train ran on. Not until this was done was a traffic train al
lowed to pass over the track. The same rule was followed upon all the work. Upon the final day it was required tha upon all high trestles and in tunnels tha track should be ful
spiked before being left, or a train let over. This took extra precaution on the side of safety. Upon the day of the change of the Alabams Central Di-
vision (Belma to Landerdale), guperintendents of other divisions, with their road masters, supervisors, master me-
chanics and many section foremen, wore sent over to see the organization and work and the preparations that had been
nade. Many of them lent $\mathrm{a}$ helping hand in the work. They saw here in practice what had only been theory before. road between Rorme, Ga, and Selma, Ala., about 200 miles,
was changed, and again men from other divisions were sent to see and aid in the work; so when the final day came the On the last day of May the Memphis \& Charleston, Knoxville \& Obio. avd North Carolina Brapch were changed, and
on June 1 the line from Bristol to Chattanooga and Brunswick. Other roads changed their branch lines a day or two
before the 1 st of June; but the main lines, as a rule, were It was no small maiter to take care of the cars and arrange
a the train service so there should be no bitches. It was not hours prior to the change, and these days were gpent in clear.
ing the road of everything, and taking the cars to the points of rendezvous All scheduled freight trains were abandoned on Upon the East Tenpessee gystem these points were Knoxvill these points all cars must go, loaded or empty, and tbere they
were parked upon the tracks prepared for the purpose. Pas. genger trains were run to points where it had been arranged
to change them, generally to the general changing point Most of the Bouthern roads have double daily passegerer ser-
vioe : upon all ropads one of thee trains, upon the day of change, was abandoned, and upon some, all. Bome, even,
did not run till next day. We were able to start the day train

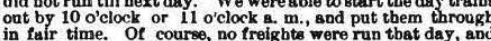
the next day was used in getting the cars which bad been
changed, out of the parks and iuto line. So our freight traf
fic over the entire South was suspended practically three The work of changing was to cummence at $3: 30$ a. m.
but many of the men were in position at an earlier bour and did commence work as soon as the last tran was waver, or an
bour or so before the fixed time. Half-past three $\mathrm{a}$. $\mathrm{m}$., ho ever, can be set dows as the keneral hour of commencement briskly, the men working with much more than "rdinar enthusiasm: but the day was warm, and atter 9 or $10 \mathrm{a}$. $\mathrm{m}$.
it began to lag. All was done, bowerer, hefore the day was it began to lag. A Al was done, bowever, hefore the day was
over, and safe, so that trains could pasa st full speed. The early or late in the day, and were paid that afternoon as soon
as the work was done. Tictrets were given the men, which as the work was done. Tickets were given the men, which
the nearest agent paid, remitting as cash to the treasurer. On some lines it was deemed best to offer prizes to tho
On who got through first. Reports ghowed some very early fin-
ishes; but the facts seem to have been that under such ishes; but the facts seem to have been that under such enfore the change and put tho fero in while changing. They
were thus reported through early, but their work was not done, and they took great chances. It was by most cousid-
ered unwwiee to offer such prizes, preferring to have a little red unwise to offer such prizes, preferring to have a little
more taken and be sure that all was safe. Sucb lines seemed to get their trains in motion with as much promptness as
others This, with freedom from accident, was the end sought.
It was found after the work had been done that there had
been little inaccuracies in driving the gauge spike, to which the rail was thrown, probably from various causee. The proper place, and then the template in the hurry may not or twisted. Whatever was the cause, it was found that fre
quently the line on the moved side was not perfect, and, of quently the line on the moved side was not perfect, and, of
course, many spikes bad to be drawn and the rail lined up and respiked. The more cerefrul the work. had been fone,
the less of this there was to do afterward. With rough track it was.
Of course, we all planned to get foreign cars home and have cours ant to us; but when the interchange stopped, we
found we had many foreigu cars, which, of course, hed to be found we had many foreign cars, which, of course, hed to be
changed. This subject had come up in convention and it bad
been voted to charge $\$ 3$ per car when axles did nut need
turning, and 85 where they did. By comparison with the been voted to charge 8 per car when axles did not need
turning, and of where they did. By comparison with the
cost of changing, ss shown in this paper, it will be geen that to our company. at least, thera was no loses at these figures
The following statements will explain the work done upon Georgia systams. formation regarding other roads that fuller statements and comparisons might le made and the sbowings be of greater
value. The figures of the Mobile \& Obio are added, having been compiled from the annual report of that roed.

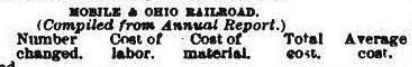

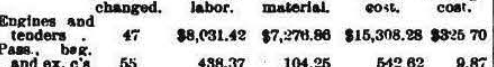

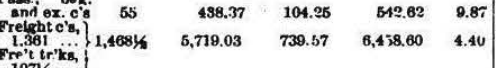

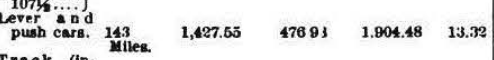
Track
cludic
ofdings

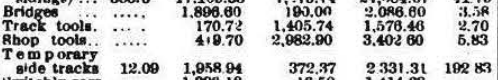

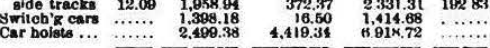

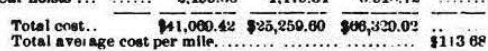

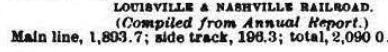
Track

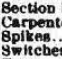

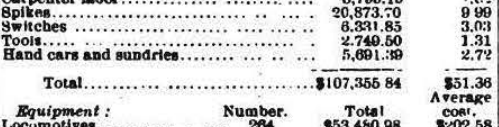

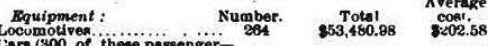

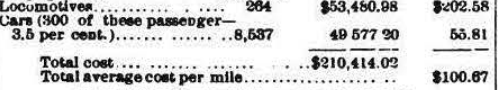

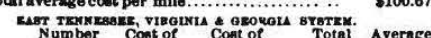
chaoged. Labor. material. cosh coot.

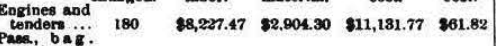

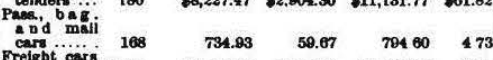

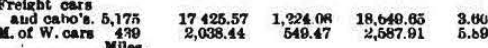

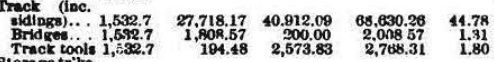

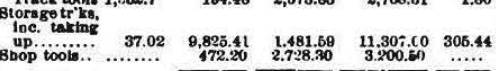

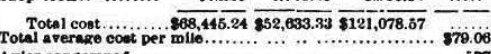
Axloes condemped.
Wheels condemned
Wheeta burst. New axl 8 used
New wheels unod

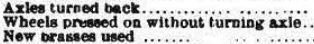

Naw brasses used
Cars narrowed (not including lever or pusi cars)
Engiues narrowed

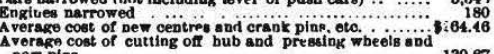

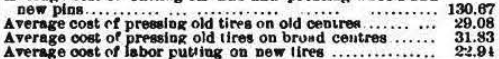

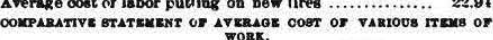

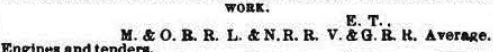

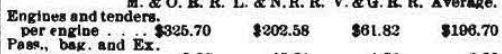

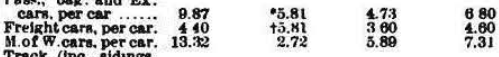

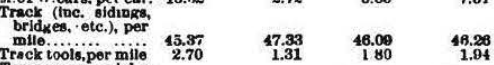

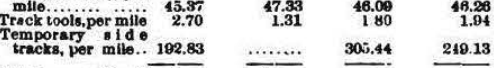

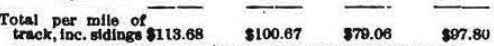
"Expenso not divided as between passenger and frelight cars.
t3. 5 per cont. passenger, baggage and express cars; 96.5 per
cont, frelght cars.
Since the preparation of this paper the general manager of
the Norfolk \& Western Railroad has kindly furnished the fowing items of expense for that line : Average

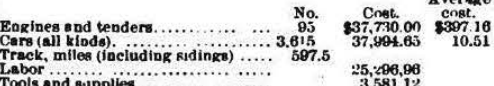

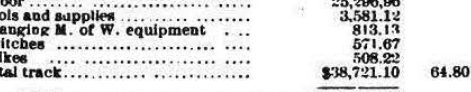

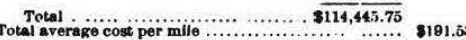
And the superintendent of the Savannah, Florida \& West-

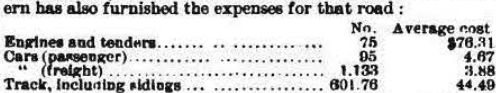
Track, incluning aldiogs ..................601.76
Nothing was said about shop or otber tools, storage tracks

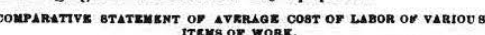

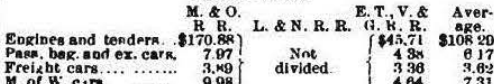

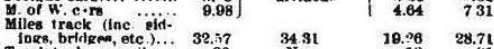

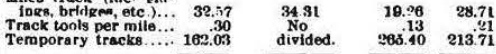

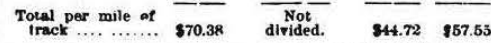
COMPARATIVE BTATEMENT OY AVRAAOE COET OF MATERIAL OY VARI

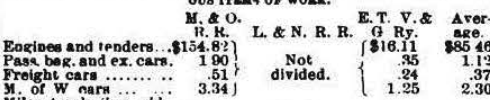

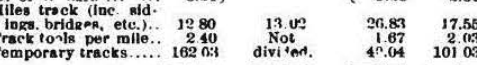

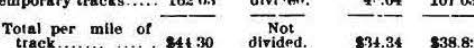

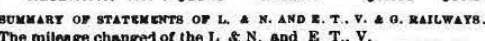

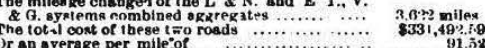

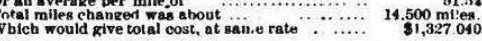
We sbould really add to this a large sum for the great
unber of vew locomotives wbich were purchased to replace old ones that could not be changed, except at large cost, and which, when done, would have boen lifht and undeairable.
Upon the basis of the work done upon the Louisville \& Nashville and East Ternessee, Virkinia \& Georgia systems, we have made the following estimates. which will perhaps
convey a better idea of th9 extent of the work than can be convey a better idea of ths extent of the work than can be
obtained in any other way

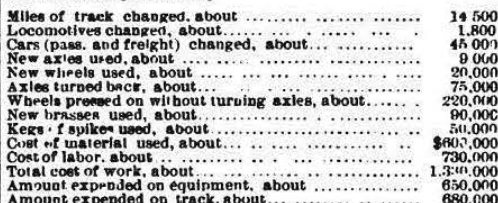

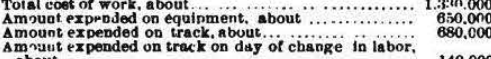
The work was done economically, and so quietly tbat the rver it was an every-day trabsaction. It was, however, work of preat magnitude, requiring much thought and
workanizal ability. That it was ably handled is evidenced mechanizal ability. That it was ably handled is evidenced
by the uniform success attained, the prompt changing at the agreed time, and the trifling inconvenience to the public.

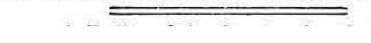

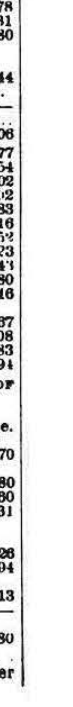




\section{Sensitivity Checks}

\section{D.1 Sensitivity Checks: Dropping Origins}

This section evaluates the sensitivity of the main results in Tables 3 and 5 to dropping observations with a given origin. Figure D.1 illustrates the stability of the results in Table 3, plotting the focal coefficient estimates from a specification of log quantities with route-year fixed effects (as in Column 5 ), omitting the given origin. Figure D.2 does the same for Table 3, plotting the focal coefficient estimates from a specification of traffic shares with route fixed effects (as in Column 2). The 95\% confidence interval for each parameter is also provided.

Figure D.1: Focal coefficient estimates from Table 3, omitting the given origin

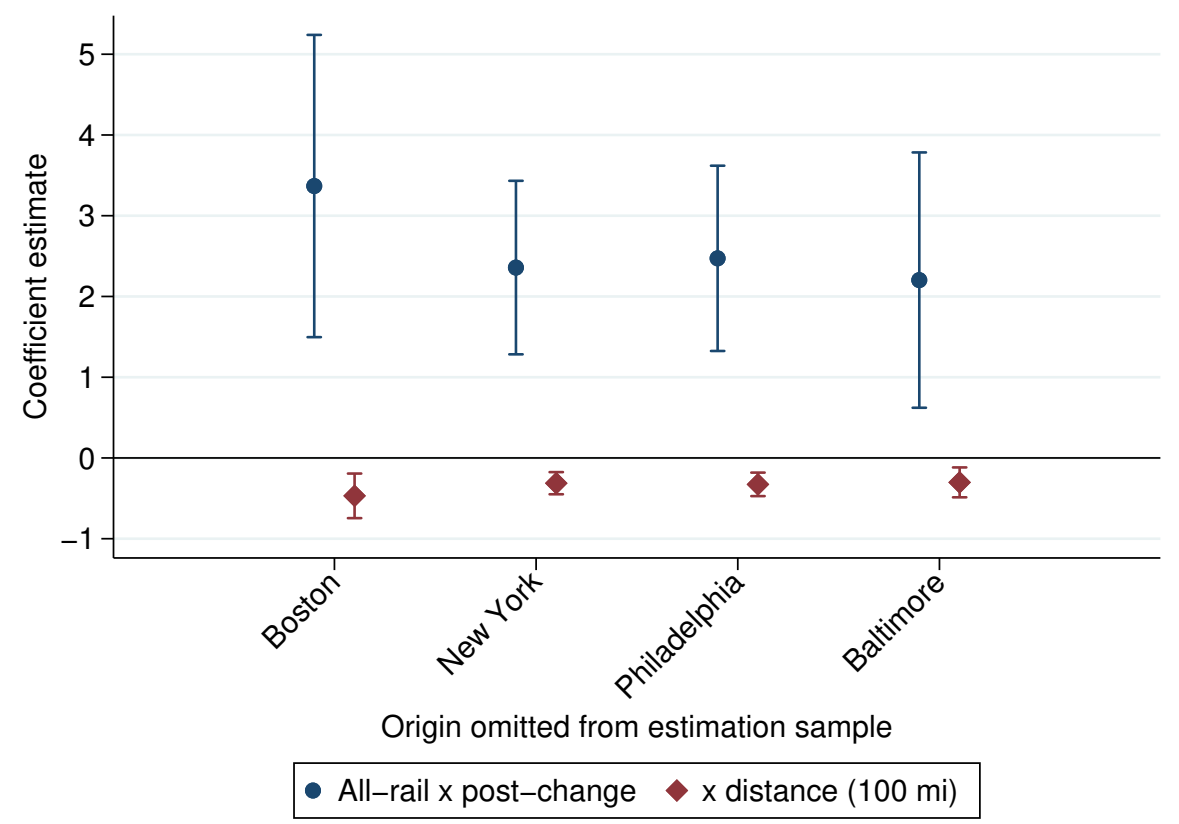

Notes: Figure plots focal coefficient estimates (and 95\% confidence intervals) from a regression of log quantities with route-year fixed effects (as in Column 5 of Table 3), omitting the given origin. 
Figure D.2: Focal coefficient estimates from Table 5, omitting the given origin

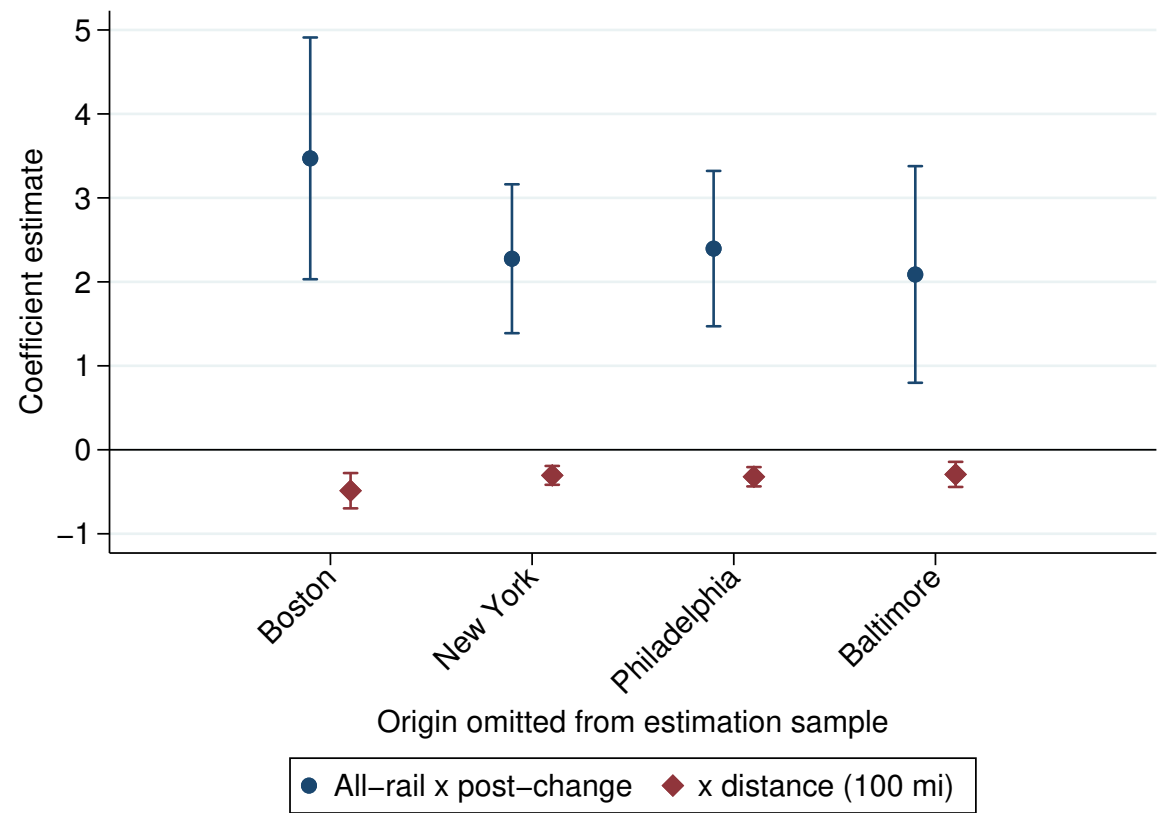

Notes: Figure plots focal coefficient estimates (and 95\% confidence intervals) from a regression of traffic shares with route fixed effects (as in Column 2 of Table 5), omitting the given origin. 


\section{D.2 Sensitivity Checks: Dropping Destinations}

This section evaluates the sensitivity of the main results in Tables 3 and 5 to dropping observations with a given destination. Figure D.3 illustrates the stability of the results in Table 3, plotting the focal coefficient estimates from a specification of log quantities with route-year fixed effects (as in Column 5), omitting the given origin. Figure D.4 does the same for Table 3, plotting the focal coefficient estimates from a specification of traffic shares with route fixed effects (as in Column 2). The $95 \%$ confidence interval for each parameter is also provided.

Figure D.3: Focal coefficient estimates from Table 3, omitting the given destination

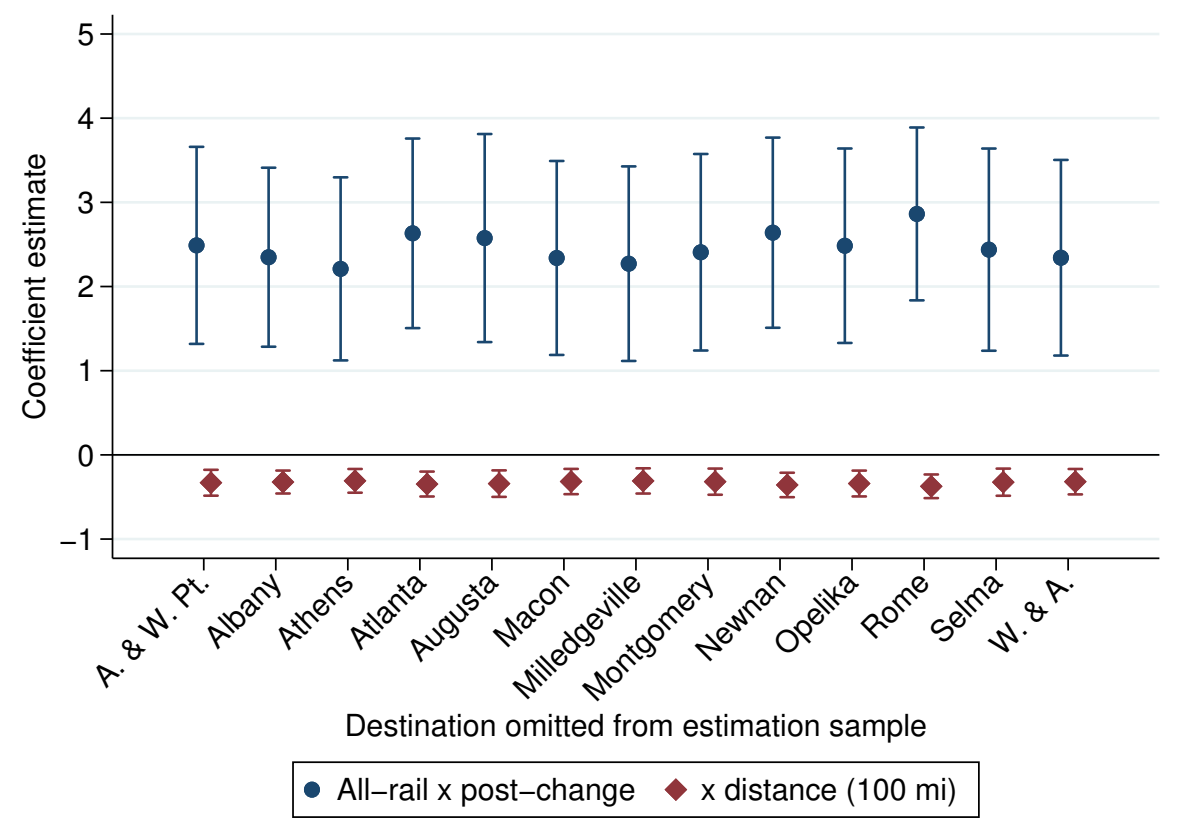

Notes: Figure plots focal coefficient estimates (and 95\% confidence intervals) from a regression of log quantities with route-year fixed effects (as in Column 5 of Table 3), omitting the given destination. 
Figure D.4: Focal coefficient estimates from Table 5, omitting the given destination

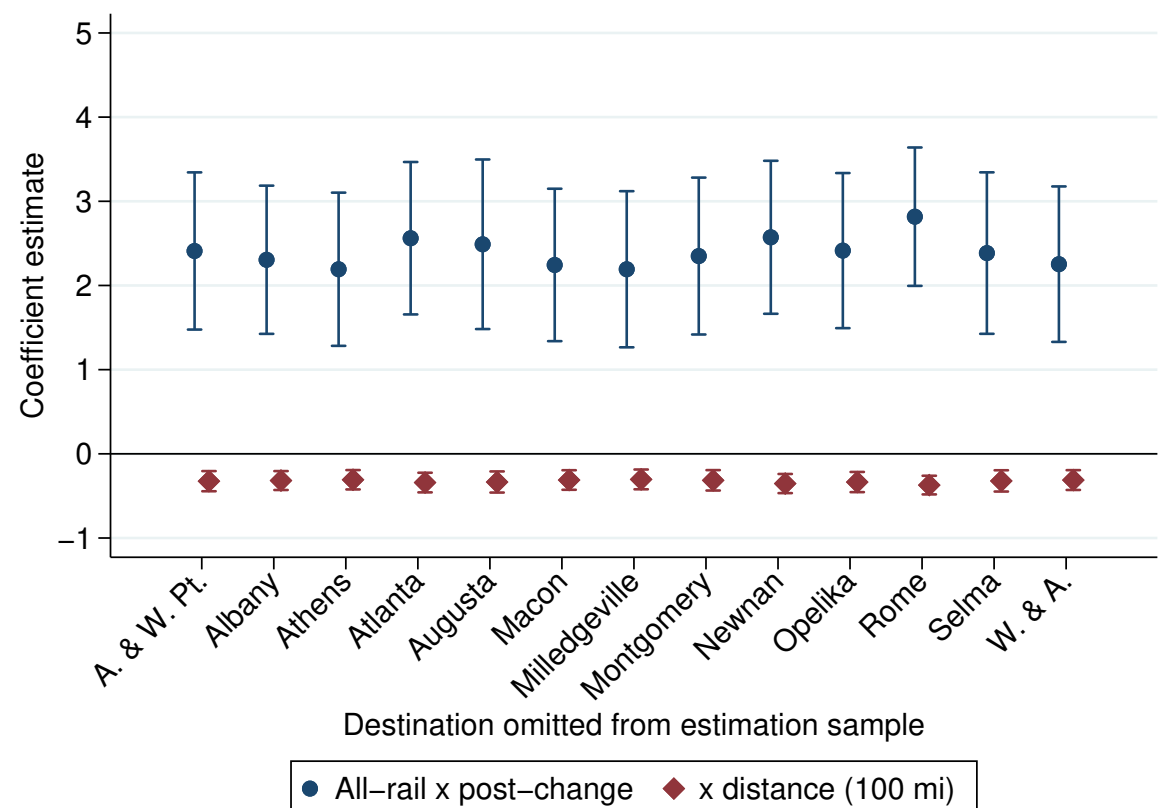

Notes: Figure plots focal coefficient estimates (and 95\% confidence intervals) from a regression of traffic shares with route fixed effects (as in Column 2 of Table 5), omitting the given destination. 


\section{D.3 Sensitivity Checks: Dropping Years}

This section evaluates the sensitivity of the main results in Tables 3 and 5 to dropping observations in a given year. Figure D.5 illustrates the stability of the results in Table 3, plotting the focal coefficient estimates from a specification of log quantities with route-year fixed effects (as in Column 5), omitting the given origin. Figure D.6 does the same for Table 3, plotting the focal coefficient estimates from a specification of traffic shares with route fixed effects (as in Column 2). The 95\% confidence interval for each parameter is also provided.

Figure D.5: Focal coefficient estimates from Table 3, omitting the given year

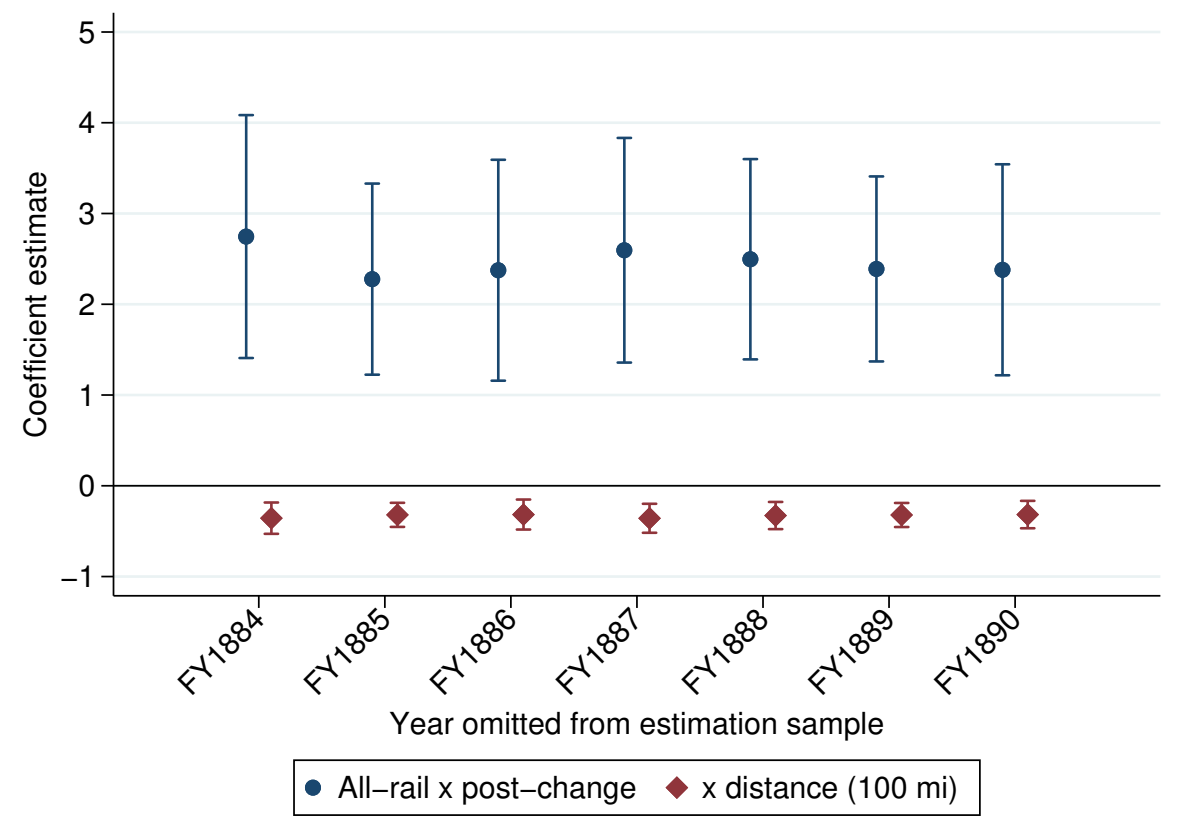

Notes: Figure plots focal coefficient estimates (and 95\% confidence intervals) from a regression of log quantities with route-year fixed effects (as in Column 5 of Table 3), omitting the given year. 
Figure D.6: Focal coefficient estimates from Table 5, omitting the given year

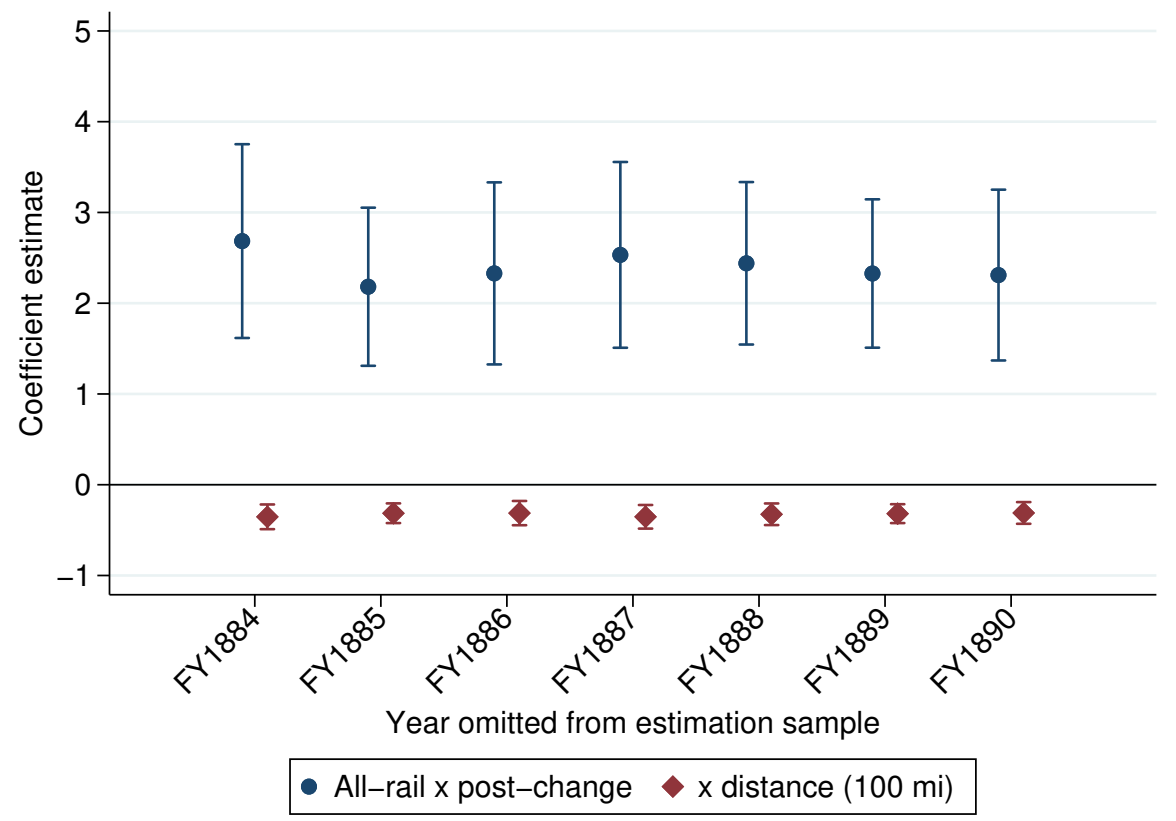

Notes: Figure plots focal coefficient estimates (and 95\% confidence intervals) from a regression of traffic shares with route fixed effects (as in Column 2 of Table 5), omitting the given year. 


\section{E Proofs of Propositions}

Proofs for Section 4.1

\section{Lemma 1.}

Standardization can generate the following payoffs to $R 1$ and $R 2$ relative to the status quo, before accounting for the fixed cost of conversion $C$ :

a. If $R 1$ converts alone: $\Delta \pi_{R 1}^{10}>0, \Delta \pi_{R 2}^{10}=0$

b. If R2 converts alone: $\Delta \pi_{R 1}^{01}<0, \Delta \pi_{R 2}^{01}<0$

c. If $R 1$ and R2 convert jointly: $\Delta \pi_{R 1}^{11}>\Delta \pi_{R 1}^{10}, \Delta \pi_{R 2}^{11}>0$

\section{Proof:}

Part 1. If neither R1 nor R2 convert to standard gauge:

$$
\begin{aligned}
& \Pi_{1}=\left(P_{1}-c-\theta\right) Q_{1}=\left(P_{1}-c-\theta\right)\left(M_{1}-a P_{1}\right) \\
& \frac{\partial \Pi_{1}}{\partial P_{1}}=M_{1}-2 a P_{1}+a(c+\theta)=0 \quad \Longrightarrow \quad P_{1}=\frac{1}{2 a}\left(M_{1}+a(c+\theta)\right), Q_{1}=\frac{1}{2}\left(M_{1}-a(c+\theta)\right) \\
& \Pi_{1}=\left(\left[\frac{1}{2 a}\left(M_{1}+a(c+\theta)\right)\right]-c-\theta\right)\left[\frac{1}{2}\left(M_{1}-a(c+\theta)\right)\right] \\
& \left.\quad=\left(\frac{1}{2}\left(\frac{M_{1}}{a}-c-\theta\right)\right)\left(\frac{1}{2} a\left(\frac{M_{1}}{a}-c-\theta\right)\right)\right)=\frac{1}{4} a\left(\frac{M_{1}}{a}-c-\theta\right)^{2}
\end{aligned}
$$

and by symmetry, $\Pi_{2}=\frac{1}{4} a\left(\frac{M_{2}}{a}-2 c-\theta\right)^{2}$.

$\mathrm{R} 1$ and $\mathrm{R} 2$ profits are thus:

$$
\begin{aligned}
& \pi_{1}^{00}=\Pi_{1}+\frac{1}{2} \Pi_{2}=\frac{1}{4} a\left(\frac{M_{1}}{a}-c-\theta\right)^{2}+\frac{1}{2}\left(\frac{1}{4} a\left(\frac{M_{2}}{a}-2 c-\theta\right)^{2}\right) \\
& \pi_{2}^{00}=\frac{1}{2} \Pi_{2}=\frac{1}{2}\left(\frac{1}{4} a\left(\frac{M_{2}}{a}-2 c-\theta\right)^{2}\right)
\end{aligned}
$$


Part 2. If only R1 converts to standard gauge:

$$
\begin{aligned}
& \Pi_{1}=\left(P_{1}-c\right) Q_{1}=\left(P_{1}-c\right)\left(M_{1}-a P_{1}\right) \\
& \frac{\partial \Pi_{1}}{\partial P_{1}}=M_{1}-2 a P_{1}+a c=0 \Longrightarrow P_{1}=\frac{1}{2 a}\left(M_{1}+a c\right), Q_{1}=\frac{1}{2}\left(M_{1}-a c\right) \\
& \Pi_{1}=\left(\left[\frac{1}{2 a}\left(M_{1}+a c\right)\right]-c\right)\left[\frac{1}{2}\left(M_{1}-a c\right)\right] \\
& \left.\quad=\left(\frac{1}{2}\left(\frac{M_{1}}{a}-c\right)\right)\left(\frac{1}{2} a\left(\frac{M_{1}}{a}-c\right)\right)\right)=\frac{1}{4} a\left(\frac{M_{1}}{a}-c\right)^{2} \\
& \Pi_{2}=\left(P_{2}-2 c-\theta\right) Q_{2}=\left(P_{2}-2 c-\theta\right)\left(M_{2}-a P_{2}\right) \\
& \frac{\partial \Pi_{2}}{\partial P_{2}}=M_{2}-2 a P_{2}+a(2 c+\theta)=0 \Longrightarrow P_{2}=\frac{1}{2 a}\left(M_{2}+a(2 c+\theta)\right), Q_{2}=\frac{1}{2}\left(M_{2}-a(2 c+\theta)\right) \\
& \Pi_{2}=\left(\left[\frac{1}{2 a}\left(M_{2}+a(2 c+\theta)\right)\right]-c-\theta\right)\left[\frac{1}{2}\left(M_{2}-a(2 c+\theta)\right)\right] \\
& \left.\quad=\left(\frac{1}{2}\left(\frac{M_{2}}{a}-2 c-\theta\right)\right)\left(\frac{1}{2} a\left(\frac{M_{2}}{a}-2 c-\theta\right)\right)\right)=\frac{1}{4} a\left(\frac{M_{2}}{a}-2 c-\theta\right)^{2}
\end{aligned}
$$

$\mathrm{R} 1$ and $\mathrm{R} 2$ profits are thus:

$$
\begin{aligned}
& \pi_{1}^{10}=\Pi_{1}+\frac{1}{2} \Pi_{2}=\frac{1}{4} a\left(\frac{M_{1}}{a}-c\right)^{2}+\frac{1}{2}\left(\frac{1}{4} a\left(\frac{M_{2}}{a}-2 c-\theta\right)^{2}\right) \\
& \pi_{2}^{10}=\frac{1}{2} \Pi_{2}=\frac{1}{2}\left(\frac{1}{4} a\left(\frac{M_{2}}{a}-2 c-\theta\right)^{2}\right)
\end{aligned}
$$


Part 3. If only R2 converts to standard gauge:

$$
\begin{aligned}
& \Pi_{1}=\left(P_{1}-c-\theta\right) Q_{1}=\left(P_{1}-c-\theta\right)\left(M_{1}-a P_{1}\right) \\
& \frac{\partial \Pi_{1}}{\partial P_{1}}=M_{1}-2 a P_{1}+a(c+\theta)=0 \Longrightarrow P_{1}=\frac{1}{2 a}\left(M_{1}+a(c+\theta)\right), Q_{1}=\frac{1}{2}\left(M_{1}-a(c+\theta)\right) \\
& \Pi_{1}=\left(\left[\frac{1}{2 a}\left(M_{1}+a(c+\theta)\right)\right]-c-\theta\right)\left[\frac{1}{2}\left(M_{1}-a(c+\theta)\right)\right] \\
& \left.\quad=\left(\frac{1}{2}\left(\frac{M_{1}}{a}-c-\theta\right)\right)\left(\frac{1}{2} a\left(\frac{M_{1}}{a}-c-\theta\right)\right)\right)=\frac{1}{4} a\left(\frac{M_{1}}{a}-c-\theta\right)^{2} \\
& \Pi_{2}=\left(P_{2}-2 c-2 \theta\right) Q_{2}=\left(P_{2}-2 c-2 \theta\right)\left(M_{2}-a P_{2}\right) \\
& \frac{\partial \Pi_{2}}{\partial P_{2}}=M_{2}-2 a P_{2}+a(2 c+2 \theta)=0 \Longrightarrow P_{2}=\frac{1}{2 a}\left(M_{2}+a(2 c+2 \theta)\right), Q_{2}=\frac{1}{2}\left(M_{2}-a(2 c+2 \theta)\right) \\
& \Pi_{2}=\left(\left[\frac{1}{2 a}\left(M_{2}+a(2 c+2 \theta)\right)\right]-c-2 \theta\right)\left[\frac{1}{2}\left(M_{2}-a(2 c+2 \theta)\right)\right] \\
& \quad=\left(\frac{1}{2}\left(\frac{M_{2}}{a}-2 c-2 \theta\right)\right)\left(\frac{1}{2} a\left(\frac{M_{2}}{a}-2 c-2 \theta\right)\right)=\frac{1}{4} a\left(\frac{M_{2}}{a}-2 c-2 \theta\right)^{2}
\end{aligned}
$$

$\mathrm{R} 1$ and $\mathrm{R} 2$ profits are thus:

$$
\begin{aligned}
& \pi_{1}^{01}=\Pi_{1}+\frac{1}{2} \Pi_{2}=\frac{1}{4} a\left(\frac{M_{1}}{a}-c-\theta\right)^{2}+\frac{1}{2}\left(\frac{1}{4} a\left(\frac{M_{2}}{a}-2 c-2 \theta\right)^{2}\right) \\
& \pi_{2}^{01}=\frac{1}{2} \Pi_{2}=\frac{1}{2}\left(\frac{1}{4} a\left(\frac{M_{2}}{a}-2 c-2 \theta\right)^{2}\right)
\end{aligned}
$$


Part 4. If both R1 and R2 convert to standard gauge:

$$
\begin{aligned}
& \Pi_{1}=\left(P_{1}-c\right) Q_{1}=\left(P_{1}-c\right)\left(M_{1}-a P_{1}\right) \\
& \frac{\partial \Pi_{1}}{\partial P_{1}}=M_{1}-2 a P_{1}+a c=0 \quad \Longrightarrow \quad P_{1}=\frac{1}{2 a}\left(M_{1}+a c\right), Q_{1}=\frac{1}{2}\left(M_{1}-a c\right) \\
& \Pi_{1}=\left(\left[\frac{1}{2 a}\left(M_{1}+a c\right)\right]-c\right)\left[\frac{1}{2}\left(M_{1}-a c\right)\right] \\
& \left.\quad=\left(\frac{1}{2}\left(\frac{M_{1}}{a}-c\right)\right)\left(\frac{1}{2} a\left(\frac{M_{1}}{a}-c\right)\right)\right)=\frac{1}{4} a\left(\frac{M_{1}}{a}-c\right)^{2}
\end{aligned}
$$

and by symmetry, $\Pi_{2}=\frac{1}{4} a\left(\frac{M_{2}}{a}-2 c\right)^{2}$.

$\mathrm{R} 1$ and $\mathrm{R} 2$ profits are thus:

$$
\begin{aligned}
& \pi_{1}^{11}=\Pi_{1}+\frac{1}{2} \Pi_{2}=\frac{1}{4} a\left(\frac{M_{1}}{a}-c\right)^{2}+\frac{1}{2}\left(\frac{1}{4} a\left(\frac{M_{2}}{a}-2 c\right)^{2}\right) \\
& \pi_{2}^{11}=\frac{1}{2} \Pi_{2}=\frac{1}{2}\left(\frac{1}{4} a\left(\frac{M_{2}}{a}-2 c\right)^{2}\right)
\end{aligned}
$$


Part 5. Comparisons to the status quo

If $\mathrm{R} 1$ converts alone:

$$
\begin{aligned}
& \Delta \pi_{R 1}^{10}=\pi_{R 1}^{10}-\pi_{R 1}^{00}=\frac{1}{4} a\left(\frac{M_{1}}{a}-c\right)^{2}-\frac{1}{4} a\left(\frac{M_{1}}{a}-c-\theta\right)^{2} \\
& \quad=\frac{1}{4} a\left(\left(\frac{M_{1}}{a}-c\right)^{2}-\left(\frac{M_{1}}{a}-c-\theta\right)^{2}\right)=\frac{1}{4} a\left(2 \theta\left(\frac{M_{1}}{a}-c\right)-\theta^{2}\right)=\frac{1}{2} \theta\left(M_{1}-a c-\frac{1}{2} a \theta\right)>0 \\
& \Delta \pi_{R 2}^{10}=\pi_{R 2}^{10}-\pi_{R 2}^{00}=0
\end{aligned}
$$

If $\mathrm{R} 2$ converts alone:

$$
\begin{aligned}
& \Delta \pi_{R 1}^{01}=\pi_{R 1}^{01}-\pi_{R 1}^{00}=\frac{1}{2}\left(\frac{1}{4} a\left(\frac{M_{2}}{a}-2 c-2 \theta\right)^{2}\right)-\frac{1}{2}\left(\frac{1}{4} a\left(\frac{M_{2}}{a}-2 c-\theta\right)^{2}\right) \\
& \quad=\frac{1}{8} a\left(\left(\frac{M_{2}}{a}-2 c-2 \theta\right)^{2}-\left(\frac{M_{2}}{a}-2 c-\theta\right)^{2}\right) \\
& \quad=\frac{1}{8} a\left(\left(\frac{M_{2}}{a}-2 c-\theta-\theta\right)^{2}-\left(\frac{M_{2}}{a}-2 c-\theta\right)^{2}\right) \\
& =\frac{1}{8} a\left(-2 \theta\left(\frac{M_{2}}{a}-2 c-\theta\right)+\theta^{2}\right)=-\frac{1}{4} \theta\left(M_{2}-2 a c-\frac{3}{2} a \theta\right)<0 \\
& \Delta \pi_{R 2}^{10}=\pi_{R 2}^{10}-\pi_{R 2}^{00}=-\frac{1}{4} \theta\left(M_{2}-2 a c-\frac{3}{2} a \theta\right)<0
\end{aligned}
$$

If $\mathrm{R} 1$ and $\mathrm{R} 2$ convert jointly:

$$
\begin{aligned}
& \Delta \pi_{R 1}^{11}=\pi_{R 1}^{11}-\pi_{R 1}^{00}=\Delta \pi_{R 1}^{10}+\left[\frac{1}{2}\left(\frac{1}{4} a\left(\frac{M_{2}}{a}-2 c\right)^{2}\right)-\frac{1}{2}\left(\frac{1}{4} a\left(\frac{M_{2}}{a}-2 c-\theta\right)^{2}\right)\right] \\
& =\frac{1}{2} \theta\left(M_{1}-a c-\frac{1}{2} a \theta\right)+\left[\frac{1}{2}\left(\frac{1}{4} a\left(\frac{M_{2}}{a}-2 c\right)^{2}\right)-\frac{1}{2}\left(\frac{1}{4} a\left(\frac{M_{2}}{a}-2 c-\theta\right)^{2}\right)\right] \\
& =\frac{1}{2} \theta\left(M_{1}-a c-\frac{1}{2} a \theta\right)+\frac{1}{8} a\left(\left(\frac{M_{2}}{a}-2 c\right)^{2}-\left(\frac{M_{2}}{a}-2 c-\theta\right)^{2}\right) \\
& =\frac{1}{2} \theta\left(M_{1}-a c-\frac{1}{2} a \theta\right)+\frac{1}{8} a\left(2 \theta\left(\frac{M_{2}}{a}-2 c\right)-\theta^{2}\right) \\
& =\frac{1}{2} \theta\left(M_{1}-a c-\frac{1}{2} a \theta\right)+\frac{1}{4} \theta\left(M_{2}-2 a c-\frac{1}{2} a \theta\right)=\frac{1}{4} \theta\left(2 M_{1}+M_{2}-4 a c-\frac{3}{2} a \theta\right)>0 \\
& \Delta \pi_{R 2}^{11}=\pi_{R 2}^{11}-\pi_{R 2}^{00}=\frac{1}{4} \theta\left(M_{2}-2 a c-\frac{1}{2} a \theta\right)>0
\end{aligned}
$$




\section{Proposition 1.}

In the absence of competition, provided $\Delta \pi_{R 1}^{10}<C<\Delta \pi_{R 2}^{11}$, there are two equilibria for standardization: either both firms convert to standard gauge, or neither firm converts (the status quo). Unilateral conversion to standard gauge is never an equilibrium.

\section{Proof:}

As a preliminary, we will establish that $\Delta \pi_{R 1}^{10}<\Delta \pi_{R 2}^{11}$, so that $\exists C$ s.t. $C \in\left(\Delta \pi_{R 1}^{10}, \Delta \pi_{R 2}^{11}\right)$ :

$$
\begin{aligned}
2 M_{1} & <M_{2} \Longrightarrow M_{1}<\frac{1}{2} M_{2} \Longrightarrow M_{1}-\frac{1}{4} a \theta<\frac{1}{2} M_{2} \Longrightarrow M_{1}-a c-\frac{1}{2} a \theta<\frac{1}{2} M_{2}-a c-\frac{1}{4} a \theta \\
& \Longrightarrow M_{1}-a c-\frac{1}{2} a \theta<\frac{1}{2}\left(M_{2}-2 a c-\frac{1}{2} a \theta\right) \\
& \Longrightarrow \Delta \pi_{R 1}^{10}=\frac{1}{2}\left(M_{1}-a c-\frac{1}{2} a \theta\right)<\frac{1}{4}\left(M_{2}-2 a c-\frac{1}{2} a \theta\right)=\Delta \pi_{R 2}^{11}
\end{aligned}
$$

Status quo equilibrium: R1 does not convert to standard gauge $\Longleftrightarrow \mathrm{R} 2$ does not convert.

- ( $\Longrightarrow)$ Suppose R1 does not convert to standard gauge. Then R2 will not convert to standard gauge, because $0>\Delta \pi_{R 2}^{01}-C$, by Lemma 1 .

- $(\Longleftarrow)$ Suppose R2 does not convert to standard gauge. Then R1 will not convert to standard gauge, because $0>\Delta \pi_{R 1}^{10}-C$, by the condition assumed.

Standardization equilibrium: R1 converts to standard gauge $\Longleftrightarrow \mathrm{R} 2$ converts.

- $(\Longrightarrow)$ Suppose R1 converts to standard gauge. Then R2 will also convert to standard gauge, because $\Delta \pi_{R 2}^{11}-C>0=\Delta \pi_{R 2}^{10}$, by Lemma 1 and the condition assumed.

- $(\Longleftarrow)$ Suppose R2 converts to standard gauge. Then R1 will also convert to standard gauge, because $\Delta \pi_{R 1}^{11}-C>0>\Delta \pi_{R 1}^{01}$, by Lemma 1 and the condition assumed. 


\section{Proposition 2.}

Collective standardization is only an equilibrium outcome with collusion.

\section{Proof:}

The proof consists of two parts: (1) Collective standardization is not an equilibrium with competition, and (2) it can be an equilibrium with collusion. For the sake of exposition we will set the fixed cost $C$ of changing the gauge to $C=0$, but the results hold with $C>0$ subject to the regularity conditions below. We also assume that in the collusive scenario, R1-R2 and R3-R4 set a single, common price $P$ to maximize joint profits, consistent with this paper's setting.

The requisite regularity conditions are:

(RC1) Each party can unilaterally break the cartel but cannot unilaterally form it.

(RC2) When R1-R2 standardizes alone, its profits in a competitive market (subject to limit pricing) are greater than its profits in a collusive market (subject to side payments).

(RC3) The fixed cost of standardization $(C)$ is less than half of monopoly profits under standardization (in the notation used below: $C<\frac{1}{2} \Pi_{\text {joint }}^{11}$ ).

Part 1. Collective standardization is not an equilibrium with competition.

With symmetric, undifferentiated competition, prices will be competed to marginal costs, as per the Bertrand paradox. Profits in the status quo are thus zero for both R1-R2 and R3-R4.

If either R1-R2 or R3-R4 standardizes, it can set the monopolist profit-maximizing price or a limit price that prices the other out of the market and earns positive profits. Concretely: WLOG, suppose R1-R2 standardizes and R3-R4 doesn't, and let $P^{*}$ denote the monopolist profit-maximizing price. Then, if (i) $P^{*}<c_{2}+\theta$, then R1-R2 can price at $P=P^{*}$, whereas if (ii) $P^{*}>c_{2}+\theta$, then R1-R2 can set a limit price of $P=c_{2}+\theta$ - in both cases, pricing R3-R4 out of the market, and yielding positive profits. If both R1-R2 and R3-R4 standardize, prices will again be competed to marginal costs (such that R3-R4 has no incentive to then do so). In this case, the model has two equilibria, whether one (and only one) of R1-R2 and R3-R4 standardizes.

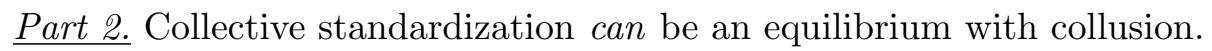

To show that collective standardization is an equilibrium under collusion, we'll begin by calculating payoffs to R1-R2 and R3-R4 under status quo, one-party, and joint standardization. 
If neither or both routings standardize, they will be symmetric and split profits. If neither standardizes, equilibrium cartel price, quantity, and profits can be identified as follows:

$$
\begin{aligned}
& \Pi=(P-2 c-\theta)\left(Q_{R_{12}}+Q_{R_{34}}\right)=2(P-2 c-\theta)(M-\lambda-a P) \\
& \quad=2\left(P(M-\lambda)-a P^{2}-(2 c+\theta)(M-\lambda)+(2 c+\theta) a P\right. \\
& \frac{\partial \Pi}{\partial P}=2(M-\lambda-2 a P+(2 c+\theta) a)=0 \\
& \quad \Longrightarrow \quad P^{00}=\frac{1}{2 a}[M-\lambda+(2 c+\theta) a] \\
& \quad \Longrightarrow \quad Q_{R_{12}}^{00}=Q_{R_{34}}^{00}=\frac{1}{2}(M-\lambda-(2 c+\theta) a)
\end{aligned}
$$

such that:

$$
\begin{aligned}
& \Pi_{\text {joint }}^{00}=(P-2 c-\theta)\left(Q_{R_{12}}+Q_{R_{34}}\right) \\
& \quad=\left[\frac{1}{2 a}(M-\lambda+(2 c+\theta) a)-2 c-\theta\right](M-\lambda-(2 c+\theta) a) \\
& \quad=\frac{1}{2 a}(M-\lambda+(2 c+\theta) a-4 c a-2 \theta a)(M-\lambda-(2 c+\theta) a) \\
& \quad=\frac{1}{2 a}(M-\lambda-(2 c+\theta) a)(M-\lambda-(2 c+\theta) a) \\
& \quad=\frac{1}{2 a}(M-\lambda-(2 c+\theta) a)^{2}
\end{aligned}
$$

If both standardize, $\theta=0$ and $\lambda$ drops out, such that:

$$
\begin{aligned}
& P^{11}=\frac{1}{2 a}[M+(2 c) a] \\
& Q_{R_{12}}^{11}=Q_{R_{34}}^{11}=\frac{1}{2}(M-(2 c) a) \\
& \Pi_{\text {joint }}^{11}=\frac{1}{2 a}(M-(2 c) a)^{2}
\end{aligned}
$$

Now suppose WLOG that R1-R2 standardizes alone. In this event, the cartel maximizes profits by having R1-R2 carry all traffic (at lower cost, as there are no capacity constraints), charge monopoly prices $\left(P^{11}\right)$, and split the profits $\left(\Pi_{\text {joint }}^{11}\right)$ with $\mathrm{R} 3-\mathrm{R} 4$. In principle this scenario could be sustained with side payments: to make R3-R4 indifferent between this and joint standardization, R1-R2 must pay R3-R4 $\left(\frac{1}{2} \Pi_{\text {joint }}^{11}-C\right)$ and would then retain profit of $\frac{1}{2} \Pi_{\text {joint }}^{11}$.

However, because R1-R2 can unilaterally leave the cartel ( $\mathrm{RC} 1$ ), side payments are not incentive compatible: once it has standardized, R1-R2 can increase profits by exiting the cartel and reverting to the competitive equilibrium where it is a monopolist subject to limit pricing ( $\mathrm{RC} 2$ ), and $\mathrm{R} 3-\mathrm{R} 4$ makes zero profits and has no incentive to standardize. With collusion, the R3-R4 best response to standardization by R1-R2 is thus to standardize as well. 


\section{Proofs for Section 4.2}

Proposition 3. Effects of standardization on collusive price and quantities

Eliminating the break in gauge reduces the collusive price by $\frac{1}{4} \theta$, redistributes market share from steamships to all-rail, and increases total shipments by $\frac{1}{2} \theta(a-b)$.

Proof:

Part 1. In the pre-period, where $B_{R}=B_{S}=1$ :

$$
\begin{aligned}
\Pi & =(P-c)\left(Q_{R}+Q_{S}\right)-\theta\left(Q_{R}+Q_{S}\right)=(P-c-\theta)\left(Q_{R}+Q_{S}\right) \\
& =(P-c-\theta)[(1-(a-b) P)+(1-(a-b) P)] \\
& =2(P-c-\theta)(1-(a-b) P) \\
& =2\left(P-c-\theta-(a-b) P^{2}+(c+\theta)(a-b) P\right) \\
\frac{\partial \Pi}{\partial P} & =2(1-2(a-b) P+(c+\theta)(a-b))=0 \quad \Longrightarrow \quad P=\frac{1}{2(a-b)}+\frac{1}{2}(c+\theta)
\end{aligned}
$$

Quantities $Q_{R}$ and $Q_{S}$ are then as follows:

$$
\begin{aligned}
Q_{R} & =1-(a-b) P=1-(a-b)\left[\frac{1}{2(a-b)}+\frac{1}{2}(c+\theta)\right] \\
& =1-\frac{1}{2}-\frac{1}{2}(a-b)(c+\theta)=\frac{1}{2}(1-(a-b)(c+\theta))
\end{aligned}
$$

and by symmetry, $Q_{S}=\frac{1}{2}(1-(a-b)(c+\theta))$.

Part 2. In the post-period, where $B_{R}=0$ and $B_{S}=1$ :

$$
\begin{aligned}
\Pi & =(P-c)\left(Q_{R}+Q_{S}\right)-\theta\left(Q_{S}\right)=(P-c) Q_{R}+(P-c-\theta) Q_{S} \\
& =(P-c)(1+\lambda-(a-b) P)+(P-c-\theta)(1-\lambda-(a-b) P) \\
& =2(P-c)(1-(a-b) P)-\theta(1-\lambda-(a-b) P) \\
& =2\left(P-c-(a-b) P^{2}+c(a-b) P-\theta(1-\lambda-(a-b) P)\right) \\
\frac{\partial \Pi}{\partial P} & =2(1-2(a-b) P+c(a-b))+\theta(a-b)=0 \quad \Longrightarrow \quad P=\frac{1}{2(a-b)}+\frac{1}{2}\left(c+\frac{1}{2} \theta\right)
\end{aligned}
$$


Quantities $Q_{R}$ and $Q_{S}$ are then as follows:

$$
\begin{aligned}
Q_{R} & =1+\lambda-(a-b) P=1+\lambda-(a-b)\left[\frac{1}{2(a-b)}+\frac{1}{2}\left(c+\frac{1}{2} \theta\right)\right] \\
& =1+\lambda-\frac{1}{2}-\frac{1}{2}(a-b)\left(c+\frac{1}{2} \theta\right)=\lambda+\frac{1}{2}\left(1-(a-b)\left(c+\frac{1}{2} \theta\right)\right)
\end{aligned}
$$

and

$$
\begin{aligned}
Q_{S} & =1-\lambda-(a-b) P=1-\lambda-(a-b)\left[\frac{1}{2(a-b)}+\frac{1}{2}\left(c+\frac{1}{2} \theta\right)\right] \\
& =1-\lambda-\frac{1}{2}-\frac{1}{2}(a-b)\left(c+\frac{1}{2} \theta\right)=-\lambda+\frac{1}{2}\left(1-(a-b)\left(c+\frac{1}{2} \theta\right)\right)
\end{aligned}
$$

\section{Part 3. Pre vs. Post Comparisons}

Part 3a. Prices

Post-gauge change, the change in the collusive price is:

$$
\begin{aligned}
\Delta P & =P^{\text {post }}-P^{\text {pre }} \\
& =\left[\frac{1}{2(a-b)}+\frac{1}{2}\left(c+\frac{1}{2} \theta\right)\right]-\left[\frac{1}{2(a-b)}+\frac{1}{2}(c+\theta)\right]=\frac{1}{4} \theta-\frac{1}{2} \theta=-\frac{1}{4} \theta<0
\end{aligned}
$$

\section{Part 3b. Quantities}

Post-gauge change, the change in all-rail shipments is:

$$
\begin{aligned}
& \Delta Q_{R}=Q_{R}^{\text {post }}-Q_{R}^{\text {pre }} \\
& \quad=\left[\lambda+\frac{1}{2}\left(1-(a-b)\left(c+\frac{1}{2} \theta\right)\right)\right]-\left[\frac{1}{2}(1-(a-b)(c+\theta))\right]=\lambda+\frac{1}{4}(a-b) \theta
\end{aligned}
$$

whereas the change in steamship shipments is:

$$
\begin{aligned}
\Delta Q_{S} & =Q_{S}^{\text {post }}-Q_{S}^{\text {pre }} \\
{ }^{\prime} & {\left[-\lambda+\frac{1}{2}\left(1-(a-b)\left(c+\frac{1}{2} \theta\right)\right)\right]-\left[\frac{1}{2}(1-(a-b)(c+\theta))\right]=-\lambda+\frac{1}{4}(a-b) \theta }
\end{aligned}
$$

Adding the two together, the change in total shipments is:

$$
\Delta Q_{T O T}=\Delta Q_{R}+\Delta Q_{S}=\frac{1}{2}(a-b) \theta
$$


Corollary 3.1. Conditions under which prices and total quantity may not change

(i) If $\theta=0$, the collusive price and total shipments are unaffected by removing the break in gauge.

(ii) If $\theta>0$, and collusive prices and quantities do not adjust after removing the break in gauge, the cost of price adjustments must be greater than the foregone profits, $\frac{1}{8} \theta^{2}(a-b)$.

\section{Proof:}

Part 1.

When $\theta=0: \Delta P=\frac{1}{4} \theta=0$ and $\Delta Q_{T O T}=\frac{1}{2}(a-b) \theta=0$.

Part 2.

To demonstrate this statement, we'll need to calculate post-gauge change profits under unadjusted prices (optimized for pre-gauge change period) and adjusted prices (optimized for post-gauge change period), which we can denote $P^{\text {pre }}$ and $P^{\text {post }}$ :

$$
\begin{aligned}
& \Pi\left(P^{\text {pre }}\right)=\left(P^{\text {pre }}-c\right) \cdot Q_{T O T}-\theta \cdot Q_{S} \\
& \quad=\left(P^{\text {pre }}-c\right) \cdot 2\left[1-(a-b) P^{\text {pre }}\right]-\theta \cdot\left[1-\lambda-(a-b) P^{\text {pre }}\right] \\
& \Pi\left(P^{\text {post }}\right)=\left(P^{\text {post }}-c\right) \cdot Q_{T O T}-\theta \cdot Q_{S} \\
& \quad=\left(P^{\text {post }}-c\right) \cdot 2\left[1-(a-b) P^{p o s t}\right]-\theta \cdot\left[1-\lambda-(a-b) P^{p o s t}\right]
\end{aligned}
$$

Taking the difference:

$$
\begin{aligned}
& \Pi\left(P^{\text {post }}\right)-\Pi\left(P^{\text {pre }}\right) \\
&=\left[2\left(1-(a-b) P^{\text {post }}\right)\left(P^{\text {post }}-c\right)-\left(1-\lambda-(a-b) P^{\text {post }}\right) \theta\right] \\
&-\left[2\left(1-(a-b) P^{\text {pre }}\right)\left(P^{\text {pre }}-c\right)-\left(1-\lambda-(a-b) P^{\text {pre }}\right) \theta\right] \\
&= {\left[2\left(P^{\text {post }}-(a-b)\left(P^{\text {post }}\right)^{2}+c(a-b) P^{\text {post }}\right)+\theta(a-b) P^{\text {post }}\right] } \\
&-\left[2\left(P^{\text {pre }}-(a-b)\left(P^{\text {pre }}\right)^{2}+c(a-b) P^{\text {pre }}\right)+\theta(a-b) P^{\text {pre }}\right] \\
&=(2+(2 c+\theta)(a-b))\left(P^{\text {post }}-P^{\text {pre }}\right)-2(a-b)\left(\left(P^{\text {post }}\right)^{2}-\left(P^{\text {pre }}\right)^{2}\right) \\
&=\left(P^{\text {post }}-P^{\text {pre }}\right)\left(2+(2 c+\theta)(a-b)-2(a-b)\left(P^{\text {post }}+P^{\text {pre }}\right)\right) \\
&=\left(-\frac{1}{4} \theta\right)\left(\left(2+(2 c+\theta)(a-b)-2(a-b)\left(\frac{1}{a-b}+c+\frac{3}{4} \theta\right)\right)\right. \\
&=\left(-\frac{1}{4} \theta\right)\left(\left(2+(2 c+\theta)(a-b)-2-2 c(a-b)-\frac{3}{2} \theta(a-b)\right)\right. \\
&=\left(-\frac{1}{4} \theta\right)\left(-\frac{1}{2} \theta(a-b)\right)=\frac{1}{8} \theta^{2}(a-b)
\end{aligned}
$$

If the cartel does not adjust its price, then the cost of the price adjustment must be greater than this amount, which is the incremental profit it would realize by re-optimizing $P$. 


\section{Proofs for Section 4.3}

Proposition 4. Effects of standardization in a competitive market

Eliminating the break in gauge has an ambiguous effect on the all-rail price, depending on the size of a demand effect, which puts upward pressure on the all-rail price, and the pass-through of cost savings, which puts downward pressure. Steamship prices strictly decline, market share shifts from steamships to all-rail, and total shipments increase by $\frac{a \theta(a-b)}{2 a-b}$.

\section{Proof:}

Part 1. In the pre-period, where $B_{R}=B_{S}=1$ :

$$
\begin{gathered}
\Pi_{R}=\left(1-a P_{R}+b P_{S}\right)\left(P_{R}-c-\theta\right)=\left(P_{R}-a P_{R}^{2}+b P_{S} P_{R}\right)+\left(1-a P_{R}+b P_{S}\right)(-c-\theta) \\
\frac{\partial \Pi_{R}}{\partial P_{R}}=1-2 a P_{R}+b P_{S}+a(c+\theta)=0 \quad \Longrightarrow \quad P_{R}=\left(1+b P_{S}+a(c+\theta)\right) / 2 a \\
\Pi_{S}=\left(1-a P_{S}+b P_{R}\right)\left(P_{S}-c-\theta\right)=\left(P_{S}-a P_{S}^{2}+b P_{R} P_{S}\right)+\left(1-a P_{S}+b P_{R}\right)(-c-\theta) \\
\frac{\partial \Pi_{S}}{\partial P_{S}}=1-2 a P_{S}+b P_{R}+a(c+\theta)=0 \quad \Longrightarrow \quad P_{S}=\left(1+b P_{R}+a(c+\theta)\right) / 2 a
\end{gathered}
$$

Combining the two, we can solve for $P_{R}$ and $P_{S}$ :

$$
\begin{aligned}
& P_{R}=\frac{1+b\left(\frac{1+b P_{R}+a(c+\theta)}{2 a}\right)+a(c+\theta)}{2 a}=\frac{1}{2 a}+\frac{b}{4 a^{2}}+\frac{b^{2}}{4 a^{2}} P_{R}+\frac{b}{4 a}(c+\theta)+\frac{1}{2}(c+\theta) \\
& \frac{4 a^{2}-b^{2}}{4 a^{2}} P_{R}=\frac{1}{2 a}+\frac{b}{4 a^{2}}+\left(\frac{b}{4 a}+\frac{1}{2}\right)(c+\theta)=\frac{2 a}{4 a^{2}}+\frac{b}{4 a^{2}}+\left(\frac{a b}{4 a^{2}}+\frac{2 a^{2}}{4 a^{2}}\right)(c+\theta) \\
& P_{R}=\frac{1}{4 a^{2}-b^{2}}\left((2 a+b)+\left(a b+2 a^{2}\right)(c+\theta)\right) \\
& =\frac{1}{(2 a+b)(2 a-b)}((2 a+b)+a(2 a+b)(c+\theta))=\frac{1}{2 a-b}(1+a(c+\theta))
\end{aligned}
$$

and by symmetry, $P_{S}=\frac{1}{2 a-b}(1+a(c+\theta))$.

Quantities $Q_{R}$ and $Q_{S}$ are then as follows:

$$
\begin{aligned}
Q_{R} & =1-a P_{R}+b P_{S}=1-a\left[\frac{1}{2 a-b}(a(c+\theta)+1)\right]+b\left[\frac{1}{2 a-b}(a(c+\theta)+1)\right] \\
& =1-(a-b)\left[\frac{1}{2 a-b}(a(c+\theta)+1)\right]=1-\frac{a-b}{2 a-b}(a(c+\theta)+1)
\end{aligned}
$$

and by symmetry, $Q_{S}=1-\frac{a-b}{2 a-b}(a(c+\theta)+1)$. 
Part 2. In the post-period, where $B_{R}=0$ and $B_{S}=1$ :

$$
\begin{gathered}
\Pi_{R}=\left(1+\lambda-a P_{R}+b P_{S}\right)\left(P_{R}-c\right)=\left(P_{R}+\lambda P_{R}-a P_{R}^{2}+b P_{S} P_{R}\right)+\left(1+\lambda-a P_{R}+b P_{S}\right)(-c) \\
\frac{\partial \Pi_{R}}{\partial P_{R}}=1+\lambda-2 a P_{R}+b P_{S}+a c=0 \quad \Longrightarrow \quad P_{R}=\left(1+\lambda+b P_{S}+a c\right) / 2 a \\
\Pi_{S}=\left(1-\lambda-a P_{S}+b P_{R}\right)\left(P_{S}-c-\theta\right)=\left(P_{S}-\lambda P_{S}-a P_{S}^{2}+b P_{R} P_{S}\right)+\left(1-\lambda-a P_{S}+b P_{R}\right)(-c-\theta) \\
\frac{\partial \Pi_{S}}{\partial P_{S}}=1-\lambda-2 a P_{S}+b P_{R}+a(c+\theta)=0 \quad \Longrightarrow \quad P_{S}=\left(1-\lambda+b P_{R}+a(c+\theta)\right) / 2 a
\end{gathered}
$$

Combining the two, we can solve for $P_{R}$ and $P_{S}$ :

$$
\begin{aligned}
P_{R} & =\frac{1+\lambda+b\left(\frac{1-\lambda+b P_{R}+a(c+\theta)}{2 a}\right)+a c}{2 a} \\
& =\frac{1}{2 a}(1+\lambda)+\frac{b}{4 a^{2}}(1-\lambda)+\frac{b^{2}}{4 a^{2}} P_{R}+\frac{b}{4 a}(c+\theta)+\frac{1}{2} c \\
\frac{4 a^{2}}{4 a^{2}} b^{2} & P_{R}=\frac{1}{2 a}(1+\lambda)+\frac{b}{4 a^{2}}(1-\lambda)+\left(\frac{b}{4 a}+\frac{1}{2}\right) c+\frac{b}{4 a} \theta \\
& =\frac{2 a}{4 a^{2}}(1+\lambda)+\frac{b}{4 a^{2}}(1-\lambda)+\left(\frac{a b}{4 a^{2}}+\frac{2 a^{2}}{4 a^{2}}\right) c+\frac{a b}{4 a^{2}} \theta \\
P_{R} & =\frac{1}{4 a^{2}-b^{2}}\left(2 a(1+\lambda)+b(1-\lambda)+\left(a b+2 a^{2}\right) c+a b \theta\right) \\
& =\frac{1}{4 a^{2}-b^{2}}\left(2 a(1+\lambda)+b(1-\lambda)+\left(a b+2 a^{2}\right)(c+\theta)-2 a^{2} \theta\right) \\
& =\frac{1}{(2 a+b)(2 a-b)}\left((2 a+b)+a(2 a+b)(c+\theta)+(2 a-b) \lambda-2 a^{2} \theta\right) \\
& =\frac{1}{2 a-b}(1+a(c+\theta))+\frac{1}{2 a+b}(\lambda)-\frac{1}{(2 a+b)(2 a-b)}\left(2 a^{2} \theta\right)
\end{aligned}
$$


and

$$
\begin{aligned}
P_{S} & =\frac{1-\lambda+b\left(\frac{1+\lambda+b P_{S}+a c}{2 a}\right)+(c+\theta)}{2 a} \\
& =\frac{1}{2 a}(1-\lambda)+\frac{b}{4 a^{2}}(1+\lambda)+\frac{b^{2}}{4 a^{2}} P_{S}+\frac{b}{4 a} c+\frac{1}{2}(c+\theta) \\
\frac{4 a^{2}}{4 a^{2}} P_{S}^{2}=\frac{1}{2 a}(1-\lambda)+\frac{b}{4 a^{2}}(1+\lambda)+\left(\frac{b}{4 a}+\frac{1}{2}\right) c+\frac{1}{2} \theta & \\
& =\frac{2 a}{4 a^{2}}(1-\lambda)+\frac{b}{4 a^{2}}(1+\lambda)+\left(\frac{a b}{4 a^{2}}+\frac{2 a^{2}}{4 a^{2}}\right) c+\frac{2 a}{4 a^{2}} \theta \\
P_{S} & =\frac{1}{4 a^{2}-b^{2}}\left(2 a(1-\lambda)+b(1+\lambda)+\left(a b+2 a^{2}\right) c+2 a \theta\right) \\
& =\frac{1}{4 a^{2}-b^{2}}\left(2 a(1-\lambda)+b(1+\lambda)+\left(a b+2 a^{2}\right)(c+\theta)-a b \theta\right) \\
& =\frac{1}{(2 a+b)(2 a-b)}((2 a+b)+a(2 a+b)(c+\theta)-(2 a-b) \lambda-a b \theta) \\
& =\frac{1}{2 a-b}(1+a(c+\theta))-\frac{1}{2 a+b}(\lambda)-\frac{1}{(2 a+b)(2 a-b)}(a b \theta)
\end{aligned}
$$

Quantities $Q_{R}$ and $Q_{S}$ are then as follows:

$$
\begin{aligned}
Q_{R}= & 1+\lambda-a P_{R}+b P_{S} \\
= & 1+\lambda-a\left[\frac{1}{2 a-b}(a(c+\theta)+1)+\frac{1}{2 a+b}(\lambda)-\frac{1}{(2 a+b)(2 a-b)}\left(2 a^{2} \theta\right)\right] \\
& +b\left[\frac{1}{2 a-b}(a(c+\theta)+1)-\frac{1}{2 a+b}(\lambda)-\frac{1}{(2 a+b)(2 a-b)}(a b \theta)\right] \\
= & 1+\lambda-\frac{a-b}{2 a-b}(a(c+\theta)+1)-\frac{a+b}{2 a+b}(\lambda)+\frac{a\left(2 a^{2}-b^{2}\right)}{(2 a+b)(2 a-b)}(\theta)
\end{aligned}
$$

and

$$
\begin{aligned}
Q_{S}= & 1-\lambda-a P_{S}+b P_{R} \\
= & 1-\lambda-a\left[\frac{1}{2 a-b}(a(c+\theta)+1)-\frac{1}{2 a+b}(\lambda)-\frac{1}{(2 a+b)(2 a-b)}(a b \theta)\right] \\
& +b\left[\frac{1}{2 a-b}(a(c+\theta)+1)+\frac{1}{2 a+b}(\lambda)-\frac{1}{(2 a+b)(2 a-b)}\left(2 a^{2} \theta\right)\right] \\
= & 1-\lambda-\frac{a-b}{2 a-b}(a(c+\theta)+1)+\frac{a+b}{2 a+b}(\lambda)+\frac{a(a b-2 a b)}{(2 a+b)(2 a-b)}(\theta)
\end{aligned}
$$




\section{Part 3. Pre vs. Post Comparisons}

\section{Part 3a. Prices}

Post-gauge change, the change in the all-rail price is:

$$
\begin{aligned}
\Delta P_{R} & =P_{R}^{\text {post }}-P_{R}^{\text {pre }} \\
& =\left[\frac{1}{2 a-b}(1+a(c+\theta))+\frac{1}{2 a+b}(\lambda)-\frac{1}{(2 a+b)(2 a-b)}\left(2 a^{2} \theta\right)\right]-\left[\frac{1}{2 a-b}(1+a(c+\theta))\right] \\
& =\underbrace{\frac{1}{2 a+b}(\lambda)}_{\text {Demand effect }}-\underbrace{\frac{1}{(2 a+b)(2 a-b)}\left(2 a^{2} \theta\right)}_{\text {Cost effect }} \Longrightarrow \Delta P_{R}\left\{\begin{array}{l}
>0 \text { if } \lambda>\frac{1}{2 a+b}\left(2 a^{2} \theta\right) \\
<0 \text { if } \lambda<\frac{1}{2 a+b}\left(2 a^{2} \theta\right)
\end{array}\right.
\end{aligned}
$$

which consists of both a demand effect driven by the improvement in the relative quality of all-rail shipment (relative to steamships), which puts upward pressure on $P_{R}$, and a cost effect driven by the reduction in the cost of all-rail carriage, which puts downward pressure on $P_{R}$. The net effect on $P_{R}$ may be positive or negative.

The change in the steamship price is:

$$
\begin{aligned}
\Delta P_{S} & =P_{S}^{\text {post }}-P_{S}^{\text {pre }} \\
& =\left[\frac{1}{2 a-b}(1+a(c+\theta))-\frac{1}{2 a+b}(\lambda)-\frac{1}{(2 a+b)(2 a-b)}(a b \theta)\right]-\left[\frac{1}{2 a-b}(1+a(c+\theta))\right] \\
& =\underbrace{-\frac{1}{2 a+b}(\lambda)}_{\text {Demand effect }}-\underbrace{\frac{1}{(2 a+b)(2 a-b)}(a b \theta)}_{\text {Competitor cost effect }} \Longrightarrow \Delta P_{S}<0
\end{aligned}
$$

which consists of both a demand effect driven by the reduction in the relative quality of steamships (relative to all-rail), which puts downward pressure on $P_{S}$, and a competition effect driven by the reduction in the all-rail costs of carriage, which puts further downward pressure on $P_{S}$. The combined effect on $P_{S}$ is negative.

\section{Part 3b. Quantities}

Post-gauge change, the change in all-rail shipments is:

$$
\begin{aligned}
& \Delta Q_{R}=Q_{R}^{\text {post }}-Q_{R}^{\text {pre }} \\
& =\left[1+\lambda-\frac{a-b}{2 a-b}(a(c+\theta)+1)-\frac{a+b}{2 a+b}(\lambda)+\frac{a\left(2 a^{2}-b^{2}\right)}{(2 a+b)(2 a-b)}(\theta)\right]-\left[1-\frac{a-b}{2 a-b}(a(c+\theta)+1)\right] \\
& =\lambda-\frac{a+b}{2 a+b}(\lambda)+\frac{a\left(2 a^{2}-b^{2}\right)}{(2 a+b)(2 a-b)}(\theta)
\end{aligned}
$$


whereas the change in steamship shipments is:

$$
\begin{aligned}
\Delta Q_{S} & =Q_{S}^{\text {post }}-Q_{S}^{\text {pre }} \\
& =\left[1-\lambda-\frac{a-b}{2 a-b}(a(c+\theta)+1)+\frac{a+b}{2 a+b}(\lambda)+\frac{a(a b-2 a b)}{(2 a+b)(2 a-b)}(\theta)\right]-\left[1-\frac{a-b}{2 a-b}(a(c+\theta)+1)\right] \\
& =-\lambda+\frac{a+b}{2 a+b}(\lambda)+\frac{a(a b-2 a b)}{(2 a+b)(2 a-b)}(\theta)
\end{aligned}
$$

Adding the two together, the change in total shipments is:

$$
\Delta Q_{T O T}=\Delta Q_{R}+\Delta Q_{S}=\frac{a\left(2 a^{2}-a b-2 b^{2}\right)}{(2 a+b)(2 a-b)}(\theta)=\frac{a(2 a+b)(a-b)}{(2 a+b)(2 a-b)}(\theta)=\frac{a(a-b)}{(2 a-b)}(\theta)
$$

Corollary 4.1. Comparing the effects by market structure

Standardization generates a larger increase in total shipments under competition than collusion.

\section{Proof:}

The increase in shipments is $\frac{a \theta(a-b)}{2 a-b}$ under competition (Proposition 4), compared to $\frac{1}{2} \theta(a-b)$ under collusion (Proposition 3, although Corollary 3.1 also points out that the increase in shipments may be zero if cartel price changes are costly).

The formal comparison is as follows:

$$
\begin{gathered}
\left(\frac{a \theta(a-b)}{2 a-b}\right)-\left(\frac{1}{2} \theta(a-b)\right)=\frac{a \theta(a-b)-\frac{1}{2} \theta(a-b)(2 a-b)}{2 a-b} \\
=\frac{a \theta(a-b)-a \theta(a-b)+\frac{1}{2} b \theta(a-b)}{2 a-b}=\frac{1}{2} b \theta\left(\frac{a-b}{2 a-b}\right)>0
\end{gathered}
$$

